\title{
Common and country specific economic uncertainty*
}

\author{
Haroon Mumtaz Konstantinos Theodoridis $^{\ddagger}$
}

January 5, 2017

\begin{abstract}
We use a factor model with stochastic volatility to decompose the time-varying variance of Macroeconomic and Financial variables into contributions from country-specific uncertainty and uncertainty common to all countries. We find that the common component plays an important role in driving the time-varying volatility of nominal and financial variables. The cross-country co-movement in volatility of real and financial variables has increased over time with the common component becoming more important over the last decade. Simulations from a two-country DSGE model featuring Epstein Zin preferences suggest that increased globalisation and trade openness may be the driving force behind the increased cross-country correlation in volatility.
\end{abstract}

JEL Codes: C15,C32, E32

Key Words: FAVAR, Stochastic Volatility, Uncertainty Shocks, DSGE Model

\section{Introduction}

Recent turmoil in financial markets has led to a substantial increase in macroeconomic volatility across the industrialised world. This is clear from the simple calculation in figure 1 which shows the average of the rolling standard deviation of the main macroeconomic and financial variables for eleven OECD countries. This simple measure of economic volatility shows an increase across all countries over the post-2007 period highlighting the severity of the financial crisis. It is interesting to note that this high correlation of volatility is not just confined to the recent financial crisis but appears to be a prominent feature of this statistic over several episodes in the past. A casual examination of the figure suggests that this measure of volatility moved especially closely together during the mid-1970s, the early 1980s and then during the beginning and end of the last decade. The full sample correlation between these volatility measures is high, averaging across pairwise combinations at $50 \%$.

The aim of this paper is to investigate the comovement in volatility from an empirical and theoretical perspective. Using a dynamic factor model with stochastic volatility, we decompose the movements in the volatility of real activity, inflation and financial series from these eleven OECD countries into the contributions from country specific and OECD wide uncertainty. We find that OECD wide uncertainty plays an important role in driving the variance of real and nominal variables and is especially important for the latter series. Moreover, we estimate that the contribution of common uncertainty has increased over the sample period and the volatility of key variables displays a higher correlation after the late 1990s.

We then build a two country model that features households with Epstein-Zin preferences. One of the key implications of the model set-up is the presence of heteroscedastic endogenous variables, with this feature induced by agents' preferences. We show that in a two country environment, shocks that lead to transfer of resources across countries imply comovement in the second moments of endogenous variables.

${ }^{*}$ The views expressed in this paper are those of the authors, and not necessarily those of the Bank of England. We thank two anonymous referees and the editor, Charles Engel, for useful comments.

${ }^{\dagger}$ Queen Mary College. Email: h.mumtaz@qmul.ac.uk

${ }^{\ddagger}$ Bank of England. Email: Konstantinos.Theodoridis@bankofengland.co.uk 
This comovement rises as trade links in the model become stronger. In contrast, changes in monetary policy rule and/or the Phillips curve are unable to explain the increase in the importance of the common component in volatility.

This paper is closely related to two recent strands of the empirical Macro literature. The aim of the paper is similar in spirit to the work on international business cycles (see for example Kose et al. (2003)) and the research on inflation co-movements (see Mumtaz and Surico (2008)) that has sought to establish the importance of a common factor in explaining the movements in these variables. We focus on comovement in the second moment and show that this feature is important from an empirical and theoretical perspective. Our analysis is also closely related to the recent literature on uncertainty that has focussed on estimating proxies for economic uncertainty. However, we investigate the role of common movements in uncertainty, an aspect that has been relatively unexplored in this literature. This investigation is related to the analysis in Berger et al. (2014) and Berger et al. (2016) who estimate global uncertainty associated with output and inflation. However, our work explores common macroeconomic uncertainty that encompasses both macroeconomic and financial variables. Moreover, in contrast to Berger et al. (2014) and Berger et al. (2016), a major aim of the current paper is to build a DSGE model to provide a theoretical explanation for the empirical findings.

Our results have important policy implications. In particular, they highlight potential consequences of globalisation that have been largely ignored in the literature-i.e. an increasing comovement in the time-varying volatility of output, inflation and stock returns. This suggests that policy makers may need to focus more on economic developments that cause uncertainty in countries that are linked through trade. This implication is especially relevent given the recent debt crisis in the Euro Area that has resulted in an increase in volatility in a number of countries.

The paper is organised as follows: Sections 2 and 2.1 introduce the empirical model and discuss the estimation method. The results from the empirical model are presented in Section 3 . We introduce the DSGE model and present the model simulations in Section 4.

\section{Common and country-specific uncertainty}

In order to estimate country-specific and common (or 'world') specific measures of uncertainty, we use a dynamic factor model with time-varying volatility. The factor model is defined as

$$
X_{i t}=B_{i}^{C} F_{t}^{C}+B_{i}^{W} F_{t}^{W}+e_{i t}
$$

where $X_{i t}$ is a panel of macroeconomic and financial data for the set of OECD countries described below. This panel of data is summarised by three components: a set of $K_{W}$ common or 'world' factors $F_{t}^{W}$, a set $K_{C}$ country-specific factors $F_{t}^{C}$ and idiosyncratic components $e_{i t}$. The world and the country factors follow VAR processes:

$$
\begin{aligned}
& F_{t}^{W}=\zeta+\sum_{j=1}^{P} p_{j} F_{t-j}^{W}+\Upsilon_{t}^{1 / 2} g_{t} \\
& F_{t}^{C}=\alpha+\sum_{j=1}^{P} \rho_{j} F_{t-j}^{C}+\Omega_{t}^{1 / 2} v_{t}
\end{aligned}
$$

while the idiosyncratic components have an AR transition equation

$$
e_{i t}=\sum_{j=1}^{J} \mu_{i, j} e_{i t-j}+h_{i t}^{1 / 2} \varepsilon_{i t}
$$

where $g_{t}, v_{t}, \varepsilon_{i t} \sim N(0,1)$. Note that the error terms in equations 2 , 3 and 4 are heteroscedastic. The error covariance matrices in the VAR models 2 and 3 are defined as

$$
\Upsilon_{t}=C^{-1} D_{t} C^{-1^{\prime}}
$$




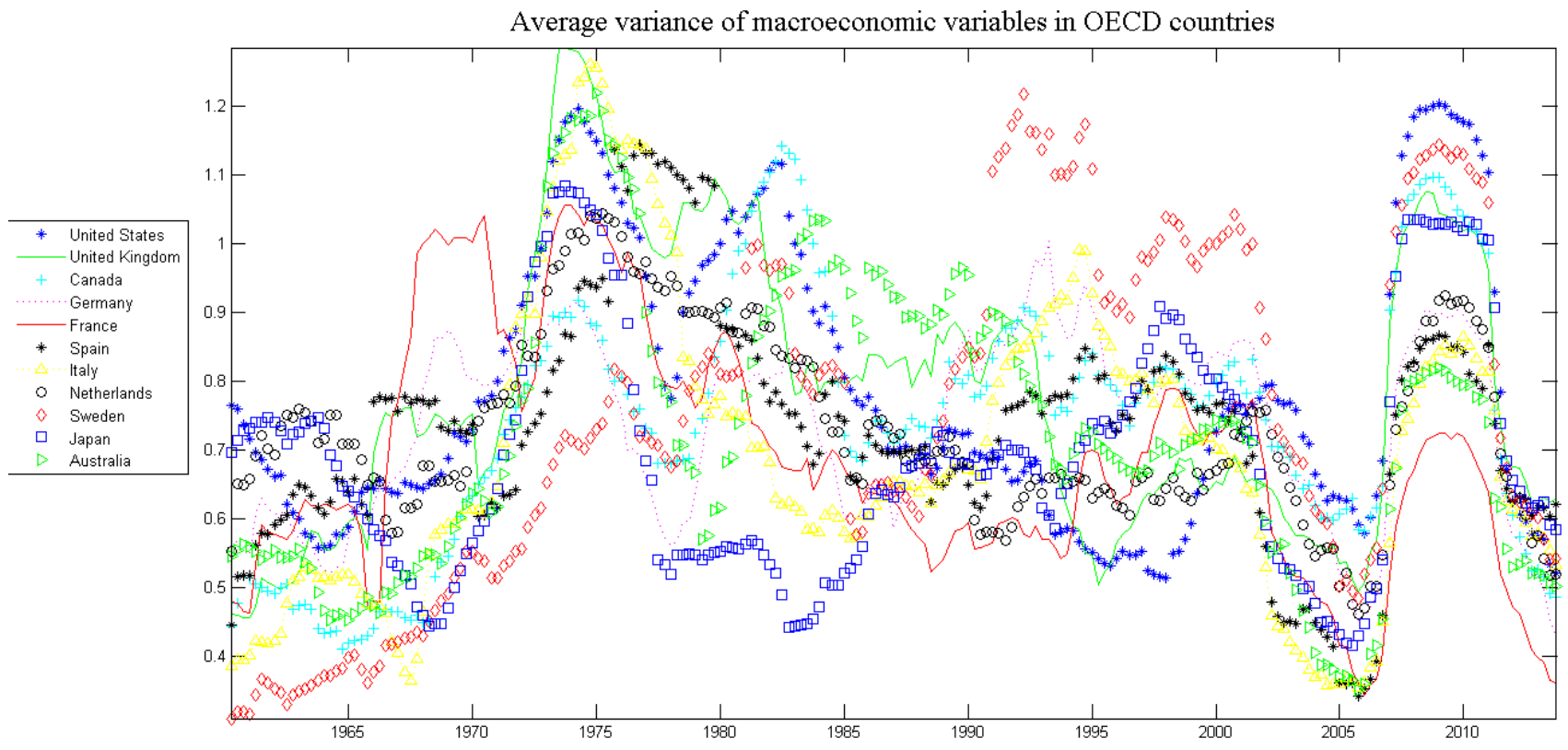

Figure 1: Two year rolling estimate of the average variance of macroeconomic variables in 11 OECD countries. The data set for each country is described in section 2.2. For the purposes of this figure, the rolling standard deviation is calculated for each series and then the mean across the series is calculated. The data is standardised prior to this calculation.

$$
\Omega_{t}=A^{-1} H_{t} A^{-1^{\prime}}
$$

where $A$ and $C$ are lower triangular and $D_{t}$ and $H_{t}$ are diagonal matrices defined as

$$
\begin{aligned}
& D_{t}=\operatorname{diag}\left(s_{k} \gamma_{t}\right) \\
& H_{t}=\operatorname{diag}\left(S_{k} \lambda_{t}\right)
\end{aligned}
$$

The time-varying volatility is captured by $\gamma_{t}$ and $\lambda_{t}$ with $s_{k}$ and $S_{k}$ the scaling factors for $k=1,2, \ldots K_{m}$ for $m=W, C$. The overall volatilites evolve as an $\mathrm{AR}(1)$ process:

$$
\begin{aligned}
& \ln \gamma_{t}=\bar{\alpha}+\bar{\beta} \ln \gamma_{t-1}+\bar{Q}^{1 / 2} \bar{\eta}_{t} \\
& \ln \lambda_{t}=\tilde{\alpha}+\tilde{\beta} \ln \lambda_{t-1}+\tilde{Q}^{1 / 2} \tilde{\eta}_{t}
\end{aligned}
$$

The structure defined by equations 5 and 6 suggests that the volatility specification is characterised by the following features: First, the specification captures the overall volatility in the orthogonalized residuals of the VAR models. As explained in Carriero et al. (2012), the common volatilities can be interpreted as the average of the variance of the shocks with equal weight given to each individual volatility. Note that the errors to these equations represent the shocks to 'world' and country factors. Thus, $\gamma_{t}$ and $\lambda_{t}$ capture the average volatility of the unpredictable part of the common component and the countryspecific component. We interpret these volatilities as measures of uncertainty associated with OECD wide economic conditions and country specific economic conditions.

The variance of the shocks to the idiosyncratic components are also assumed to heteroscedastic with $h_{i t}$ evolving as a stochastic volatility process

$$
\ln h_{i t}=a_{i}+b_{i} \ln h_{i t-1}+q_{i}^{1 / 2} n_{i t}
$$


The structure of the model implies that the variance of each series at time $t$ can be written as a function of $\Upsilon_{t}, \Omega_{t}$ and $h_{t}$. In particular

$$
\operatorname{var}\left(X_{i t}\right)=\left(B_{i}^{C}\right)^{2} \operatorname{var}\left(F_{t}^{C}\right)+\left(B_{i}^{W}\right)^{2} \operatorname{var}\left(F_{t}^{W}\right)+\operatorname{var}\left(e_{i t}\right)
$$

where the variance terms on the RHS of equation 11 can be calculated using the standard VAR formula for the variance of the endogenous variables. Note that these variance terms are time-varying as they are functions of $\lambda_{t}, \gamma_{t}$ and $h_{i t}$ respectively. The volatility of each series in our panel is thus driven by uncertainty that is common to all countries, uncertainty that is country-specific and a residual term that captures sectoral volatility and data uncertainty. Our framework, therefore, allows us to calculate how volatility of key series (such as GDP growth, CPI inflation and stock market returns) is driven by uncertainty that is common to all countries and uncertainty that is country and series-specific.

This empirical model is related to a number of contributions in the recent literature on measuring uncertainty. In particular, the spirit of our model is similar to the procedure used in Jurado et al. (2013) to estimate US economic uncertainty. The uncertainty measure in Jurado et al. $(2013)$ is the average time-varying variance in the unpredictable component of a large set of real and financial time-series. The volatility specification in our factor model has a similar intepretation- it attempts to capture the average volatility in the shocks to the factors that summarise real and financial conditions. In contrast to Jurado et al. (2013), however, our model allows the estimation of uncertainty at the country and at the 'world' level 1 -

It is interesting to note that this specification is more general than those employed in Mumtaz and Surico (2008), Berger et al. (2014) and Berger et al. (2016). These studies focus on the volatility of the unpredictable component of output growth or inflation factors. In particular, these studies estimate factor models of the following basic form:

$$
y_{i t}=\Gamma_{R, i} R_{t}+\Gamma_{\tilde{C}} \tilde{C}_{t}+\varepsilon_{i t}
$$

where $y_{i t}$ is chosen to be a cross-country panel of inflation rates by Mumtaz and Surico (2008), and GDP growth by Berger et al. (2016) ${ }^{2}$ In this model, $R_{t}$ represents an inflation or GDP growth factor that is common across countries with $\Gamma_{i}$ denoting the factor loadings. Similarly, $\tilde{C}_{t}$ denotes the country-specific factor in either inflation or GDP growth with the associated factor loadings given by $\Gamma_{\tilde{C}}$. The dynamics of $R_{t}$ and $\tilde{C}_{t}$ are assumed to be described by uni-variate AR processes that feature stochastic volatility. These stochastic volatilties are intepreted as uncertainty at the 'world' and country levels. These models differ from our specification in two key dimensions: First, unlike Mumtaz and Surico (2008) and Berger et al. (2016), our data set features a range of macroeconomic and financial variables for each country included in the panel. This means that the set of factors $F_{t}^{W}$ and $F_{t}^{C}$ in equation 1 capture common and country-specific economic conditions and not simply common inflation or GDP growth. Second, the law of motion for the set of factors $F_{t}^{W}$ and $F_{t}^{C}$ are assumed to be VARs rather than uni-variate AR processes. The variance of the VAR shocks is modelled using the common stochastic volatility specification of Carriero et al. (2012). This common volatility summarises the uncertainty in common and countryspecific economic conditions as captured by $F_{t}^{W}$ and $F_{t}^{C}$. We are thus able to interpret the resulting uncertainty measures as pertaining to economic uncertainty rather than a narrower measure focussing on a particular variable.

\subsection{Estimation and model specification}

The factor model in equations 1 to 10 is estimated via Gibbs sampling. The technical appendix provides details of the priors and the conditional posterior distributions. In the benchmark specifications, we use

\footnotetext{
1 Mumtaz and Theodoridis (2014) use a factor model with common stochastic volatility to estimate the time-varying impact of uncertainty shocks on the US economy. Their specification does not, however, distinguish between OECD and countr-specific uncertainty.

${ }^{2}$ Note that we Berger et al. (2016) include each country's inflation as an exogenous regressor.
} 
50,000 replications and base our inference on the last 5,000 replications. The recursive means of the retained draws (see technical appendix) show little fluctuation providing support for convergence of the algorithm 3

In order to maintain parsimony, $P$ the lag lengths in the VARs are fixed at 2 . In addition, we allow for first order serial correlation in the idiosyncratic errors $e_{i t}$. The number of common and county-specific factors is an important specification choice. For the model selection exercise we set $K_{W}=K_{C}$ in equation 1. We consider models with 2 to 5 common and country factors and select the model which minimises the Bayesian Deviance Information Criterion (DIC). 4

Introduced in Spiegelhalter et al. (2002), the DIC is a generalisation of the Akaike information criterion - it penalises model complexity while rewarding fit to the data. As shown in the technical appendix, the DIC can be calculated as $D I C=\bar{D}+p_{D}$ where $\bar{D}$ measures goodness of fit and $p_{D}$ approximates model complexity. A model with a lower $D I C$ is preferred. Table 1 shows that the $D I C$ is minimised for the model with 4 world and country factors and thus we set $K=4$ in our benchmark model.

\begin{tabular}{ll}
\hline & $D I C$ \\
2 factors & $1.65 \times 10^{5}$ \\
3 factors & $1.75 \times 10^{5}$ \\
4 factors & $1.52 \times 10^{5}$ \\
5 factors & $1.64 \times 10^{5}$ \\
\hline
\end{tabular}

Table 1: Model Comparison via DIC. Best fit indicated by lowest DIC

\subsection{Data}

As alluded to above, the model is estimated using quarterly data on eleven OECD countries. We consider data for the United States, United Kingdom, Canada, Germany, France, Spain, Italy, the Netherlands, Sweden, Japan and Australia. We limit our attention to these industrial countries mainly because of data availability - data on real and financial sectors of the economy is available for a reasonably long time span for these countries. Both of these features are essential for our analysis as we aim to incorporate uncertainty in a broad range of series and to also include periods which were subject to interesting fluctuations (such as the 1970s).

For each country the data runs from 1960Q1 to 2013Q3. The number of series included for each country varies according to data availability. However, we attempt to maintain a similar composition of macroeconomic and financial series. For each country, the data set includes real activity variables (for e.g. exports, imports, consumption, investment, production, GDP), measures of inflation and earnings, interest rates and term spreads, corporate bond spreads, exchange rates and stock prices. Where relevant and available, oil prices are also included in the country specific data sets. Where necessary, the variables are $\log$ differenced to induce stationarity. Finally, all series are standardised. The technical appendix provides a list of the series used and the data sources.

\footnotetext{
${ }^{3}$ The technical appendix presents results from a small Monte-Carlo experiment that shows that this MCMC algorithm performs well.

${ }^{4}$ We vary the country and common factors in a symmetric manner in this exercise. In theory it is possible to consider combinations of a different number of these factors. Note, however, that as a computationally intensive particle filter algorithm (see appendix) is used to compute the likelihood for the purpose of DIC calculation, computational feasibility limits us to the symmetric approach.
} 


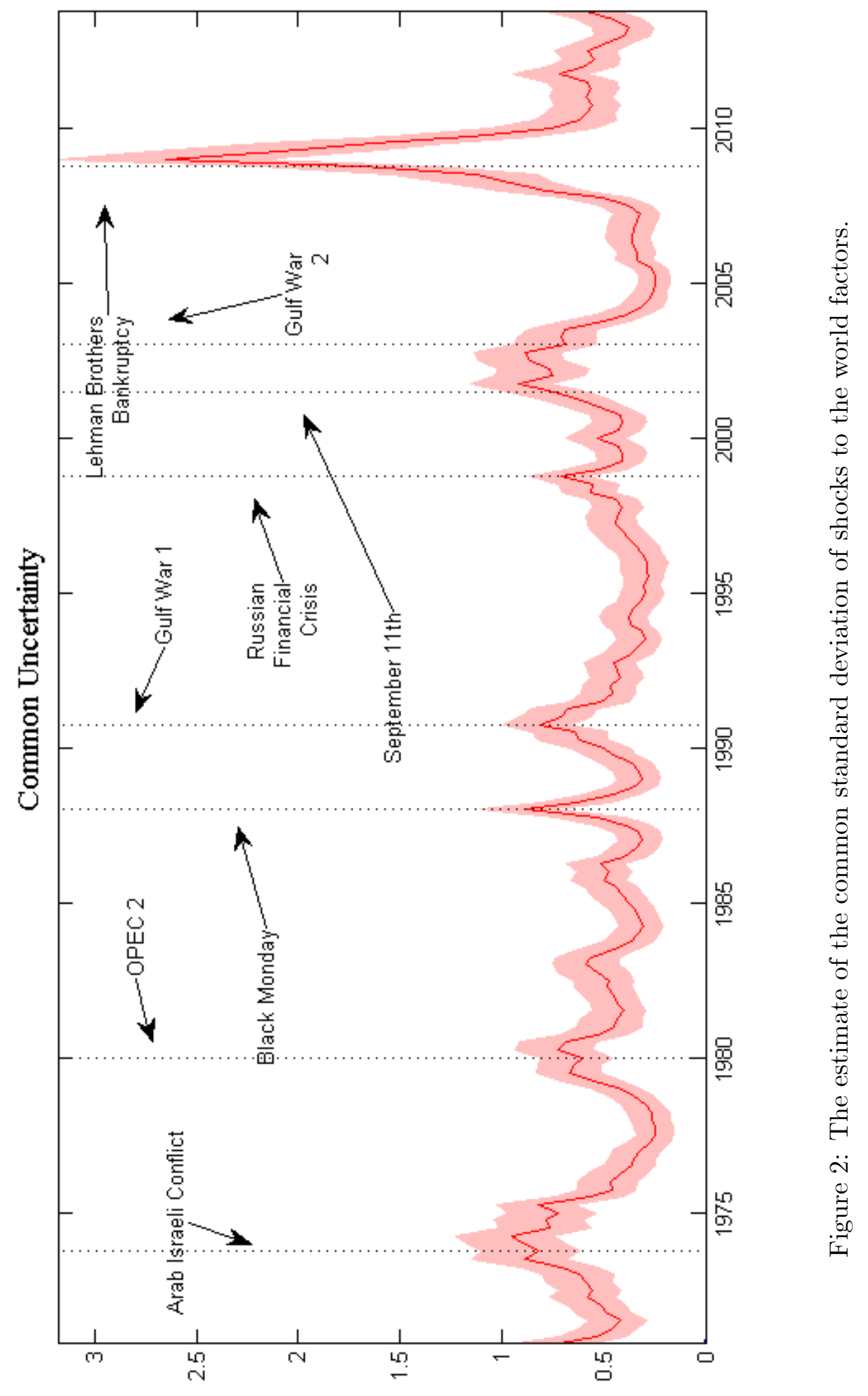



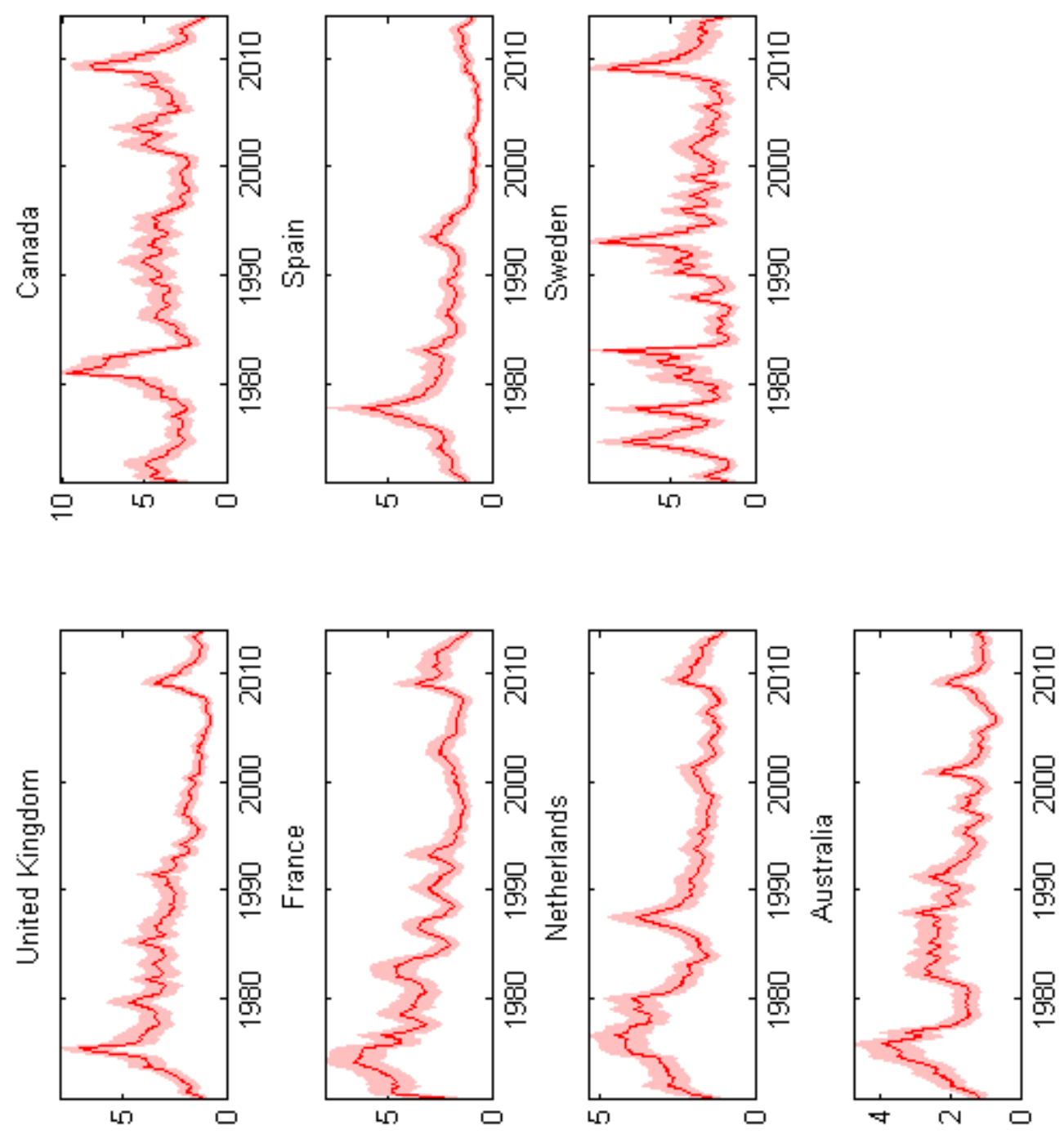

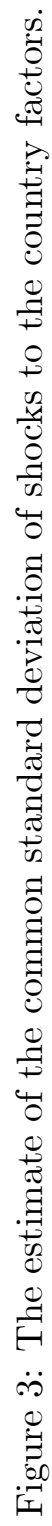




\section{Empirical results}

\subsection{The estimate of common and country-specific uncertainty}

Figure 2 presents the posterior estimate of $\gamma_{t}^{1 / 2}$, the common standard deviation of the shocks to the 'world' factors. We interpret this as a measure of uncertainty that is common across our panel of countries. It is interesting to note that this measure of common or 'world uncertainty' was at its highest over the recent financial crisis in 2009, again emphasizing the scale of the recent recession and its wide-ranging effect on the countries in our sample. The vertical lines in the figure indicate that previous peaks in this measure have coincided with important events such as wars in the middle east, oil shocks, major financial crises and the September 11th terrorist attacks. This measure of common uncertainty shows noticeable differences from the output growth based measure presented in Berger et al. (2016). In particular, common output growth uncertainty shown in Berger et al. (2016) remains relatively muted during periods of financial stress and political uncertainty during the early and late 1980s and at the beginning of the 2000s. In contrast, these events can be clearly linked to peaks in our measure as we account for financial stress by including financial variables and capture major global political events through their impact on asset prices such as oil and exchange rates ${ }^{5}$

Figure 3 shows the estimated country specific uncertainty measures-i.e. $\lambda_{t, c}^{1 / 2}$ for countries $c=$ $1,2, \ldots 11$. The estimate country specific uncertainty for the United States reached its peak during the early 1980s that were characterised by a recession and change in the practice of monetary policy referred to as the 'Volcker Experiment'. The mid-1980s saw another increase in US-specific uncertainty corresponding to the savings and loan crisis in 1985-1986. The late 1980s and early 1990s were also characterised by periods of increased uncertainty with the US economy buffeted by a stock market crash, recession and the onset of a credit crunch and the war in Iraq. Uncertainty declined after the mid-1990s but rose following the September 11th terrorist attacks in 2001 remaining elevated until the middle of the decade. Uncertainty was also higher during the recent recession. Note that this estimate of US-specific uncertainty has a correlation of 0.5 with the measure proposed in Jurado et al. (2013). While the two measures coincide during some time periods, several peaks in the Jurado et al. (2013) uncertainty measure are classified as common or 'world' uncertainty by our model 6

The UK specific uncertainty measure peaked during the Sterling crisis of 1976. In the following years, this measure displays spikes during the recession of early 1980s, the exchange crisis in 1985, the ERM exit in 1992. The inflation targetting period was characterised by low volatility until the recent recession when the measure increased again. Canadian uncertainty peaked during 1981, when the country experienced one of its worst recessions. Prominent increases in volatility can also be seen during the early 2000s when the Canadian economy experienced a slowdown coinciding with a large appreciation of the Canadian dollar. Finally, Canada-specific uncertainty increased sharply during the recent recession. German uncertainty is at its highest during the period of re-unification and the ERM crisis in the early 1990s. Note also that the two strongest post-war German recessions in 1974 and 2008 are characterised by increases in uncertainty with the former rise estimated to be substantially larger and the latter episode largely captured by the rise in world-specific uncertainty. The uncertainty in the remaining Euro-Area countries follows a similar pattern, with highs estimated during the oil shock of the early 1970s, the stock market crash of the late1980s, the recessions following the ERM crisis and then during the great recession $[7$ It is interesting to note that uncertainty in Sweden appears to fluctuate more than the Euro-Area countries, with large increases coinciding with the oil shocks of the 1970s, the large depreciation in the exchange rate in 1982,

\footnotetext{
${ }^{5}$ To verify this, we re-estimate our empirical model eliminating any non-real activity series from our panel. The resulting measure of common uncertainty (see technical appendix) is similar to the measure of Berger et al. (2016), but appears disconnected with periods of financial stress.

${ }^{6}$ The correlation between the Jurado et al. (2013) measure and the sum of US-specific and common uncertainty is 0.6.

${ }^{7}$ Note that we do not include CDS spreads or ratings data for Euro-Area countries as these series are not available over the sample used to estimate the model. This may potentially affect the estimates of country-specific uncertainty towards the end of the sample.
} 
the financial crisis of the early 1990s and finally during the downturn in 2008-2009.

Japanese uncertainty was high during the mid-1970s. It rose again with the bursting of the real-estate bubble in 1990-1991, in the aftermath of the Asian financial crisis and then in 2008/2009. In Australia, country-specific uncertainty was at its peak during the recession of the mid-1970s. Uncertainty remained elevated through the 1980s peaking after the stock market crash of 1987. Uncertainty rose again in 1991, when the Australian economy was embroiled in a deep recession. The slowdowns in 2001 and then in 2008/2009 also coincided with increasing uncertainty. 


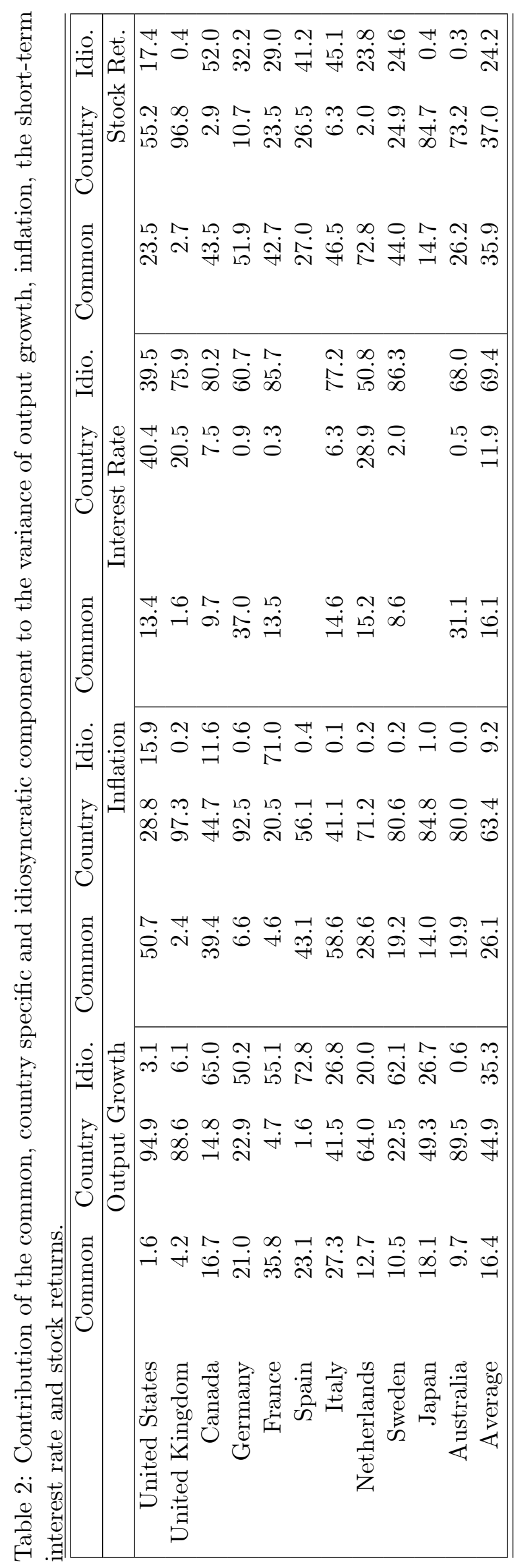




\section{$3.2 \quad$ Variance decomposition}

One of the key questions that we wish to address using our empirical model is to investigate how important the common uncertainty measure has been in driving the volatility of key macroeconomic and financial variables. We do this by decomposing the unconditional variance into contributions from $\lambda_{t}, \gamma_{t}$ and $h_{i t}$ respectively. The structure of the model implies that these contributions can be calculated simply using equation 11. Note that as the variance in the model are time-varying, the implied decomposition changes over time as well.

Table 2 presents the contribution of of 'world' or common, country-specific and idiosyncratic uncertainty to the unconditional volatility of output growth, Inflation, the short-term government rate and stock returns. Note that the table presents the average of the contributions across time. The first three columns of the table show the decomposition for output growth. Output growth is defined as the quarterly growth of GDP for all countries except Sweden where this variable is unavailable and we report the results for the volatility of the growth of industrial production. The country-specific uncertainty is, in general, estimated to be more important for output volatility than 'world' uncertainty implying that domestic uncertainty shocks are largely responsible for driving this variable. However, the role played by common uncertainty is non-negligible. On average, this contribution ranges from a modest $2 \%$ to $5 \%$ for the United States and the United Kingdom to a high of around 35\% for France. The average contribution is greater than $10 \%$ for countries other than United States and United Kingdom.

Columns 4 to 6 of table 2 decompose the unconditional volatility of CPI inflation. Across countries, common uncertainty is estimated to be more important for inflation volatility than the variance of output growth, with a cross-country mean contribution of 26\%. Average contributions are around $40 \%$ to $50 \%$ for countries such as United States, Canada, Italy and Spain, with the contribution in Japan, Australia, Netherlands and Sweden ranging between $14 \%$ to $30 \%$. In contrast, the importance of 'world' uncertainty is estimated to be small for inflation variance in the United Kingdom, Germany and France. For these countries, inflation variance is persistently high during the 1970s and the early 1980s with this pattern shared by country-specific uncertainty for the United Kingdom and Germany and by idiosyncratic uncertainty for France.

Columns 7 to 9 of the table show the decomposition of the unconditional variance of the short-term government rate. Note that this variable was not included in the data set for Japan and Spain because the available data over some sub-samples was characterised by discrete changes in this variable, with this feature resulting in estimation difficulties ${ }^{8}$ For countries such as the US, Germany, Netherlands and Australia, the contribution of common uncertainty to the volatility of this variable is higher than the estimate for output growth variance. It is interesting to note that idiosyncratic uncertainty plays a major role. If one interprets the idiosyncratic component of the interest rate as an approximation to the monetary policy shock, then this suggests that monetary policy uncertainty has played an important role in driving the variance of short-term rates.

'World' uncertainty also makes an important contribution to the variance of stock returns (columns 10 to 12 of table 2 ). For example, the average contribution of common uncertainty is around $25 \%$ for the United States and Australia and ranges from $25 \%$ to over $70 \%$ for Canada and the Euro-Area countries. On average, common uncertainty is estimated to more important for stock return variance than the remaining variables considered above.

\footnotetext{
${ }^{8}$ Discrete values for the interest rate introduces occasional zeros in the residuals leading to numerical problems in the stochastic volatility part of the MCMC algorithm.
} 

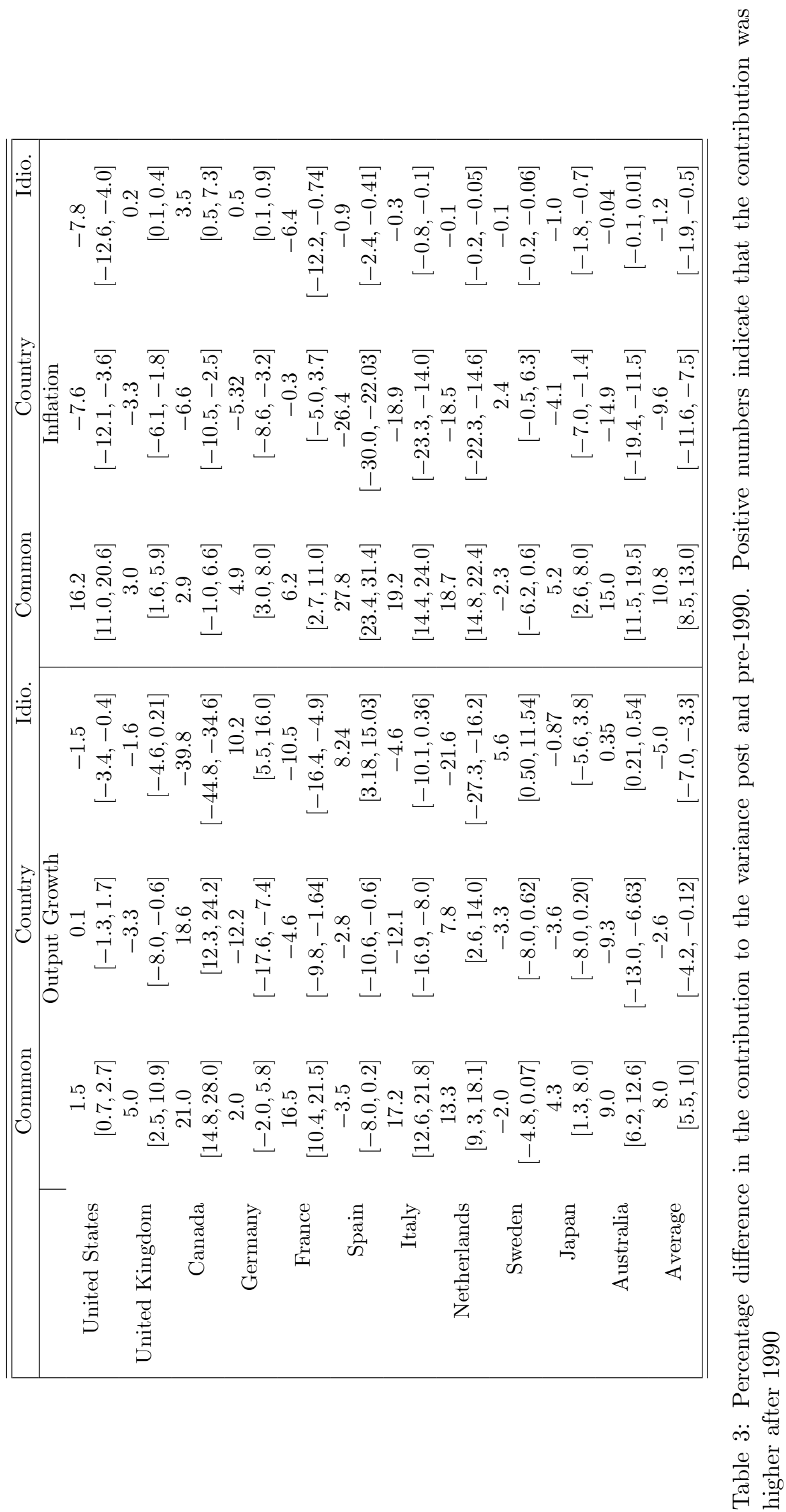


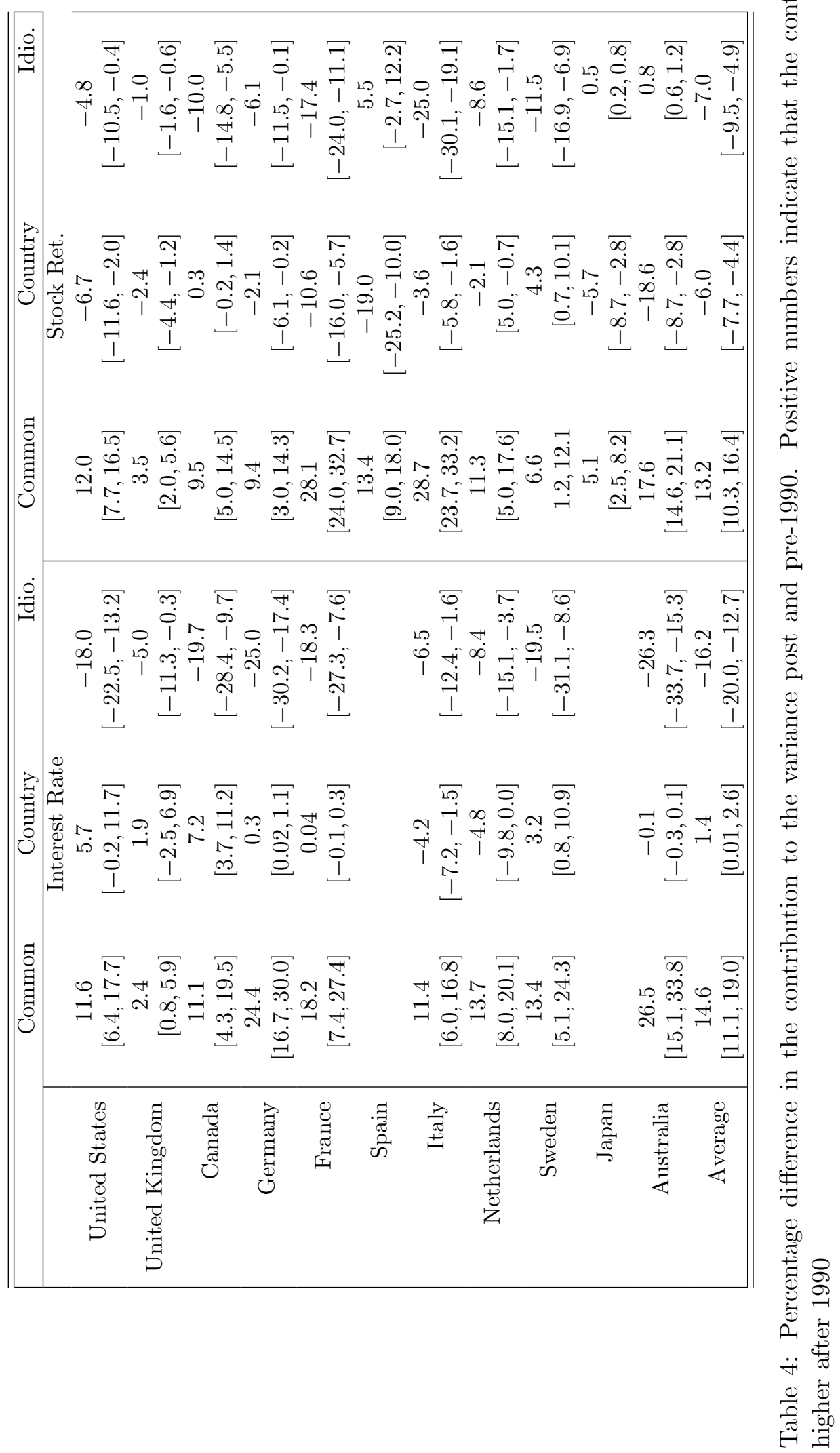




\subsubsection{Changes in the contributions over time}

In tables 3 and 4 , we consider the temporal evolution of the contribution of the common, country-specific and idiosyncratic uncertainty to the variance of output growth, the short-term government rate and stock returns. The tables shows the distribution of the percentage difference in the average contribution calculated after and before 1989 Q4, with positive numbers indicating that the post-1990 contribution was larger.

Consider the change in the contribution of the common component. It is clear from the last row of the table that, on average, the post-1990 contribution of common uncertainty was higher for the variance of all variables, with the largest increase evident for the financial variables $9^{9}$ The $68 \%$ error bands suggest that the null hypothesis of no change can be rejected. Looking at individual countries, this increase in the contribution of common uncertainty appears to be a general phenomenon as far as interest rate and stock return variance is concerned. The change in the contribution is especially larger for the United States, Canada, Germany, France, Italy and Australia. A similar pattern is evident for the change in the contribution of common uncertainty to inflation variance, with the change estimated to be greater than $10 \%$ for United States, Italy, Spain and Australia. The results for the contribution of common uncertainty to output growth variance are more heterogenous. While countries such as Canada, France and Australia appear to have experienced a moderate to large increase in the contribution of common uncertainty, the estimated change is small or statistically equal to zero for the United States, Germany and Spain

The counterpart to the increasing importance of the common component is a decline in the contribution of the country-specific and idiosyncratic components for output growth, inflation and stock returns and a decline in the role of the idiosyncratic uncertainty in the case of the short-term interest rate.

In summary, the variance decomposition exercise suggests three results. First, we find that the role played by 'world' uncertainty in driving the variance of real and nominal variables is non-trivial on average. Second, common uncertainty appears to be, on average, more important for the variance of inflation and stock returns than output growth. Finally, the contribution of common uncertainty is estimated to be higher after the 1990s and the co-movement in volatility of key variables has increased. This phenomenon is especially evident for inflation, interest rate and stock return variance. In the next section we test if these results are robust to changes in the specification of the benchmark model.

\subsection{Sensitivity Analysis}

In order to test the robustness of these results, we carry out key sensitivity checks. While our model features time-varying variances, the parameters of the observation and transition equations are assumed to be fixed. To investigate the impact of this assumption, we re-estimate the model over the post-1985 period. This period corresponds roughly to a shift in macroeconomic dynamics for OECD countries, with lower volatility and lower inflation signalling the start of the 'Great Moderation'. The resulting variance decomposition is shown in figure 2 in the technical appendix. The figures show that the key results are preserved. In particular, common uncertainty is estimated to be important in driving the variance of output growth, inflation, interest rates and stock returns with the average contribution increasing after the late 1990s. As a second check, we re-estimate the benchmark model restricting the sample to $2006 \mathrm{Q}$. This is done to account for the possibility of large parameter changes over the recent financial crisis. Figures 3 in the technical appendix again show that the main features of the variance decomposition are preserved in the this alternative specification.

\footnotetext{
${ }^{9}$ Note that, if the post-1990 average is calculated excluding the period after 2006Q4 the same conclusions are reached. The average percentage change in the contribution of the common component [68\% error bands] is 4.6 [2.3, 6.7], 7.0 [4.8,9.4], $10.3[7.6,14.0], 8.2[5.0,11.6]$ for the variance of output growth, inflation, interest rate and stock returns.
} 


\section{Explaining the empirical results. A DSGE model}

The empirical analysis in the paper suggests that the time-varying volatility of key macroeconomic and financial variables is characterised by a common component across countries and that this co-movement has become more important over time. In this section, we build a DSGE model to provide a theoretical explanation for these results. The proposed New Keynesian model features two-countries with recursive preferences (Epstein and Zin (1989) and Weil (1989, 1990)) and long-run risk (Bansal and Yaron (2004), Rabanal et al. (2011) and Rabanal and Rubio-Ramirez (2015)).

The work Colacito and Croce (2013), Kollmann (2015) and Gourio et al. (2013) has also employed recursive preferences and long-run risks in order to understand the correlation patterns between assets prices and macroeconomic aggregates observed in the data across countries. Similar to Benigno et al. (2011), the model presented here can be viewed as an extension of this previous work along several dimensions: we model the supply side more comprehensively as a production economy and add nominal frictions.

\subsection{Summary of the model}

Households in each country form Epstein-Zin preferences, consume, supply labour and invest on a internationally traded riskless bond. Part of the consumption is produced domestically and the rest is imported from the foreign economy. On the supply side, there is a continuum of monopolistically competitive firms that produce an intermediate good by combining labour and (fixed) physical capital. The output of this process is used for the production of the final good, which can be either consumed domestically or exported, by a perfectly competitive sector. Similarly, the foreign consumption good is imported by a perfectly competitive sector. Prices in the intermediate sector are based on Calvo (1983) schemes, while import prices obey the law of one price. Monetary authorities set policy based on a Taylor type rule (Taylor (1993)). Each economy is disturbed by a non-stationary productivity, a stationary productivity and a financial shock. The two stochastic trends are assumed to be co-integrated to ensure the existence of a balanced path. Furthermore, the financial shock is the one used by Smets and Wouters (2007)-i.e. it decreases the value of the bond exogenously. In short, our theoretical setup can be viewed as the two-country version of the model developed by Rudebusch and Swanson (2012) and Swanson (2015). Technical details on the model variables and equations can be found in the technical appendix of the paper. The appendix also provides details on the calibration of the parameters. The calibration is largely standard and uses the parameter values proposed in previous studies.

\subsection{Key implications from the model}

\subsubsection{Heteroscedasticity}

It is interesting to note that this model implies that the volatility of endogenous variables is time-varying without the explicitly need for heteroscedastic shocks. As explained by Rudebusch and Swanson (2012) and Swanson (2015), this heteroscedasticity is a consequence of the nonlinearity of the lifetime preference function as well as the fact that this is a production economy. According to the authors, the existence of labour in the model, the fact that shocks do not enter in the model multiplicatively with respect to wealth and the property that agents' wealth consists of both human and physical capital makes the utility kernel non-homothetic. This induces a small degree of conditional heteroscedasticity, which is further enhanced by the high risk aversion.

As discussed in Theodoridis and Mumtaz (2015), the economic intuition behind this is as follows: The non-homotheticity in household's preferences makes agents' responses to economic shocks depend on the current level of the state of the economy. For instance, when the current level of consumption is low (or the marginal utility of consumption is high) then consumption uncertainty is higher (relative to the case where the initial level of consumption/output is high) and this reflects agents' elevated concerns 

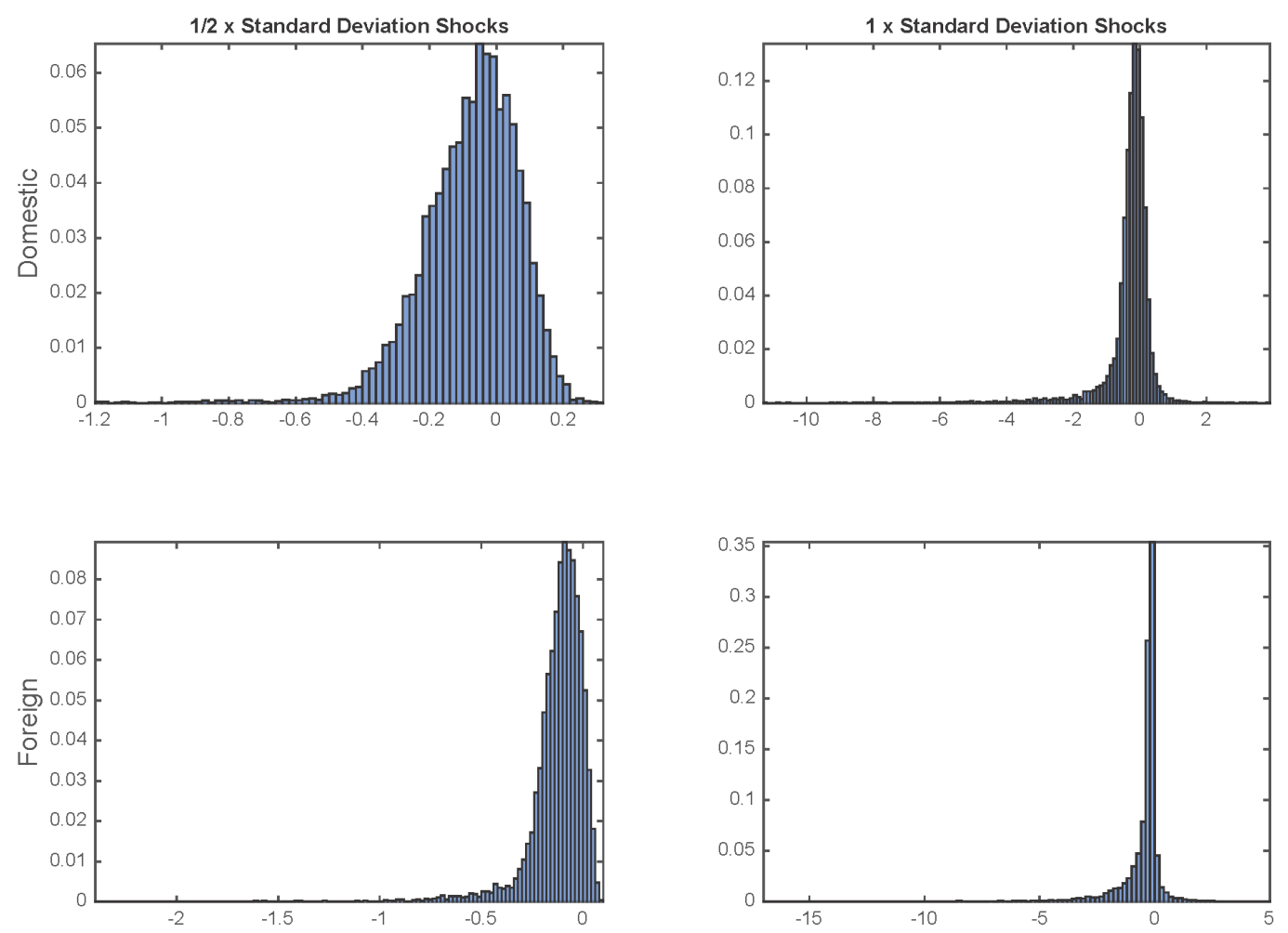

Figure 4: Starting from the stochastic steady state, the model is simulated from 50000 periods using only the foreign financial shock. The histogram illustrates the distribution of the domestic and foreign GDP as deviation from their stochastic steady-state.

about future shocks. As an adverse shock that lowers output further is going to induce a proportionally larger reduction in utility relative to the case where the initial level of consumption/output was high. This channel is the further enhanced by Epstein-Zin preferences as the risk parameter reflects how much agents dislike elevated future uncertainty (Piazzesi and Schneider (2007); Rudebusch and Swanson (2012)).

Loosely speaking, agents in this economy price adverse shocks more heavily in 'bad times' when compared to 'good times'. This behaviour induces a 'wedge' between the mode of the distribution of the state of the economy and its mean as the latter captures these elevated concerns.

Figure 4 illustrates this phenomenon. We use the model developed in this study to simulate the data using only the foreign financial shock ${ }^{10}$ The top row of Figure 4 shows the probability density function of domestic GDP when $1 / 2$ and 1 times the standard deviation foreign financial shocks are used. The second row reports the same information for the foreign GDP. It is apparent that even under $1 / 2$ times standard deviation financial shocks the probability density functions displays a 'downward risk', meaning that the average GDP is below its mode. Furthermore, the asymmetry becomes more pronounced as the size of the shocks increase indicating that agents' economic behavior is also a function of the state of the economy.

Figure 5 elaborates further on the mechanism that delivers these non-linearities. Following Basu and

${ }^{10}$ The technical appendix presents these simulations using the supply shock. The results are very similar to those obtained
using the financial shock.



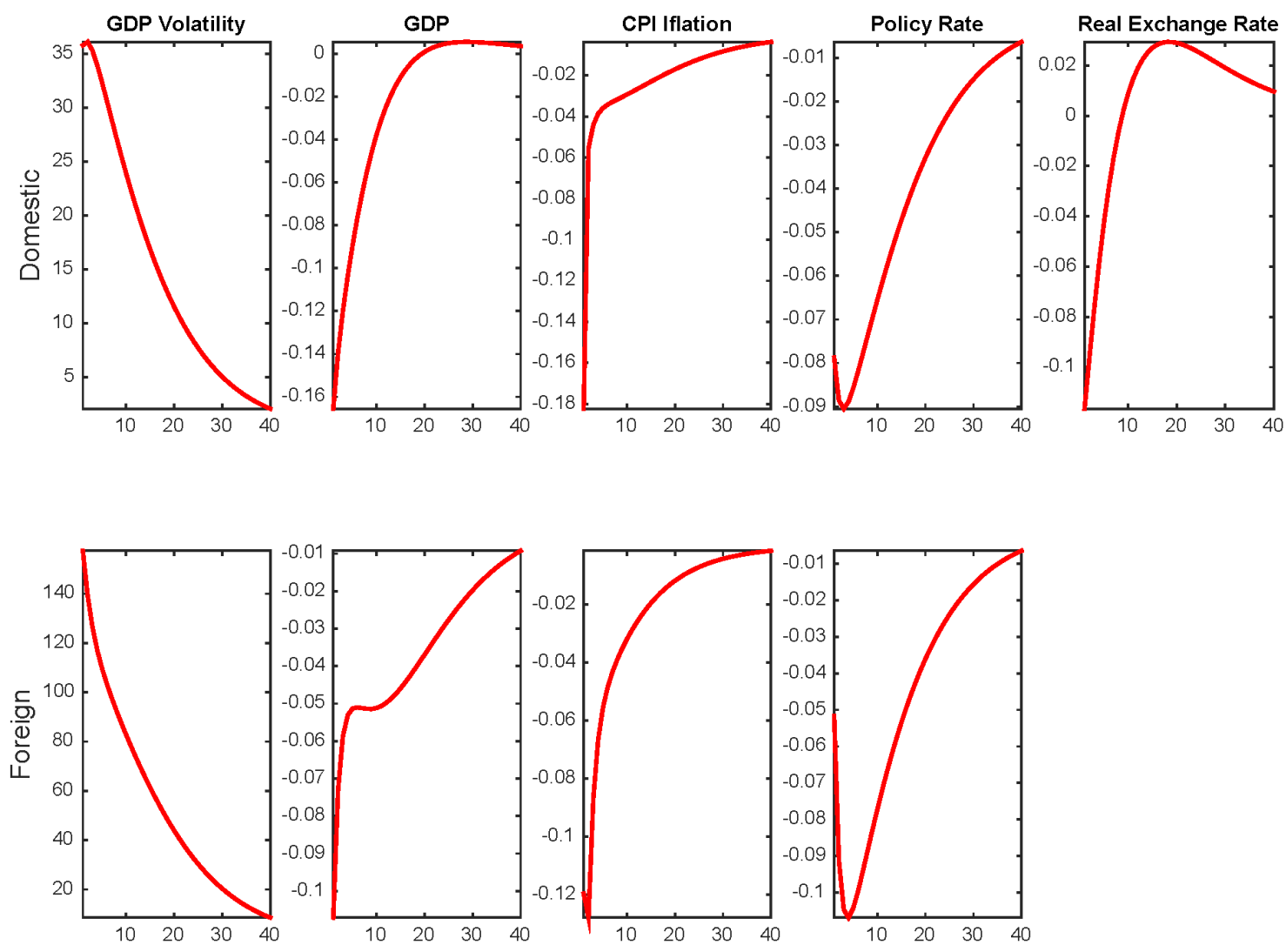

Figure 5: Response to a financial shock. See equation 13 for the definition of GDP volatility. The responses are calculated relative to the stochastic steady state (Juillard and Kamenik, 2005). 
Bundick (2011) and Swanson (2015), we define the volatility of domestic and foreign GDP as follows:

$$
\begin{aligned}
\hat{\sigma}_{Y_{t}}^{2} & =100 \ln \frac{\sigma_{Y_{t}}^{2}}{\sigma_{Y}^{2}} \\
\hat{\sigma}_{Y_{t}^{*}}^{2} & =100 \ln \frac{\sigma_{Y_{t}^{*}}^{2}}{\sigma_{Y^{*}}^{2}} \\
\sigma_{Y_{t}}^{2} & =E_{t}\left(Y_{t+1}-E_{t} Y_{t+1}\right)^{2} \\
\sigma_{Y_{t}^{*}}^{2} & =E_{t}\left(Y_{t+1}^{*}-E_{t} Y_{t+1}^{*}\right)^{2}
\end{aligned}
$$

where $\sigma_{Y}$ and $\sigma_{Y^{*}}$ are the stochastic steady-state values of the domestic and foreign GDP volatility, respectively ${ }^{11}$ The financial shock in this study is similar to the household's budget constraint (Smets and Wouters (2007)) bond shock and it can be thought of as a 'haircut' to the financial wealth (the value of the bonds) 12 This shock increases the effective interest rate faced by foreign households and this suppresses demand and inflation. However, in our model there is an additional channel that lowers demand further and this is uncertainty. Foreign agents see that their consumption falls but they are also assign a non-zero probability to a future shock that is more adverse in terms of its impact on consumption. As they dislike future uncertainty, they reduce consumption further to hedge against future consumption risks. These elevated concerns are captured by the mean of the state vector $\left(E_{t} Y_{t+1}^{*}\right)$ and this opens up a 'wedge' between $Y_{t+1}^{*}$ and $E_{t} Y_{t+1}^{*}$ and volatility rises.

The fall in the foreign demand and, consequently, domestic exports contributes to the volatility increase in the domestic economy (via a similar mechanism like the one discussed above). Moreover, as explained by Colacito and Croce (2013) domestic agents realise that the difficulties faced by the foreign economy limits their ability to hedge against future adverse domestic shocks via risk sharing. In other words, as the degree of risk sharing decreases domestic volatility rises (see Figure 4).

In figure 6, we plots the realised volatility of domestic and foreign output, inflation, policy rate and equity returns when all shocks are active. These simulations further confirm that the data generated by the model with homoscedastic shocks display time-varying variance. ${ }^{13}$

\subsubsection{Comovement in volatility}

The model also implies cross-country comovement in the volatility of endogenous variables. First, as the two economies are symmetric, agents in both countries display precautionary behaviour in response to shocks. Furthermore, shocks originating in the domestic economy are transmitted to the foreign one via asset links (UIP condition) or/and good (imported consumption) trade links. These channels: (i) magnify the precautionary behaviour (see Colacito and Croce (2013, Appendix A)) (ii) cause higher moments to be correlated across the two economies. For example, consider a situation where a positive shock increases the supply of the domestic good and thus reduces domestic uncertainty. As the home economy marginal utility of consumption drops home economy agents find it optimal to transfer resources to the foreign country. This transfer of resources has an ameliorating impact on the volatility of foreign variables and thus induces a correlation between the second moments across countries.

In order to demonstrate this feature, we calculate the correlations across countries of the simulated volatilities shown in figure 6. The first column of table 5 displays the results under the benchmark calibration.

\footnotetext{
${ }^{11}$ The stochastic steady states are calculated as in Juillard and Kamenik $(2005)$.

${ }^{12}$ Smets and Wouters (2007) view this perturbation as a reduced-form net-worth shock.

${ }^{13}$ The volatility is calculated via simulation. The model is simulated for 100000 periods. The first 50000 observations are discarded to eliminate the effects of the initial conditions. The remaining 50000 periods are used to calculate the realised standard deviation of these series based on a 40-quarter rolling window.A very similar picture is obtained when a univariate stochastic volatility model is used to estimate the realised volatility of the simulated data.
} 

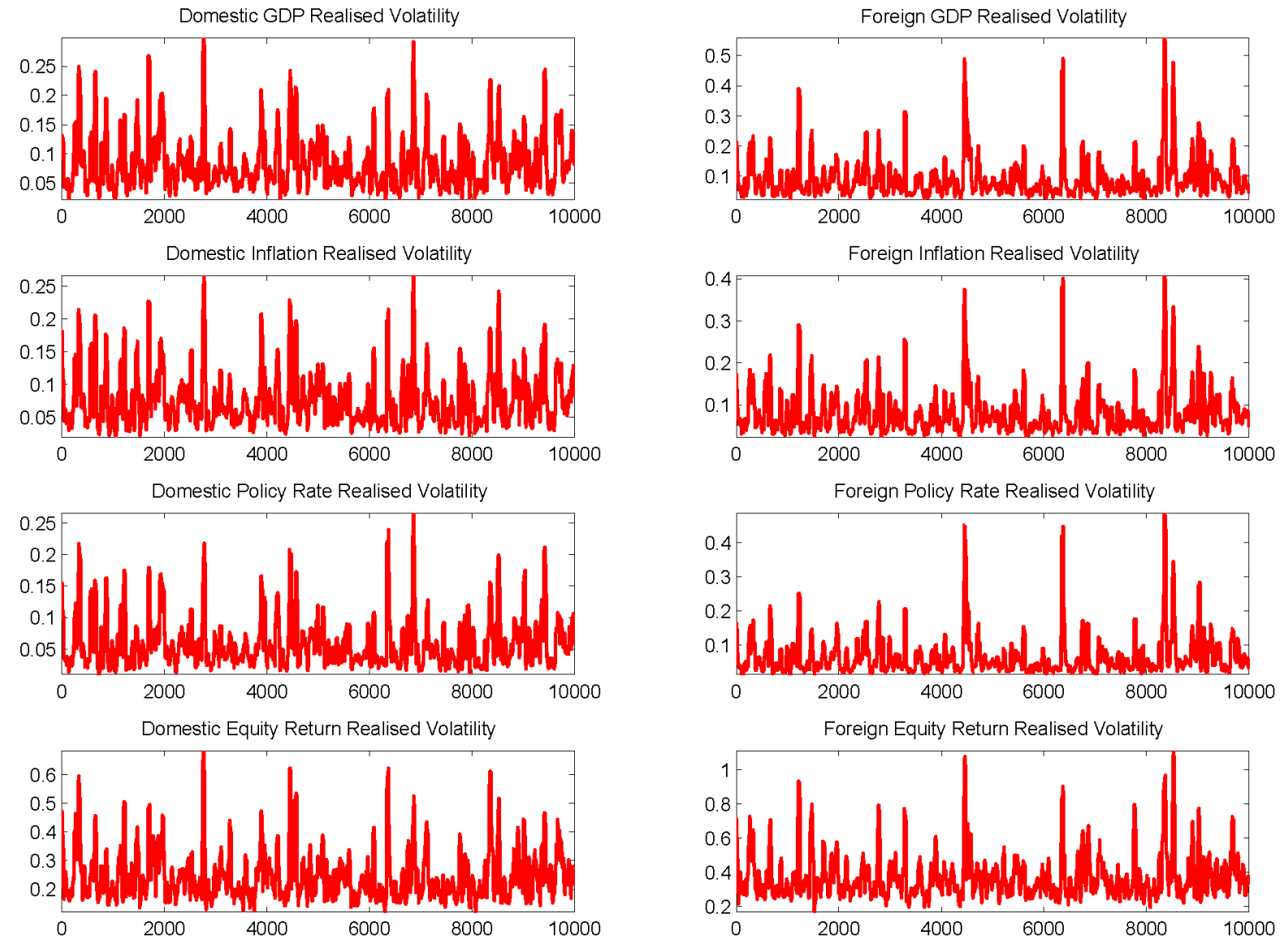

Figure 6: Realised volatility of key model variables. 


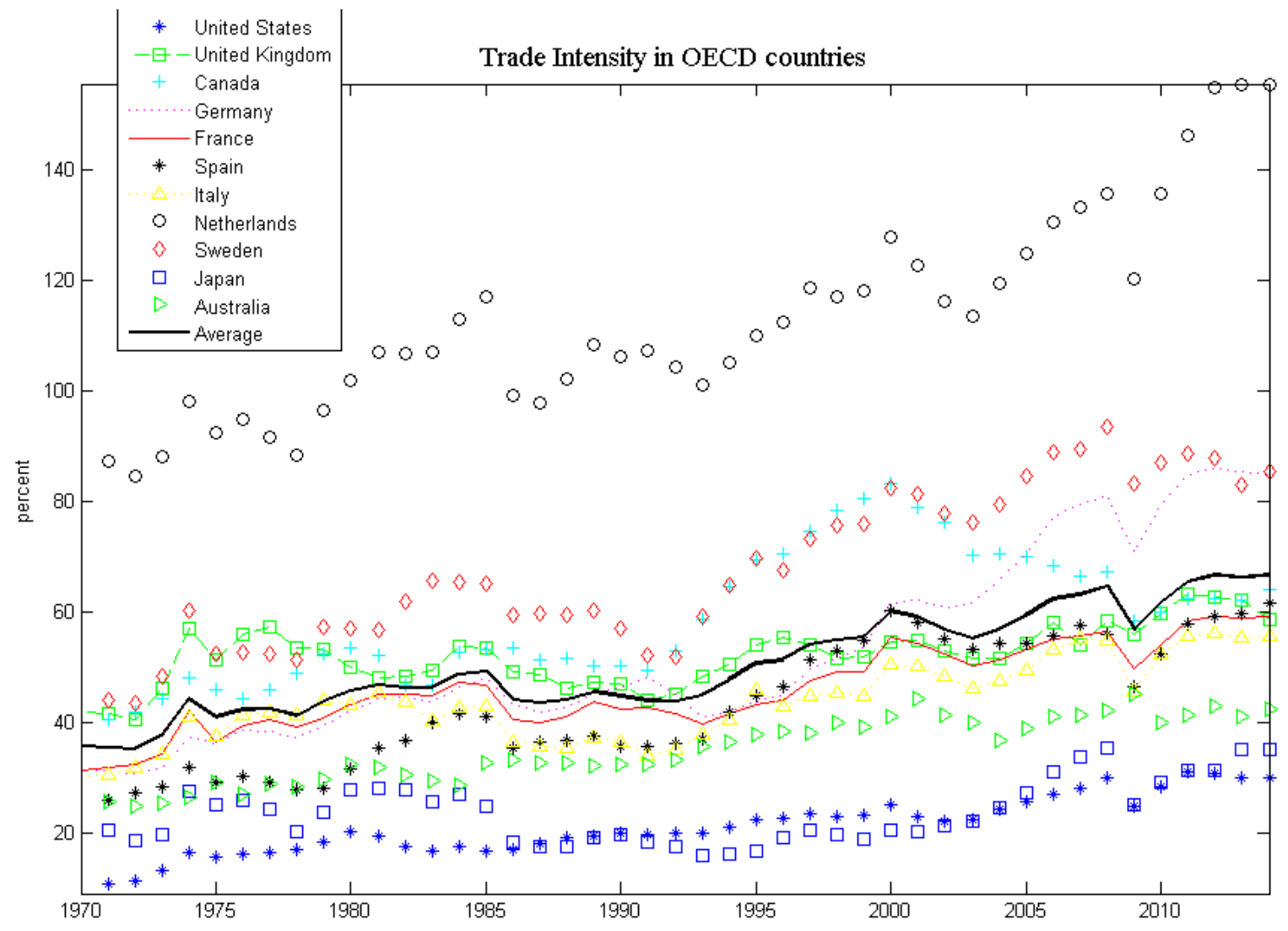

Figure 7: Ratio of total trade to GDP. Source: World Bank 
Table 5: Correlation amongst the time-varying variance of output $\left(\sigma_{t}^{Y}\right)$, inflation $\left(\sigma_{t}^{\pi}\right)$, interest rates $\left(\sigma_{t}^{R}\right)$ and equity returns $\left(\sigma_{t}^{Q^{E}}\right)$ across countries. The superscript $*$ denotes the foreign country.

\begin{tabular}{l|c|c|c|c}
\hline \hline Moments & Benchmark & Strong Home Bias & Smaller response to inflation & Lower Price/wage rigidity \\
\hline \hline $\operatorname{Corr}\left(\sigma_{t}^{Y}, \sigma_{t}^{Y^{*}}\right)$ & 0.60 & 0.28 & 0.63 & 0.80 \\
$\operatorname{Corr}\left(\sigma_{t}^{\pi}, \sigma_{t}^{\pi^{*}}\right)$ & 0.77 & 0.36 & 0.69 & 0.94 \\
$\operatorname{Corr}\left(\sigma_{t}^{R}, \sigma_{t}^{R^{*}}\right)$ & 0.68 & 0.35 & 0.64 & 0.86 \\
$\operatorname{Corr}\left(\sigma_{t}^{Q^{E}}, \sigma_{t}^{Q^{E, *}}\right)$ & 0.83 & 0.46 & 0.75 & 0.77 \\
\hline \hline
\end{tabular}

The estimated correlations capture a number of features highlighted by the empirical results. First, the estimated correlations are non-negligible and show that the volatility co-moves across countries. Second, the correlation of the volatility of output is lower than the correlation of the variance of inflation and the financial variables. This feature is driven by the precautionary mechanism described earlier, where agents with recursive preferences are keen to give up expected future consumption in order to ensure a less volatile future consumption profile and this leads to a transfer of consumption across countries. For this transfer to occur, prices and especially the exchange rate need to adjust in order for the markets to clear. Since domestic prices are staggered (Calvo contracts) most of the variability of the CPI inflation is driven by import prices and, as the law of one price holds for importing firms, by the exchange rate variability. Due to the symmetry of the model, exchange rate uncertainty has very similar effects on CPI inflation in both countries and this induces the higher moments of CPI inflation across countries to co-move strongly. Strong cross-country CPI inflation volatility co-movement implies that the interest rate variance across counties is correlated as monetary authorities stabilise inflation by adjusting the policy rate. In contrast, the equity price volatility correlation is driven by the stochastic discount factor. Equity prices are functions of the stochastic discount factor. As the UIP condition attempts to equalise the stochastic discount factor across countries (risk sharing), this results in a closer co-movement of volatility of this variable.

The second column of table 5 presents second moment correlations estimated assuming a stronger home bias. A comparison with the benchmark correlations make it clear that as the degree of home bias falls, the second moment correlations rise dramatically. As the economy becomes more open, agents are more willing to hedge against future risks about expected utility by transferring resources abroad. Therefore, globalisation and an increase in trade provides one explanation for the empirical result that the role of the common uncertainty component has increased over time and consequently, the volatility of output, inflation and financial variables has become more correlated. Figure 7 shows that the ratio of total trade to GDP, a measure of trade intensity, rose sharply in the countries in our panel after 1990. This date broadly coincides with the increase in the contribution of common uncertainty evident in tables 3 and 4 and again points to the role of globalisation in driving the second moment co-movement estimated by the empirical model.

Of course, a number of other structural changes also took place in the OECD and globalisation is not the only possible explanation for the increased importance of common uncertainty. The DSGE model allows us to consider the plausibility of alternative explanations for this result. First, numerous studies have shown that after the mid-1980s a number of countries in our panel changed their practice of monetary policy and adopted a more anti-inflationary stance (see for example Clarida et al. (1998)). In order to consider the role of systematic policy, we re-calculate the cross-country volatility correlation under the assumption that the coefficient on inflation in the Taylor rule in both countries falls from 1.5 to 1.01. As monetary authorities do not target inflation aggressively, price dispersion rises, magnifying the resource costs associated with sticky prices. This increases the unconditional variance of real and nominal variables in each country but, as shown in the third column of table 5, does not change the second moment correlations relative to the benchmark case. This result suggests that as long as preferences 
of policy makers regarding inflation are symmetric across countries, any change on the weight placed on inflation does not trigger a change in the way that agents try to ensure against future utility risks. Given that anti-inflationary monetary policy was in place across our panel of countries after the mid1990s, a change in the practice of monetary policy is less likely to be an explanation for the increasing role of common uncertainty. Fernandez-Villaverde and Rubio-Ramirez (2008) and Hofmann et al. (2012) present evidence showing that the degree of price and wage nominal rigidities increased during the Great Moderation. The fourth column of table 5 presents the estimated second moment correlations assuming a lower degree of nominal rigidities than the benchmark case. A comparison of these results with the benchmark correlations suggest that a rise in nominal rigidities is associated with decreased comovement in some of the volatilities thus casting doubt on this structural shift as a factor behind the increased role played by the common uncertainty component.

\section{Conclusions}

This paper uses a factor model with stochastic volatility to decompose the time-varying volatility of output, inflation, interest rates and stock returns into contributions from country-specific uncertainty and uncertainty common to all countries. We find that the common component plays an important role in driving the time-varying volatility implying that the second moments are correlated across countries. The empirical results suggest that the role of the common component has increased after the mid-1990s and the second moments of real and financial variables have become more correlated in the recent past. The correlations are estimated to be larger for nominal and financial variables.

In an attempt to provide an economic explanation for these results, we build a two-country DSGE model featuring Epstein Zin preferences. One of the key implications of this preference set-up is that the volatility of endogenous states in the model is time-varying. Moreover, agents are keen to give up expected future consumption in order to ensure a less volatile future consumption profile and this leads to a transfer of consumption across countries. These transfers and risk-sharing result in a close co-movement in second moments across countries. Simulations from the model suggest that an increase in trade openness leads to a closer movement in volatilties and thus provides one explanation for the increasing importance of the common uncertainty factor suggested by the empirical model.

\section{References}

Bansal, Ravi and Amir Yaron, 2004, Risks for the Long Run: A Potential Resolution of Asset Pricing Puzzles, The Journal of Finance 59(4), 1481-1509.

Basu, Susanto and Brent Bundick, 2011, Uncertainty Shocks in a Model of Effective Demand, Boston College Working Papers in Economics 774, Boston College Department of Economics.

Benigno, Gianluca, Pierpaolo Benigno and Salvatore Nistico, 2011, Risk, Monetary Policy and the Exchange Rate, NBER Macroeconomics Annual 2011, Volume 26, NBER Chapters, National Bureau of Economic Research, Inc.

Berger, Tino, Sibylle Grabert and Bernd Kempa, 2016, Global and Country-Specific Output Growth Uncertainty and Macroeconomic Performance, Oxford Bulletin of Economics and Statistics 78(5), 694716.

Berger, Tino, Sibylle Herz and Bernd Kempa, 2014, Global Macroeconomic Uncertainty, mimeo, University of Bern.

Calvo, Guillermo A., 1983, Staggered prices in a utility-maximizing framework, Journal of Monetary Economics 12(3), 383-398. 
Carriero, Andrea, Todd Clark and Massimiliano Marcellino, 2012, Common Drifting Volatility in Large Bayesian VARs, CEPR Discussion Papers 8894, C.E.P.R. Discussion Papers.

Clarida, Richard, Jordi Gali and Mark Gertler, 1998, Monetary policy rules in practice Some international evidence, European Economic Review 42(6), 1033-1067.

Colacito, Riccardo and Mariano M. Croce, 2013, International Asset Pricing with Recursive Preferences, Journal of Finance 68(6), 2651-2686.

Epstein, Larry G and Stanley E Zin, 1989, Substitution, Risk Aversion, and the Temporal Behavior of Consumption and Asset Returns: A Theoretical Framework, Econometrica 57(4), 937-69.

Fernandez-Villaverde, Jesus and Juan F. Rubio-Ramirez, 2008, How Structural Are Structural Parameters?, NBER Macroeconomics Annual 2007, Volume 22, NBER Chapters, National Bureau of Economic Research, Inc, pp. 83-137.

Gourio, Francois, Michael Siemer and Adrien Verdelhan, 2013, International risk cycles, Journal of International Economics 89(2), 471 - 484.

Hofmann, Boris, Gert Peersman and Roland Straub, 2012, Time variation in U.S. wage dynamics, Journal of Monetary Economics 59(8), 769-783.

Juillard, Michel and Ondra Kamenik, 2005, Solving SDGE Models: Approximation About The Stochastic Steady State, Computing in Economics and Finance 2005 106, Society for Computational Economics.

Jurado, Kyle, Sydney C. Ludvigson and Serena Ng, 2013, Measuring Uncertainty, NBER Working Papers 19456, National Bureau of Economic Research, Inc.

Kollmann, Robert, 2015, Exchange Rates Dynamics with Long-Run Risk and Recursive Preferences, Open Economies Review 26(2), 175-196.

Kose, M. Ayhan, Christopher Otrok and Charles H. Whiteman, 2003, International Business Cycles: World, Region, and Country-Specific Factors, American Economic Review 93(4), 1216-1239.

Mumtaz, Haroon and Konstantinos Theodoridis, 2014, The Changing Transmission of Uncertainty shocks in the US: An Empirical Analysis, Working Papers 735, Queen Mary University of London, School of Economics and Finance.

Mumtaz, Haroon and Paolo Surico, 2008, Evolving International Inflation Dynamics: Evidence from a Time-varying Dynamic Factor Model, CEPR Discussion Papers 6767, C.E.P.R. Discussion Papers.

Piazzesi, Monika and Martin Schneider, 2007, Equilibrium Yield Curves, in Daron Acemoglu, Kenneth Rogoff and Michael Woodford (editors), NBER Macroeconomics Annual 2006, Volume 21, NBER Chapters, National Bureau of Economic Research, Inc, pp. 389-472.

Rabanal, Pau and Juan F. Rubio-Ramirez, 2015, Can international macroeconomic models explain lowfrequency movements of real exchange rates?, Journal of International Economics 96(1), 199-211.

Rabanal, Pau, Juan F. Rubio-Ramírez and Vicente Tuesta, 2011, Cointegrated TFP processes and international business cycles, Journal of Monetary Economics 58(2), 156-171.

Rudebusch, Glenn D. and Eric T. Swanson, 2012, The Bond Premium in a DSGE Model with Long-Run Real and Nominal Risks, American Economic Journal: Macroeconomics 4(1), 105-43.

Smets, Frank and Rafael Wouters, 2007, Shocks and Frictions in US Business Cycles: a Bayesian DSGE Approach, American Economic Review 97, 586-606. 
Spiegelhalter, David J., Nicola G. Best, Bradley P. Carlin and Angelika Van Der Linde, 2002, Bayesian measures of model complexity and fit, Journal of the Royal Statistical Society: Series B (Statistical Methodology) 64(4), 583-639.

Swanson, Eric, 2015, A Macroeconomic Model of Equities and Real, Nominal, and Defaultable Debt, Mimeo.

Taylor, John B., 1993, Discretion versus policy rules in practice, Carnegie-Rochester Conference Series on Public Policy 39, 195-214.

Theodoridis, Konstantinos and Haroon Mumtaz, 2015, Dynamic Effects of Monetary Policy Shocks on Macroeconomic Volatility, Technical report.

Weil, Philippe, 1989, The equity premium puzzle and the risk-free rate puzzle, Journal of Monetary Economics 24(3), 401-421.

Weil, Philippe, 1990, Nonexpected Utility in Macroeconomics, The Quarterly Journal of Economics 105(1), 29-42. 


\title{
Technical Appendix: Common and country specific economic uncertainty*
}

\author{
Haroon Mumtaz $\quad$ Konstantinos Theodoridis ${ }^{\ddagger}$
}

October 4, 2016

\begin{abstract}
JEL Codes: C15,C32, E32

Key Words: FAVAR, Stochastic Volatility, Uncertainty Shocks, DSGE Model
\end{abstract}

\section{$1 \quad$ Model}

The factor model is defined as

$$
\begin{aligned}
X_{i t} & =B_{i}^{C} F_{t}^{C}+B_{i}^{W} F_{t}^{W}+e_{i t} \\
F_{t}^{C} & =\alpha+\sum_{j=1}^{P} \rho_{j} F_{t-j}^{C}+\Omega_{t}^{1 / 2} v_{t} \\
F_{t}^{W} & =\zeta+\sum_{j=1}^{P} p_{j} F_{t-j}^{W}+\Upsilon_{t}^{1 / 2} g_{t} \\
e_{i t} & =\sum_{j=1} \mu_{i, j} e_{i t-j}+h_{i t}^{1 / 2} \varepsilon_{i t} \\
R_{t} & =\operatorname{diag}\left(h_{1 t}, . . h_{N t}\right) \\
\Omega_{t} & =A^{-1} H_{t} A^{-1^{\prime}} \\
\Upsilon_{t} & =C^{-1} D_{t} C^{-1^{\prime}} \\
H_{t} & =\operatorname{diag}\left(S_{k} \lambda_{t}\right) \\
D_{t} & =\operatorname{diag}\left(s_{k} \gamma_{t}\right) \\
\ln \lambda_{t} & =\tilde{\alpha}+\tilde{\beta} \ln \lambda_{t-1}+\tilde{Q}^{1 / 2} \tilde{\eta}_{t} \\
\ln \gamma_{t} & =\bar{\alpha}+\bar{\beta} \ln \gamma_{t-1}+\bar{Q}^{1 / 2} \bar{\eta}_{t} \\
\ln h_{i t} & =a_{i}+b_{i} \ln h_{i t-1}+q_{i}^{1 / 2} n_{i t} \\
& \varepsilon_{i t}, v_{t}, \tilde{\eta}_{t}, \bar{\eta}_{t}, n_{i t}{ }^{N}(0,1)
\end{aligned}
$$

\section{Estimation}

In order to deal with rotational indeterminancy we impose the condition that the top $n \times n$ block of the factor loading matrix for each country is diagonal with positive diagonal elements (see Geweke and Zhou (1996)). $n$ denotes the total number of factors. Following Delnegro and Otrok (2005) we fix the initial conditions for the the stochastic volatilities $\lambda_{0}, \gamma_{0}$ and $h_{i 0}$ to fix the scale of the factors.

\footnotetext{
*The views expressed in this paper are those of the authors, and not necessarily those of the Bank of England.

†Queen Mary College. Email: h.mumtaz@qmul.ac.uk

‡Bank of England. Email: Konstantinos.Theodoridis@bankofengland.co.uk
} 


\subsection{Priors}

\subsubsection{Factor loadings}

The prior on $\tilde{B}_{i}=\left[B_{i}^{C} ; B_{i}^{W}\right]$ is normal and is assumed to be $N\left(B_{i, 0}, V_{B}\right)$ where $B_{i, 0}$ is set equal to the loadings obtained using a principal component estimate of $F_{t}=\left[F_{t}^{C}, F_{t}^{W}\right]$. The variance $V_{B}$ is assumed to be equal to 1 . The initial estimate of the factors $F_{t}^{P C}$ provides the initial value of the factors $F_{0 \backslash 0}$ with the initial variance set equal to the identity matrix.

\subsubsection{VAR Coefficients}

Following Banbura et al. (2010) we introduce a natural conjugate prior for the VAR parameters via dummy observations. In our application, the prior means are chosen as the OLS estimates of the coefficients of an AR(1) regression estimated for each endogenous variable using a training sample. As is standard for US data, we set the overall prior tightness $\tau=0.1$. We use the same prior for the AR coefficients of the idiosyncratic errors

\subsubsection{Elements of $S, A, s, C$ and the parameters of the common volatility transition equation}

The elements of $S$ have an inverse Gamma prior: $P\left(S_{i}\right)^{\sim} I G\left(S_{0, i}, V_{0}\right)$. The degrees of freedom $V_{0}$ are set equal to 1. The prior scale parameters are set by estimating the following regression: $\bar{\lambda}_{i t}=S_{0, i} \bar{\lambda}_{t}+\varepsilon_{t}$ where $\bar{\lambda}_{t}$ is the first principal component of the stochastic volatilities $\bar{\lambda}_{i t}$ obtained using a univariate stochastic volatility model for the orthogonalised residuals of each equation of the VARs in equations 2 and 3 estimated via OLS using the principal components $F_{t}^{P C}$.

The prior for the off-diagonal elements $A$ is $A_{0} \sim N\left(\hat{a}^{\text {ols }}, V\left(\hat{a}^{\text {ols }}\right)\right)$ where $\hat{a}^{\text {ols }}$ are the off-diagonal elements of the inverse of the Cholesky decomposition of $\hat{v}^{\text {ols }}$, with each row scaled by the corresponding element on the diagonal. These OLS estimates are obtained using the initial VAR models described above. $V\left(\hat{a}^{\text {ols }}\right)$ is assumed to be diagonal with the elements set equal to 10 times the absolute value of the corresponding element of $\hat{a}^{\text {ols }}$.

The prior for $s$ and $C$ is set exactly as the priors for $S$ and $A$ described above.

We set a normal prior for the unconditional mean $\tilde{\mu}=\frac{\tilde{\alpha}}{1-\tilde{\beta}}$ and $\bar{\mu}=\frac{\bar{\alpha}}{1-\bar{\beta}}$. This prior is $N\left(\mu_{0}, Z_{0}\right)$ where $\mu_{0}=0$ and $Z_{0}=1$. The prior for $\tilde{Q}$ and $\bar{Q}$ is $I G\left(Q_{0}, V_{Q 0}\right)$ where $Q_{0}$ is the average of the variances of the shocks to the transition equations using the initial univariate stochastic volatility estimates described above and $V_{Q 0}=5$. The prior for $\tilde{\beta}$ and $\bar{\beta}$ is $N\left(F_{0}, L_{0}\right)$ where $F_{0}=0.8$ and $L_{0}=1$.

\subsubsection{Parameters of the idiosyncratic shock volatility transition equation}

We set a normal prior for the unconditional mean $\breve{\mu}=\frac{a}{1-b}$. This prior is $N\left(\mu_{0}, Z_{0}\right)$ where $\mu_{0}=0$ and $Z_{0}=1$.The prior for $q_{i}$ is $I G\left(q_{0}, V_{q 0}\right)$ where $q_{0}=0.01$ and $V_{q 0}=5$. The prior for $b$ is $N\left(F_{0}, L_{0}\right)$ where $F_{0}=0.8$ and $L_{0}=1$.

\subsection{Gibbs algorithm}

The Gibbs algorithm involves a draw from the following conditional distributions ( $\Xi$ denotes all other parameters)

1. $G\left(\alpha, \rho_{j} \backslash \Xi\right)$. Given a draw of $\lambda_{t}$, the left and the right hand side variables of the VAR models in equations 2 can be transformed to remove remove the heteroscedasticity in the following manner: Let $y_{t}=F_{t}^{C}$ and $x_{t}=\left[1, F_{t-1}^{C}, F_{t-2}^{C}, . . F_{t-j}^{C}\right]$. Then the following transformation can be applied

$$
\tilde{y}_{t}=\frac{y_{t}}{\lambda_{t}^{1 / 2}}, \tilde{x}_{t}=\frac{x_{t}}{\lambda_{t}^{1 / 2}}
$$

Then the conditional posterior distribution for the VAR coefficients is standard and given by

$$
N\left(\tilde{b}^{*}, \bar{\Omega} \otimes\left(X^{* \prime} X^{*}\right)^{-1}\right)
$$

where $\tilde{b}^{*}=\left(X^{* \prime} X^{*}\right)^{-1}\left(X^{* \prime} Y^{*}\right)$ and $Y^{*}$ and $X^{*}$ denote the transformed data appended with the dummy observations. The covariance matrix is $\bar{\Omega}=A^{-1} \operatorname{diag}(S) A^{-1 \prime}$. 
2. $G\left(\zeta, p_{j} \backslash \Xi\right)$.Given a draw of $\gamma_{t}$, the left and the right hand side variables of the VAR models in equations 3 can be transformed to remove remove the heteroscedasticity in the following manner: Let $y_{t}=F_{t}^{W}$ and $x_{t}=\left[1, F_{t-1}^{W} F_{t-2}^{W}, . . F_{t-j}^{W}\right]$. Then the following transformation can be applied

$$
\tilde{y}_{t}=\frac{y_{t}}{\gamma_{t}^{1 / 2}}, \tilde{x}_{t}=\frac{x_{t}}{\gamma_{t}^{1 / 2}}
$$

Then the conditional posterior distribution for the VAR coefficients is standard and given by

$$
N\left(\tilde{b}^{*}, \bar{\Omega} \otimes\left(X^{* \prime} X^{*}\right)^{-1}\right)
$$

where $\tilde{b}^{*}=\left(X^{* \prime} X^{*}\right)^{-1}\left(X^{* \prime} Y^{*}\right)$ and $Y^{*}$ and $X^{*}$ denote the transformed data appended with the dummy observations. The covariance matrix $\bar{\Omega}=C^{-1} \operatorname{diag}(s) C^{-1 \prime}$.

3. $G(A \backslash \Xi)$. Given a draw for the VAR parameters $\alpha, \rho_{j}$ the model can be written as $A^{\prime}\left(v_{t}\right)=\tilde{e}_{t}$ where $v_{t}=$ $F_{t}^{C}-\left(\alpha+\sum_{j=1}^{P} \rho_{j} F_{t-j}^{C}\right)$ and $\operatorname{VAR}\left(\tilde{e}_{t}\right)=H_{t}$. This is a system of linear equations with a known form of heteroscedasticity. The conditional distributions for a linear regression apply to each equation of this system after a simple GLS transformation to make the errors homoscedastic. The $j$ th equation of this system is given as $v_{j t}=-\check{\alpha} v_{-j t}+\tilde{e}_{j t}$ where the subscript $j$ denotes the $j t h$ column while $-j$ denotes columns 1 to $j-1$. Note that the variance of $\tilde{e}_{j t}$ is time-varying and given by $\lambda_{t} S_{j}$. A GLS transformation involves dividing both sides of the equation by $\sqrt{\lambda_{t} S_{j}}$ to produce $v_{j t}^{*}=-\check{\alpha} v_{-j t}^{*}+\tilde{e}_{j t}^{*}$ where ${ }^{*}$ denotes the transformed variables and $\operatorname{var}\left(\tilde{e}_{j t}^{*}\right)=1$. The conditional posterior for $\check{\alpha}$ is normal with mean and variance given by $M^{*}$ and $V^{*}$ :

$$
\begin{aligned}
M^{*} & =\left(V\left(\hat{a}^{o l s}\right)^{-1}+v_{-j t}^{* \prime} v_{-j t}^{*}\right)^{-1}\left(V\left(\hat{a}^{o l s}\right)^{-1} \hat{a}^{o l s}+v_{-j t}^{* \prime} v_{j t}^{*}\right) \\
V^{*} & =\left(V\left(\hat{a}^{o l s}\right)^{-1}+v_{-j t}^{* \prime} v_{-j t}^{*}\right)^{-1}
\end{aligned}
$$

4. $G(C \backslash \Xi)$. The conditional posterior distribution is identical to that described in step 3 above using the residuals of equation 3 .

5. $G(S \backslash \Xi)$. Given a draw for the VAR parameters $\alpha, \rho_{j}$ the model can be written as $A^{\prime}\left(v_{t}\right)=\tilde{e}_{t}$. The jth equation of this system is given by $v_{j t}=-\check{\alpha} v_{-j t}+\tilde{e}_{j t}$ where the variance of $e_{j t}$ is time-varying and given by $\lambda_{t} S_{j}$. Given a draw for $\lambda_{t}$ this equation can be re-written as $\bar{v}_{j t}=-\check{\alpha} \bar{v}_{-j t}+\bar{e}_{j t}$ where $\bar{v}_{j t}=\frac{v_{j t}}{\lambda_{t}^{1 / 2}}$ and the variance of $\bar{e}_{j t}$ is $S_{j}$. The conditional posterior is for this variance is inverse Gamma with scale parameter $\bar{e}_{j t}^{\prime} \bar{e}_{j t}+S_{0, j}$ and degrees of freedom $V_{0}+T$.

6. $G(s \backslash \Xi)$. This draw is done in exactly the same manner as step 5 above using the residuals of equation 3 , the matrix $C$ and the volatility $\gamma_{t}$.

7. Elements of $\lambda_{t}$. Conditional on the VAR coefficients, and the parameters of the volatility transition equation, the model in equations 2 and 10 has a multivariate non-linear state-space representation. Carlin et al. (1992) show that the conditional distribution of the state variables in a general state-space model can be written as the product of three terms:

$$
\tilde{h}_{t} \backslash Z_{t}, \Xi \propto f\left(\tilde{h}_{t} \backslash \tilde{h}_{t-1}\right) \times f\left(\tilde{h}_{t+1} \backslash \tilde{h}_{t}\right) \times f\left(Z_{t} \backslash \tilde{h}_{t}, \Xi\right)
$$

where $\Xi$ denotes all other parameters, $Z_{t}$ denotes the endogenous variables in equation 2 and $\tilde{h}_{t}=\ln \lambda_{t}$. In the context of stochastic volatility models, Jacquier et al. (1994) show that this density is a product of log normal densities for $\lambda_{t}$ and $\lambda_{t+1}$ and a normal density for $Z_{t}$. Carlin et al. (1992) derive the general form of the mean and variance of the underlying normal density for $f\left(\tilde{h}_{t} \backslash \tilde{h}_{t-1}, \tilde{h}_{t+1}, \Xi\right) \propto f\left(\tilde{h}_{t} \backslash \tilde{h}_{t-1}\right) \times f\left(\tilde{h}_{t+1} \backslash \tilde{h}_{t}\right)$ and show that this is given as

$$
f\left(\tilde{h}_{t} \backslash \tilde{h}_{t-1}, \tilde{h}_{t+1}, \Xi\right) \sim N\left(B_{2 t} b_{2 t}, B_{2 t}\right)
$$

where $B_{2 t}^{-1}=Q^{-1}+\bar{F}^{\prime} Q^{-1} \bar{F}$ and $b_{2 t}=\tilde{h}_{t-1} \bar{F}^{\prime} Q^{-1}+\tilde{h}_{t+1} Q^{-1} \bar{F}$. Here $\bar{F}$ denotes the autoregressive coefficient of the transition equation and $Q$ is the variance of the shock to the transition equation in companion form. Note that due to the non-linearity of the observation equation of the model an analytical expression for the 
complete conditional $\tilde{h}_{t} \backslash Z_{t}, \Xi$ is unavailable and a metropolis step is required. Following Jacquier et al. (1994) we draw from 14 using a date-by-date independence metropolis step using the density in 15 as the candidate generating density. This choice implies that the acceptance probability is given by the ratio of the conditional likelihood $f\left(Z_{t} \backslash \tilde{h}_{t}, \Xi\right)$ at the old and the new draw. To implement the algorithm we begin with an initial estimate of $\tilde{h}=\ln \bar{\lambda}_{t}$ We set the matrix $\tilde{h}^{\text {old }}$ equal to the initial volatility estimate. Then at each date the following two steps are implemented:

(a) Draw a candidate for the volatility $\tilde{h}_{t}^{\text {new }}$ using the density 14 where $b_{2 t}=\tilde{h}_{t-1}^{\text {new }} \bar{F}^{\prime} Q^{-1}+\tilde{h}_{t+1}^{\text {old }} Q^{-1} \bar{F}$ and $B_{2 t}^{-1}=Q^{-1}+\bar{F}^{\prime} Q^{-1} \bar{F}$

(b) Update $\tilde{h}_{t}^{\text {old }}=\tilde{h}_{t}^{\text {new }}$ with acceptance probability $\frac{f\left(Z_{t} \backslash \tilde{h}_{t}^{\text {new }}, \Xi\right)}{f\left(Z_{t} \backslash \tilde{h}_{t}^{\text {old }}, \Xi\right)}$ where $f\left(Z_{t} \backslash \tilde{h}_{t}, \Xi\right)$ is the likelihood of the VAR for observation $t$ and defined as $\left|\Omega_{t}\right|^{-0.5}-0.5 \exp \left(\tilde{e}_{t} \Omega_{t}^{-1} \tilde{e}_{t}^{\prime}\right)$ where $\tilde{e}_{t}=F_{t}^{c}-\left(\alpha+\sum_{j=1}^{P} \rho_{j} F_{t-j}^{C}\right)$ and $\Omega_{t}=A^{-1}\left(\exp \left(\tilde{h}_{t}\right) S\right) A^{-1^{\prime}}$

Repeating these steps for the entire time series delivers a draw of the stochastic volatilties 1

8. The draw for $\gamma_{t}$ is carried out using the procedure described in step 7 above.

9. $G\left(h_{i t} \backslash \Xi\right)$ : Given a draw for the factors, the parameters of the transition equation 12 and the factor loadings $\tilde{B}_{i}=\left[B_{i}^{C} ; B_{i}^{W}\right]$ and the autoregressive coefficients $\mu_{i, j}$, a univariate stochastic volatility model applies for each $i$ :

$$
\begin{aligned}
X_{i t}^{*} & =B_{i} F_{t}^{*}+h_{i t}^{1 / 2} \varepsilon_{i t} \\
\ln h_{i t} & =a_{i}+b_{i} \ln h_{i t-1}+q_{i}^{1 / 2} n_{i t}
\end{aligned}
$$

where $X_{i t}^{*}=X_{i t}-\sum_{j=1}^{P} \mu_{i, j} X_{i t-j}$ and $F_{t}^{*}=F_{t}-\sum_{j=1}^{P} \mu_{i, j} F_{i t-j}$. The algorithm of Jacquier et al. (1994) (described above) is used to draw $h_{i t}$.

10. $G(\tilde{\alpha}, \tilde{\beta}, \tilde{Q} \backslash \Xi)$.We re-write the transition equation in deviations from the mean

$$
\tilde{h}_{t}-\tilde{\mu}=\tilde{\beta}\left(\tilde{h}_{t-1}-\tilde{\mu}\right)+\eta_{t}
$$

where $\tilde{h}_{t}=\ln \lambda_{t}$ and the elements of the mean vector $\tilde{\mu}$ are defined as $\frac{\tilde{\alpha}}{1-\tilde{\beta}}$. Conditional on a draw for $\tilde{h}_{t}$ and $\tilde{\mu}$ the transition equation 16 is a simply a linear regression and the standard normal and inverse Gamma conditional posteriors apply. Consider $\tilde{h}_{t}^{*}=\tilde{\beta} \tilde{h}_{t-1}^{*}+\eta_{t}, V A R\left(\eta_{t}\right)=\tilde{Q}$ and $\tilde{h}_{t}^{*}=\tilde{h}_{t}-\mu, \tilde{h}_{t-1}^{*}=\tilde{h}_{t-1}-\mu$. The conditional posterior of $\tilde{\beta}$ is $N\left(\theta^{*}, L^{*}\right)$ where

$$
\begin{aligned}
\theta^{*} & =\left(L_{0}^{-1}+\frac{1}{\tilde{Q}} \tilde{h}_{t-1}^{* \prime} \tilde{h}_{t-1}^{*}\right)^{-1}\left(L_{0}^{-1} F_{0}+\frac{1}{\tilde{Q}} \tilde{h}_{t-1}^{* \prime} \tilde{h}_{t}^{*}\right) \\
L^{*} & =\left(L_{0}^{-1}+\frac{1}{\tilde{Q}} \tilde{h}_{t-1}^{* \prime} \tilde{h}_{t-1}^{*}\right)^{-1}
\end{aligned}
$$

The conditional posterior of $\tilde{Q}$ is inverse Gamma with scale parameter $\eta_{t}^{\prime} \eta_{t}+Q_{0}$ and degrees of freedom $T+V_{Q 0}$.

Given a draw for $\tilde{\beta}$, equation 16 can be expressed as $\bar{\Delta} \tilde{h}_{t}=C \mu+\eta_{t}$ where $\bar{\Delta} \tilde{h}_{t}=\tilde{h}_{t}-\tilde{\beta} \tilde{h}_{t-1}$ and $C=1-\tilde{\beta}$. The conditional posterior of $\tilde{\mu}$ is $N\left(\mu^{*}, Z^{*}\right)$ where

$$
\begin{aligned}
& \mu^{*}=\left(Z_{0}^{-1}+\frac{1}{\tilde{Q}} C^{\prime} C\right)^{-1}\left(Z_{0}^{-1} \mu_{0}+\frac{1}{\tilde{Q}} C^{\prime} \bar{\Delta} \tilde{h}_{t}\right) \\
& Z^{*}=\left(Z_{0}^{-1}+\frac{1}{\tilde{Q}} C^{\prime} C\right)^{-1}
\end{aligned}
$$

Note that $\tilde{\alpha}$ can be recovered as $\tilde{\mu}(1-\tilde{\beta})$.

\footnotetext{
${ }^{1}$ In order to take endpoints into account, the algorithm is modified slightly for the initial condition and the last observation. Details of these changes can be found in Jacquier et al. (1994).
} 
11. $G(\bar{\alpha}, \bar{\beta}, \bar{Q} \backslash \Xi)$.The draw for these parameters is carried out as in step 10 above.

12. $G\left(a_{i}, b_{i}, q_{i} \backslash \Xi\right)$. Given a draw for $h_{i t}$, the conditional posterior distributions for the parameters of the transition equations 12 are as described in step 10 .

13. $G\left(B_{i} \backslash \Xi\right)$ : Given a draw for the factors, the autoregressive coefficients $\mu_{i, j}$ and the variance of the idiosyncratic component, a seperate heteroscedastic linear regression model applies to each $X_{i t}$ and the standard formulae for linear regressions apply. In particular, the model for each $i$ is

$$
X_{i t}=B_{i} F_{t}+e_{i t}
$$

The model can be transformed to remove serial correlation and heteroscedasticity by creating $X_{i t}^{*}=\frac{\left(X_{i t}-\sum_{j=1}^{P} \mu_{i, j} X_{i t-j}\right)}{\sqrt{h_{i t}}}, \tilde{F}_{t}^{*}$ $\frac{\left(F_{t}-\sum_{j=1}^{P} \mu_{i, j} F_{i t-j}\right)}{\sqrt{h_{i t}}}$ The conditional posterior is: $N\left(B_{i}^{*}, \Lambda_{B}\right)$

$$
\begin{aligned}
& B_{i}^{*}=\left(V_{B}^{-1}+\tilde{F}_{t}^{* \prime} \tilde{F}_{t}^{*}\right)^{-1}\left(V_{B}^{-1} B_{i, 0}+\tilde{F}_{t}^{* \prime} X_{i t}^{*}\right) \\
& \Lambda_{B}=\left(V_{B}^{-1}+\tilde{F}_{t}^{* \prime} \tilde{F}_{t}^{*}\right)^{-1}
\end{aligned}
$$

Note that the factors and factor loadings are not identified seperately and the model suffers from the usual rotational indeterminancy problem. In order to deal with this we impose the condition that the top $n \times n$ block of the factor loading matrix for each country is diagonal with positive diagonal elements (see Geweke and Zhou (1996)). $n$ denotes the total number of factors.

14. $G\left(\mu_{i j} \backslash \Xi\right)$. Given a draw for the factors and the factor loadings, equation 4 represents a series of linear regressions with heteroscedastic errors. Given $h_{i t}$, the left and the right hand side can be transformed to remove heteroscedasticity (by dividing by $\sqrt{h_{i t}}$ ). Then the conditional posterior of $\mu_{i j}$ is normal with mean and variance given by the standard formulae for the linear regression model.

15. $G\left(F_{t} \backslash \Xi\right)$ : Given a draw for all other parameters, the algorithm of Carter and Kohn $(2004)$ is used to sample from the conditional posterior distribution of the factors $F_{t}$. The conditional posterior is: $F_{t} \backslash X_{i t}, \Xi \sim$ $N\left(F_{T \backslash T}, P_{T \backslash T}\right)$ and $F_{t} \backslash F_{t+1}, X_{i t}, \Xi \sim N\left(F_{t \backslash t+1, F_{t+1}}, P_{t \backslash t+1, B_{t+1}}\right)$ where $t=T-1, . .1$. As shown by Carter and Kohn (2004) the simulation proceeds as follows. First we use the Kalman filter to draw $F_{T \backslash T}$ and $P_{T \backslash T}$ and then proceed backwards in time using $F_{t \mid t+1}=F_{t \mid t}+P_{t \mid t} f^{\prime} P_{t+1 \mid t}^{-1}\left(F_{t+1}-f F_{t \backslash t}-\mu\right)$ and $P_{t \mid t+1}=$ $P_{t \mid t}-P_{t \mid t} f^{\prime} P_{t+1 \mid t}^{-1} f P_{t \mid t}$. Here $f$ denotes the autoregressive coefficients of the transition equations 2 and 3 in companion form, while $\mu$ denotes the pre-determined regressors in that equation in companion form.

\subsection{A Monte-Carlo experiment}

In order to examine the performance of this algorithm, we consider a small Monte-Carlo experiment

\subsubsection{Data Generating Process}

We generate data from the following FAVAR model with 2 world and country factors. We assume 4 countries with 10 series per country:

$$
\begin{aligned}
X_{i t} & =B_{i}^{C} F_{t}^{C}+B_{i}^{W} F_{t}^{W}+e_{i t} \\
e_{i t} & =0.8 e_{i t-1}+h_{i t}^{1 / 2} \varepsilon_{i t}
\end{aligned}
$$

where the factor loadings $B_{i}$ are drawn from $N(0,0.5)$ and $i=1,2, \ldots 40$. The stochastic volatility process $h_{i t}$ is assumed to follow the process

$$
\ln h_{i t}=-0.1+0.9 \ln h_{i t-1}+(0.5)^{\frac{1}{2}} k_{i t}, k_{i t} \sim N(0,1)
$$

The dynamics of the world and country factors are defined as

$$
\left(\begin{array}{c}
F_{1 t} \\
F_{2 t}
\end{array}\right)=\left(\begin{array}{cc}
0.3 & 0.05 \\
-0.05 & 0.4
\end{array}\right)\left(\begin{array}{l}
F_{1 t-1} \\
F_{2 t-1}
\end{array}\right)+\left(\begin{array}{cc}
0.2 & 0.05 \\
-0.05 & 0.2
\end{array}\right)\left(\begin{array}{l}
F_{1 t-2} \\
F_{2 t-2}
\end{array}\right)+\left(\begin{array}{l}
v_{1 t} \\
v_{2 t}
\end{array}\right), \operatorname{var}\left(\begin{array}{l}
v_{1 t} \\
v_{2 t}
\end{array}\right)=\Omega_{t}
$$



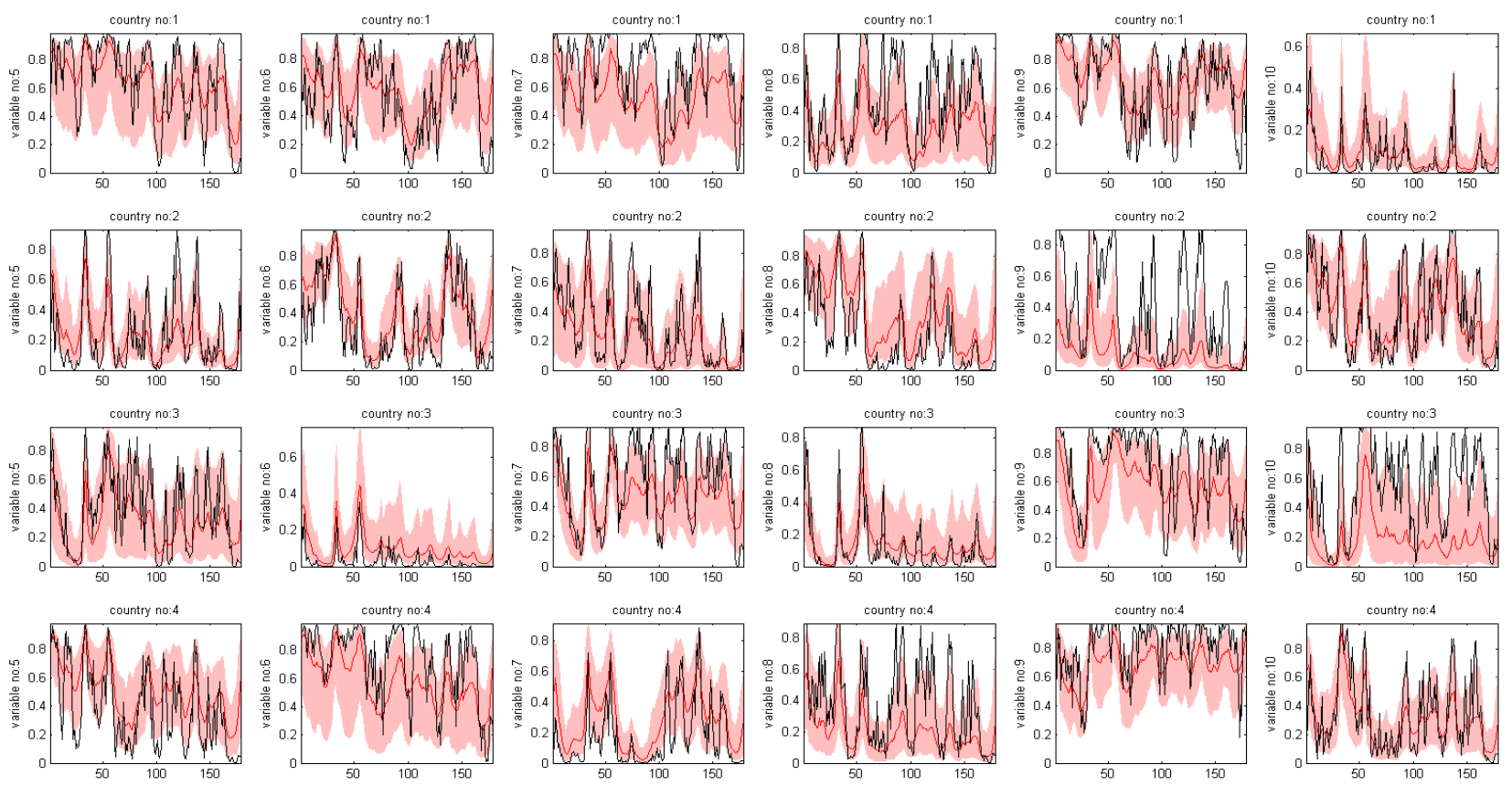

Figure 1: The contribution of the variance of $F_{t}^{W}$ to the variance of $X_{i t}$. The figure shows the estimates for the series where the factor loadings are freely estimated. The first four series for each country are not considered as the factor loadings are fixed to identify the sign of the factors.

The variance process for both the world and the country factor VARs is defined as

$$
\begin{aligned}
\Omega_{t} & =A^{-1}\left(S \lambda_{t}\right) A^{-1^{\prime}} \\
A & =\left(\begin{array}{cc}
1 & 0 \\
-1 & 1
\end{array}\right) \\
S & =\left(\begin{array}{ll}
1 & 0 \\
0 & 2
\end{array}\right) \\
\ln \lambda_{t} & =-0.1+0.9 \ln \lambda_{t-1}+(0.5)^{\frac{1}{2}} v_{t}, v_{t} \sim N(0,1)
\end{aligned}
$$

We generate 300 observations for $X_{i t}$ and drop the first 100 observations to reduce the influenceof initial conditions. Note that the state variables are generated once and then kept fixed. The experiment is repeated 100 times. At each iteration, the model is estimated using the MCMC algorithm described above using 5000 iterations with a burn-in of 4000 observations. The retained draws are used to calculate the contribution of variance of the world factor to the unconditional variance of each variable in the model. The results are shown in figure 1 . The Monte-Carlo estimates of the contribution of $\operatorname{var}\left(F_{t}^{W}\right)$ to each series tracks the true values quite closely suggesting that the algorithm works well.

\section{Recursive Means}

Figure 2 presents the recursive means of retained draws. These are calculated for every 50 draws. The estimates are fairly stable providing evidence in favour of convergence of the algorithm. 

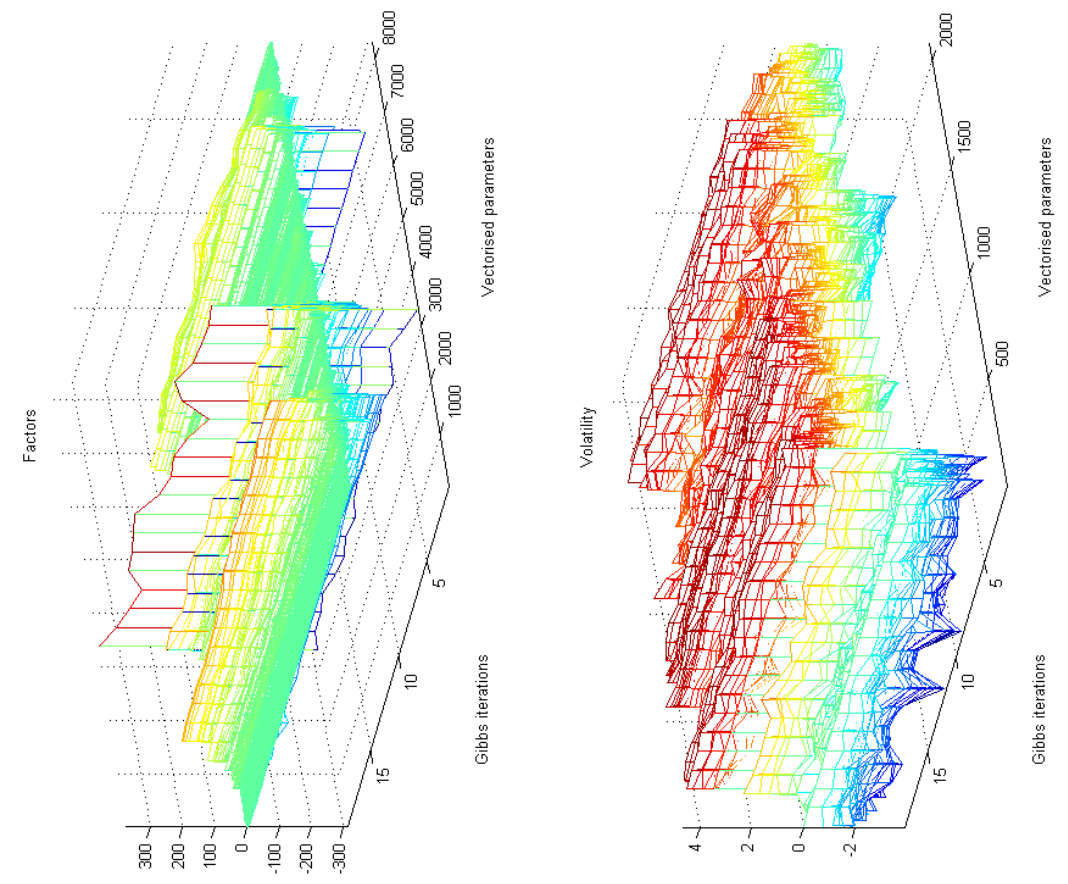

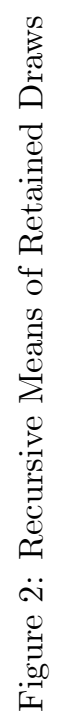
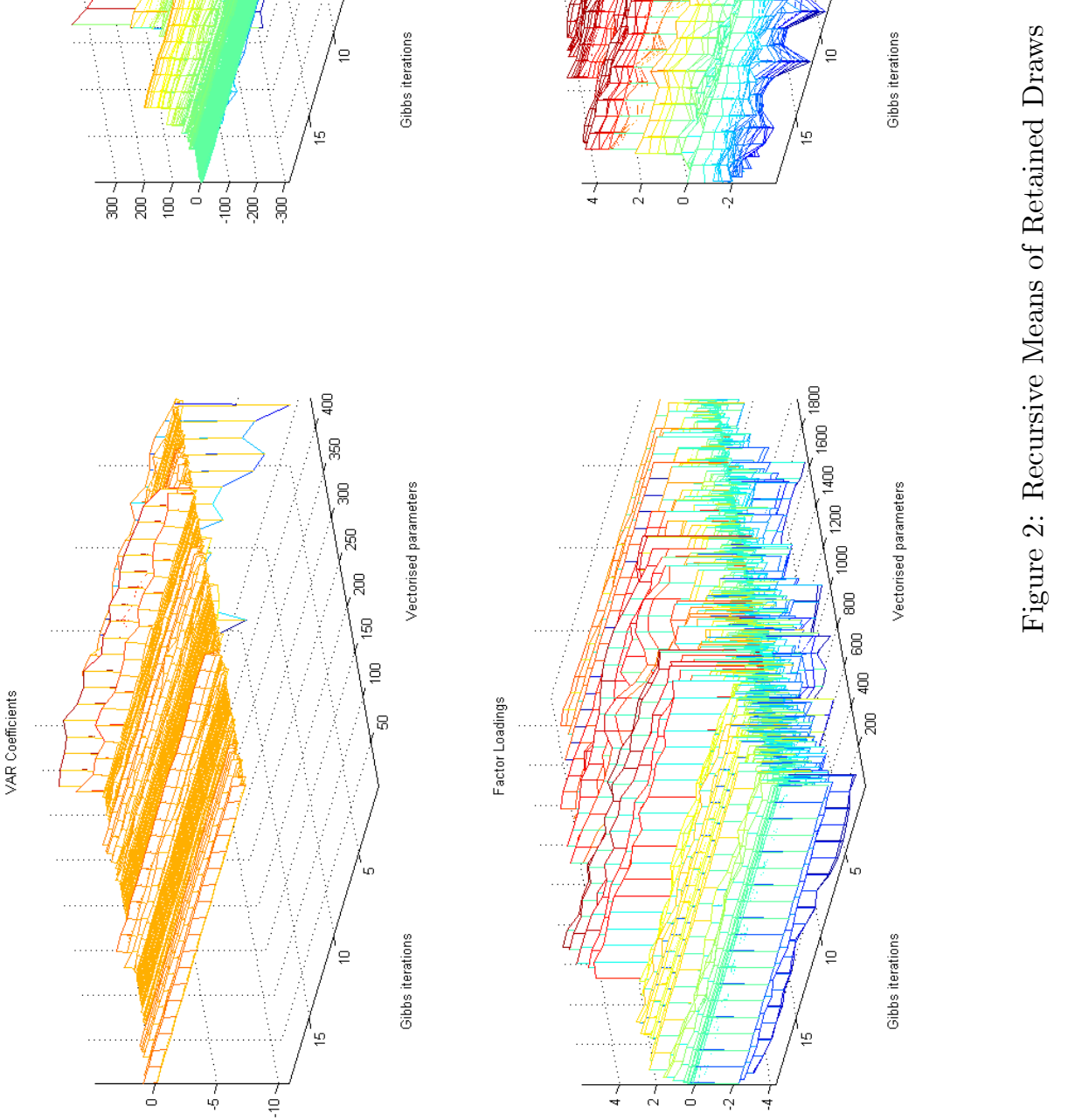


\section{Calculation of the DIC}

The $D I C$ is defined as

$$
D I C=\bar{D}+p_{D}
$$

The first term $\bar{D}=E\left(-2 \ln L\left(\Xi_{i}\right)\right)=\frac{1}{M} \sum_{i}\left(-2 \ln L\left(\Xi_{i}\right)\right)$ where $L\left(\Xi_{i}\right)$ is the likelihood evaluated at the draws of all of the parameters $\Xi_{i}$ in the MCMC chain. This term measures goodness of fit. The second term $p_{D}$ is defined as a measure of the number of effective parameters in the model (or model complexity). This is defined as $p_{D}=$ $E\left(-2 \ln L\left(\Xi_{i}\right)\right)-\left(-2 \ln L\left(E\left(\Xi_{i}\right)\right)\right)$ and can be approximated as $p_{D}=\frac{1}{M} \sum_{i}\left(-2 \ln L\left(\Xi_{i}\right)\right)-\left(-2 \ln L\left(\frac{1}{M} \sum_{i} \Xi_{i}\right)\right){ }^{2}$ Prior distributions on the parameters in our model and the presence of latent variables implies that the number of parameters (as used in the calculation of the Akaike and Schwarz information criterion) do not necessarily represent model complexity. The definition of the effective number of parameters used in the computation of the DIC avoids this problem. Note that the model with the lowest estimated DIC is preferred. Calculation of the DIC requires the calculation of the likelihood of the VAR model. The likelihood function of the model is calculated using a particle filter using 1,000 particles. We employ the Rao-Blackwellized particle filter described in section 2.5.7 of Creal (2009). In particular, given the stochastic volatility the remaining states in the model are linear and Gaussian (i.e. the factors). This version of the filter, thus simulates particles for the non-linear states and evaluates the linear states via the Kalman filter.

\section{Sensitivity Analysis}

\subsection{Estimation using post 1985 data}

Figures 3 presents the variance decomposition from the version of the model estimated using post 1985 data. The estimates show that common uncertainty makes the largest contribution to inflation and stock returns. The contribution of common uncertainty increases after the late 1990s. These features are very similar to the benchmark model.

\subsection{Estimation on pre Great Recession data}

Figure 4 presents the variance decomposition from the version of the model estimated using data up to $2006 \mathrm{Q} 4$. As above, the key features of the results are preserved: The common component of uncertainty makes a larger contribution to nominal variables such as inflation and stock prices and this contribution is larger over the last decade in the sample.

\footnotetext{
${ }^{2}$ The first term in this expression is an average of -2 times the likelihood function evaluated at each MCMC iteration. The second term is $(-2$ times $)$ the likelihood function evaluated at the posterior mean.
} 

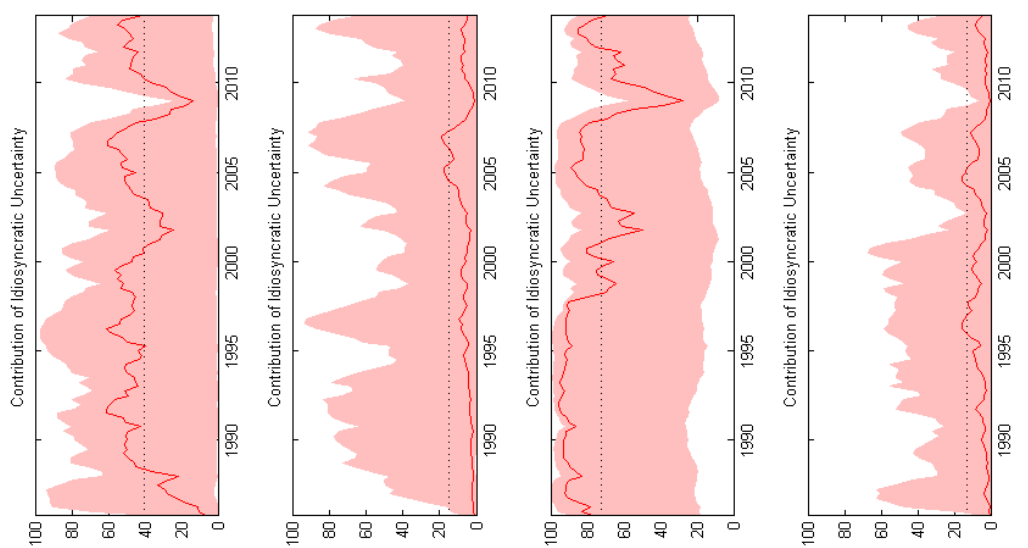

ñ
0
0
0
0
0

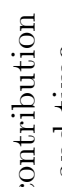

胥

곤

$\Omega$

.

$\overbrace{-1}$

Е

莡

L
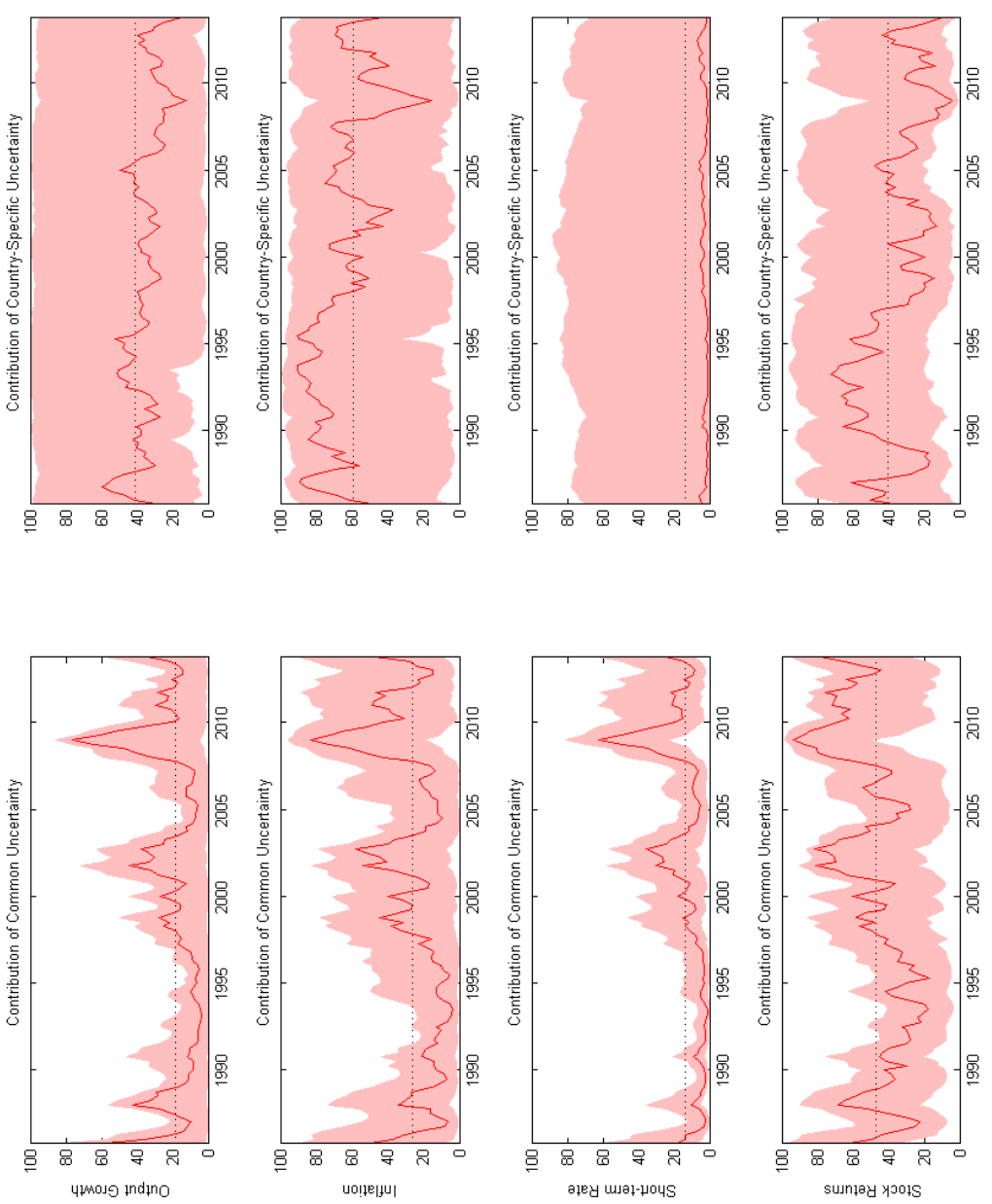

点

‥

,.$\exists$

곡 썽

를

.

盽

.

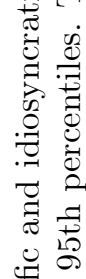

:

员告

节

E)

명

फै

궁

营

害

탈

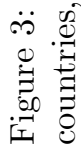



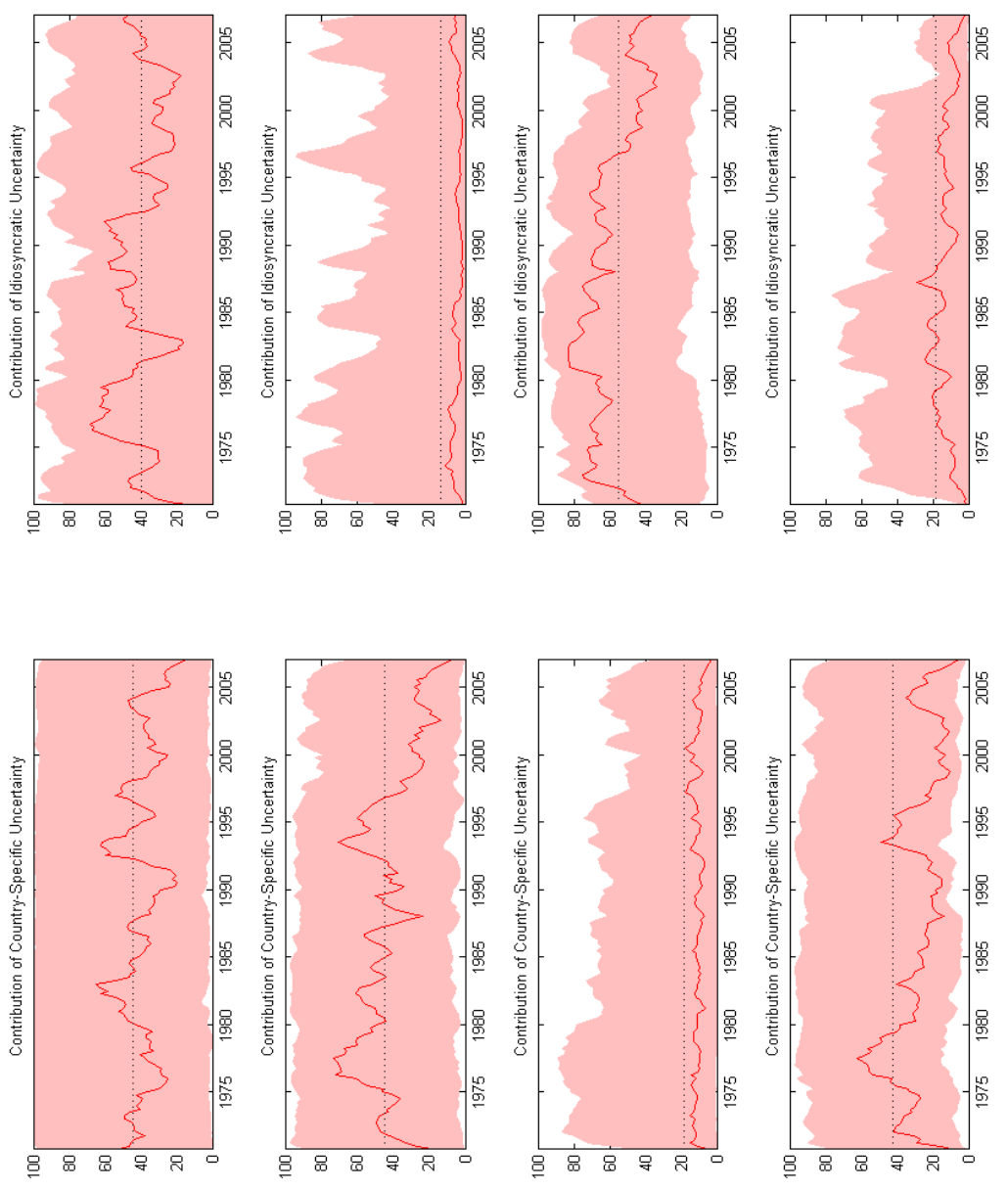

क

.0

丞

웧

.

.

ర্

E

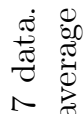

동

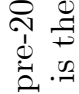

.

을

를

焉㤩

$\exists$

氜

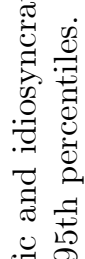
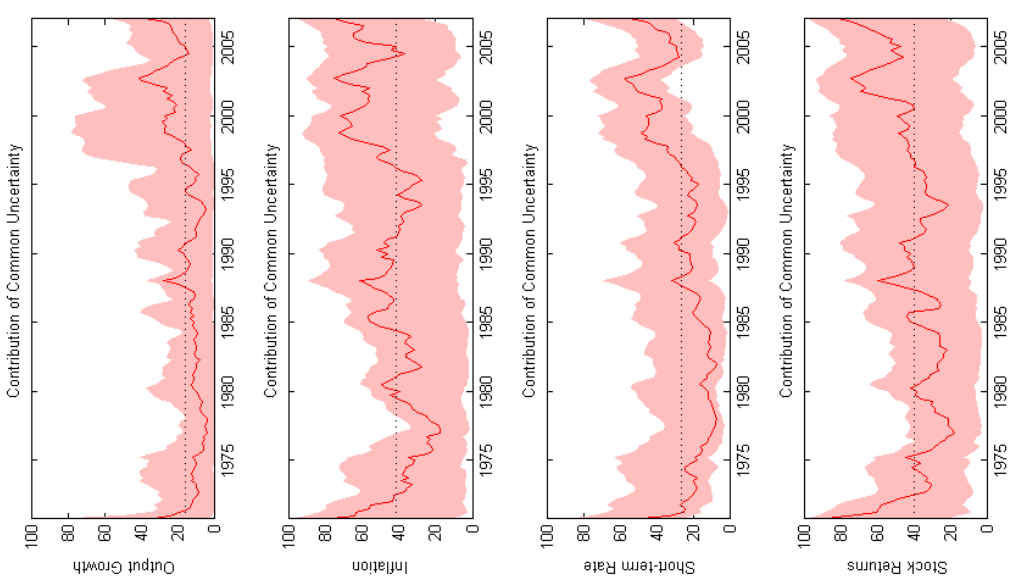

进

定

产

다

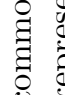

पै

도응

莺

言

过

$\ddot{\nabla}$

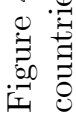




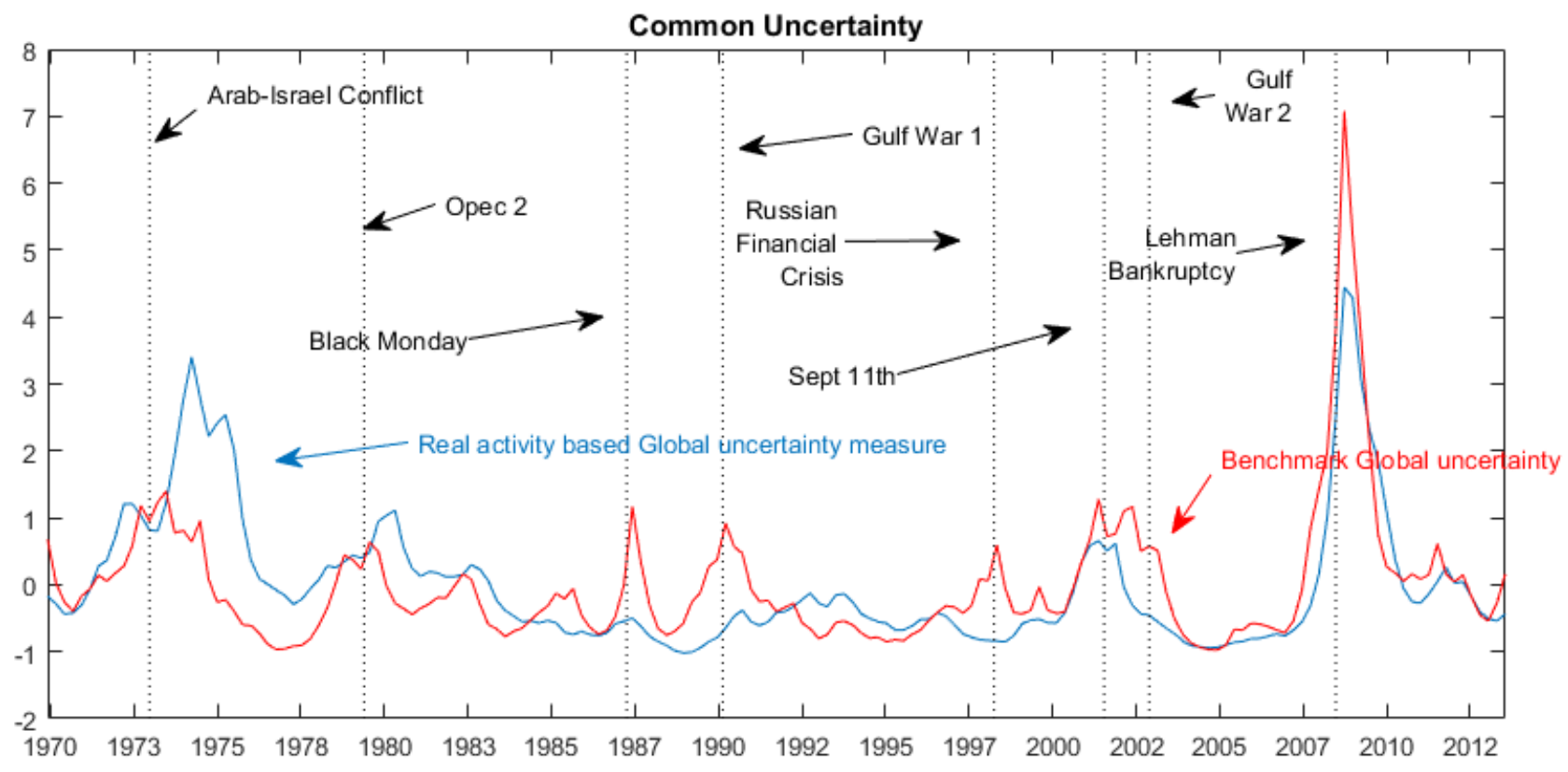

Figure 5: Comparison of benchmark global uncertainty with measure based on real activity series only.

\subsection{Comparison with real activity based measure}

$\begin{array}{rrr} & \text { Benchmark } & \text { Real Activity Only } \\ \text { United States } & 1.6 & 19.3 \\ \text { United Kingdom } & 4.2 & 4.3 \\ \text { Canada } & 16.7 & 17.8 \\ \text { Germany } & 21 & 37.3 \\ \text { France } & 35.8 & 42.7 \\ \text { Spain } & 23.1 & 8.0 \\ \text { Italy } & 27.3 & 30.5 \\ \text { Netherlands } & 12.7 & 26.9 \\ \text { Sweden } & 10.5 & 13.7 \\ \text { Japan } & 18.1 & 22.1 \\ \text { Australia } & 9.7 & 4.7 \\ \text { Average } & 16.4 & 20.7\end{array}$

Table 1: Contribution of common uncertainty to output volatility. The first column reports the benchmark results. The second column is based on the real activity based common uncertainty measure.

We estimate a restricted version of our factor model where we remove all non-real activity series from the data-set. The resulting estimate of Global uncertainty is thus only based on real activity and is a close counterpart of the measure presented in Berger et al. (2016). This measure can be seen in figure 5 alongside our benchmark uncertainty measure. First, real activity based uncertainty has a pattern very similar to the measure of Berger et al. (2016). Both have two main peaks in recession of the mid-1970s (1973-1975) and during the Great Recession. In contrast to benchmark measure, the real activity based Global uncertainty does not show any movement during major events such as black monday, Gulf War 1, Russian Financial crisis and Gulf War 2. It appears that Global output uncertainty has a strong correlation with Global recessions, but may not necessarily pick up uncertainty associated with financial and political events. In terms of contributions to volatility, this may mean that the contribution of an uncertainty measure that only takes real activity shocks into account to output volatility may be be larger. This is what we find (See table 1). For most countries the contribution of Real activity based Global uncertainty to output volatility is larger than the contribution of our benchmark measure that incorporates 
uncertainty associated with nominal and financial variables. In other words, it can be argued that ignoring financial and nominal data when constructing global uncertainty is far from innocuous.

\section{DSGE Model}

The section provides a detailed discussion of the theoretical model. The novel feature of the model developed here is that agents in both economies form recursive preferences (Epstein and Zin (1989), Weil (1989, 1990)) and they do so in a production economy with nominal frictions (New-Keynesian) and long-run risks. To best of our knowledge this is the first study that introduces Epstein and Zin preferences in a two-country New-Keynesian model. The work Colacito and Croce (2013), Kollmann (2015) and Gourio et al. (2013) has also employed recursive preferences and long-run risks in order to understand the correlation patterns between assets prices and macroeconomic aggregates observed in the data across countries. The model presented here can be viewed as an extension of this previous work along several dimensions, either by modelling supply properly (production economy), or/and adding nominal frictions.

From the work of Rudebusch and Swanson (2012) and Swanson (2015) it is known that when additively separable period preferences are combined with Epstein and Zin lifetime preferences, then the second moments of the endogenous state vector of the economy are conditionally heteroskedastic even if the the shocks in the model are homoskedastic. We find this setup attractive as it can generate time-varying second moments without relying on stochastic volatility shocks (see, Fernandez-Villaverde et al. (2011), Fernández-Villaverde et al. (2011) and Mumtaz and Theodoridis (2015), among others). Although stochastic volatility shocks are a useful tool to model an exogenous increase in the macroeconomic uncertainty, they are not always intuitive and, consequently, not easy to motivate.

To be able to understand how uncertainty affects the nominal variables in the data, we proceed by adopting standard New-Keynesian features such as monopolistic competition and nominal rigidities in order for inflation to exist in our theoretical framework.

Finally, the model consists of two equal size countries denoted by $\mathrm{H}$ (home) and $\mathrm{F}$ (foreign), furthermore, quantities and prices in country $\mathrm{F}$ are denoted by asterisks, while those in country $\mathrm{H}$ without asterisks.

\subsection{Firms}

Two types of firms are operated in each economy. The intermediate monopolistically competitive domestic firms that use labour supplied by households and (fixed) capital to produce a differentiated good that is sold to a final good producer who employs a continuum of these differentiated goods in her constant elasticity of substitution CES - production to deliver the final good. The competitive importing firms use a costless technology and turn a homogenous good - bought in the world market - into a differentiated good, which is then sold to the domestic consumers.

Domestic Firms The final good producer's CES production function is given by

$$
\begin{aligned}
\tilde{Y}_{t} & =\left[\int_{0}^{1} \tilde{Y}_{t}(h)^{\frac{\varepsilon-1}{\varepsilon}} d h\right]^{\frac{\varepsilon-1}{\varepsilon}} \\
\tilde{Y}_{t}^{*} & =\left[\int_{0}^{1} \tilde{Y}_{t}(f)^{\frac{\varepsilon-1}{\varepsilon}} d f\right]^{\frac{\varepsilon-1}{\varepsilon}}
\end{aligned}
$$

where $\varepsilon$ denotes the elasticity of substitution between the differentiated goods produced in each country. The final

good producer's demand curve for $y_{i, t}$ arises from the profit minimisation problem $-\max _{\tilde{Y}_{t}(h)}\left\{P_{H, t}\left[\int_{0}^{1} \tilde{Y}_{t}(h)^{\frac{\varepsilon-1}{\varepsilon}} d h\right]^{\frac{\varepsilon-1}{\varepsilon}}-\int_{0}^{1} P_{H}\right.$,

$$
\begin{aligned}
\tilde{Y}_{t}(h) & =\left(\frac{P_{H, t}(h)}{P_{H, t}}\right)^{-\varepsilon} \tilde{Y}_{t} \\
\tilde{Y}_{t}^{*}(f) & =\left(\frac{P_{F, t}^{*}(f)}{P_{F, t}^{*}}\right)^{-\varepsilon} \tilde{Y}_{t}^{*}
\end{aligned}
$$


The final good price index is obtained by combining (17) and 19 )

$$
\begin{aligned}
P_{H, t} & =\left[\int_{0}^{1} P_{H, t}(h)^{1-\varepsilon} d h\right]^{\frac{1}{1-\varepsilon}} \\
P_{F, t}^{*} & =\left[\int_{0}^{1} P_{F, t}^{*}(f)^{1-\varepsilon} d f\right]^{\frac{1}{1-\varepsilon}}
\end{aligned}
$$

Intermediate good producers use the following production function

$$
\begin{aligned}
\tilde{Y}_{t}(h) & =A_{t} \tilde{Z}_{t}\left(L_{t}(h)\right)^{1-\phi} K^{\phi} \\
\tilde{Y}_{t}^{*}(f) & =A_{t}^{*} \tilde{Z}_{t}^{*}\left(L_{t}^{*}(f)\right)^{1-\phi}\left(K^{*}\right)^{\phi}
\end{aligned}
$$

where

$$
\begin{aligned}
& \log \left(A_{t}\right)=\rho_{A} \log \left(A_{t-1}\right)+\sigma_{A} \epsilon_{A, t} \\
& \log \left(A_{t}^{*}\right)=\rho_{A^{*}} \log \left(A_{t-1}^{*}\right)+\sigma_{A^{*}} \epsilon_{A^{*}, t}
\end{aligned}
$$

is a stationary exogenous technological process, $\tilde{Z}_{t}$ is the non-stationary exogenous technological process with $\Gamma_{t}=\frac{\tilde{Z}_{t}}{\tilde{Z}_{t-1}}\left(\Gamma_{t}^{*}=\frac{\tilde{Z}_{t}^{*}}{\tilde{Z}_{t-1}^{*}}\right)$

$$
\begin{aligned}
\log \left(\Gamma_{t}\right) & =\kappa\left[\log \left(\tilde{Z}_{t-1}\right)-\log \left(\tilde{Z}_{t-1}^{*}\right)\right]+\rho_{\Gamma} \log \left(\Delta \Gamma_{t-1}\right)+\sigma_{\Gamma} \epsilon_{\Gamma, t} \\
\log \left(\Gamma_{t}^{*}\right) & =-\kappa\left[\log \left(\tilde{Z}_{t-1}\right)-\log \left(\tilde{Z}_{t-1}^{*}\right)\right]+\rho_{\Gamma^{*}} \log \left(\Gamma_{t-1}^{*}\right)+\sigma_{\Gamma^{*}} \epsilon_{\Gamma^{*}, t}
\end{aligned}
$$

$L_{t}(h)$ is the amount of homogeneous labour rented by the firm and $K$ denotes the amount of (fixed) physical capital. The intermediate firm select $L_{t}(h)$ in order to minimise its production cost

$$
\min _{L_{t}(h)} \tilde{W}_{t} L_{t}(h)+M C_{t} P_{H, t}\left[\tilde{Y}_{t}(h)-A_{t} \tilde{Z}_{t}\left(L_{t}(h)\right)^{1-\phi} K^{\phi}\right]
$$

The real marginal cost for the intermediate firms is given by the first order condition of 29 with respect to $L_{t}(h)$ is

$$
\begin{aligned}
M C_{t}(h) & =\frac{\tilde{W}_{t} L_{t}(h)}{\bar{P}_{H, t}(1-\phi) \tilde{Y}_{t}(h)} \\
M C_{t}^{*}(f) & =\frac{\tilde{W}_{t}^{*} L_{t}^{*}(f)}{\bar{P}_{F, t}^{*}(1-\phi) \tilde{Y}_{t}^{*}(f)}
\end{aligned}
$$

Domestic intermediate good producers are subject to Calvo-type price setting (Calvo (1983)), meaning that only a fraction $-\left(1-\xi_{H}\right)$ - of firms who receives a random signal are allowed to optimally reset their prices

$$
\max _{\breve{P}_{H, t}(h)} E_{t} \sum_{j=0}^{\infty} M_{t, t+j} \xi_{H}^{j}\left[\left\{\frac{\breve{P}_{H, t}(h)}{P_{H, t+j}}-M C_{t+j}(h)\right\} \tilde{Y}_{t+j}(h)\right]
$$

subject to

$$
\tilde{Y}_{t}(h)=\left(\frac{P_{H, t}(h)}{P_{H, t}}\right)^{-\varepsilon} \tilde{Y}_{t}
$$

The first-order condition is expressed as system of difference equations

$$
\begin{aligned}
K_{H, t} & =M C_{t} \tilde{Y}_{t}^{d}+\beta \xi_{H} E_{t} M_{t+1}\left(\frac{1}{\Pi_{H, t+1}}\right)^{-\varepsilon} K_{H, t+1} \\
F_{H, t} & =\tilde{Y}_{t}^{d}+\beta \xi_{H} E_{t} M_{t+1}\left(\frac{1}{\Pi_{H, t+1}}\right)^{1-\varepsilon} F_{H, t+1} \\
\bar{\Pi}_{H, t} & =\frac{\varepsilon}{\varepsilon-1} \frac{K_{H, t}}{F_{H, t}} \\
1 & =\xi_{H}\left(\frac{1}{\Pi_{H, t+1}}\right)^{1-\varepsilon}+\left(1-\xi_{H}\right) \bar{\Pi}_{H, t}^{1-\varepsilon}
\end{aligned}
$$




$$
\begin{aligned}
K_{F, t}^{*} & =M C_{t}^{*} \tilde{Y}_{t}^{d, *}+\beta \xi_{H} E_{t} M_{t+1}^{*}\left(\frac{1}{\Pi_{F, t+1}^{*}}\right)^{-\varepsilon} K_{F, t+1}^{*} \\
F_{F, t}^{*} & =\tilde{Y}_{t}^{d, *}+\beta \xi_{H} E_{t} M_{t+1}^{*}\left(\frac{1}{\Pi_{F, t+1}^{*}}\right)^{1-\varepsilon} F_{F, t+1}^{*} \\
\bar{\Pi}_{F, t}^{*} & =\frac{\varepsilon}{\varepsilon-1} \frac{K_{F, t}^{*}}{F_{F, t}^{*}} \\
1 & =\xi_{H}\left(\frac{1}{\Pi_{F, t+1}^{*}}\right)^{1-\varepsilon}+\left(1-\xi_{H}\right)\left(\bar{\Pi}_{F, t}^{*}\right)^{1-\varepsilon}
\end{aligned}
$$

where $\bar{\Pi}_{H, t} \equiv \frac{\breve{P}_{H, t}}{P_{H, t}}$ and $\bar{\Pi}_{F, t}^{*} \equiv \frac{\breve{P}_{F, t}^{*}}{P_{F, t}^{*}}$.

Market clearing condition in the domestic sector

$$
\begin{aligned}
\tilde{Y}_{t} & =\int_{0}^{1}\left(\frac{P_{H, t}(h)}{P_{H, t}}\right)^{-\varepsilon} d h \tilde{Y}_{t}^{d}=\Delta_{H, t} \tilde{Y}_{t}^{d} \\
\tilde{Y}_{t}^{*} & =\int_{0}^{1}\left(\frac{P_{F, t}^{*}(f)}{P_{F, t}^{*}}\right)^{-\varepsilon} d f \tilde{Y}_{t}^{d, *}=\Delta_{F, t}^{*} \tilde{Y}_{t}^{d, *}
\end{aligned}
$$

where $\Delta_{H, t}=\int_{0}^{1}\left(\frac{P_{H, t}(h)}{P_{H, t}}\right)^{-\varepsilon} d h$ and $\Delta_{F, t}^{*}=\int_{0}^{1}\left(\frac{P_{F, t}^{*}(f)}{P_{F, t}^{*}}\right)^{-\varepsilon} d f$ ae the price dispersion terms and they are given by

$$
\begin{aligned}
\Delta_{H, t}^{\frac{1}{1-\phi}} & =\left(1-\xi_{H}\right) \bar{\Pi}_{H, t}^{-\frac{\varepsilon}{1-\phi}}+\xi_{H}\left(\frac{1}{\Pi_{H, t}}\right)^{-\frac{\varepsilon}{1-\phi}} \Delta_{H, t-1}^{\frac{1}{1-\phi}} \\
\left(\Delta_{F, t}^{*}\right)^{\frac{1}{1-\phi}} & =\left(1-\xi_{H}\right)\left(\bar{\Pi}_{F, t}^{*}\right)^{-\frac{\varepsilon}{1-\phi}}+\xi_{H}\left(\frac{1}{\Pi_{F, t}^{*}}\right)^{-\frac{\varepsilon}{1-\phi}}\left(\Delta_{F, t-1}^{*}\right)^{\frac{1}{1-\phi}}
\end{aligned}
$$

Importing firms The import sector is much simpler, it consists of a continuum of competitive firms that buy a homogenous good from the foreign economy $\tilde{C}_{F, t}^{*}\left(\tilde{C}_{H, t}\right)$ at price $P_{F, t}^{*}\left(P_{H_{t}}\right)$. These firms have access to a costless technology and transform the homogenous good into a differentiated product $\tilde{C}_{F, t}(h)\left(\tilde{C}_{H, t}^{*}(f)\right)$ consumed by domestic households. Perfect competition and zero production cost imply the low of one price holds meaning

$$
\begin{aligned}
P_{F, t} & =S_{t} P_{F, t}^{*} \\
P_{H, t}^{*} & =\frac{P_{H, t}}{S_{t}}
\end{aligned}
$$

where $S_{t}$ is the nominal exchange rate.

\subsection{Households}

The domestic economy is populated by a continuum of households that attain utility from consumption $\tilde{C}_{t}(h)$ $\left(\tilde{C}_{t}^{*}(f)\right)$ and leisure $1-L_{t}(h)\left(1-L_{t}^{*}(f)\right)$. Household's preference preferences are separable

$$
\begin{aligned}
u\left(\tilde{C}_{t}(h), \tilde{Z}_{t}, L_{t}(h)\right) & =\frac{\tilde{C}_{t}(h)^{1-\sigma_{C}}}{1-\sigma_{C}}-\chi_{0} \tilde{Z}_{t}^{1-\sigma_{C}} \frac{L_{t}(h)^{1+\sigma_{L}}}{1+\sigma_{L}} \\
u\left(\tilde{C}_{t}^{*}(f), \tilde{Z}_{t}^{*}, L_{t}^{*}(f)\right) & =\frac{\tilde{C}_{t}^{*}(f)^{1-\sigma_{C}}}{1-\sigma_{C}}-\chi_{0}\left(\tilde{Z}_{t}^{*}\right)^{1-\sigma_{C}} \frac{L_{t}^{*}(f)^{1+\sigma_{L}}}{1+\sigma_{L}}
\end{aligned}
$$

where $\sigma_{L}$ the inverse of the Frisch elasticity and $\sigma_{C}$ the inverse of intertemporal elasticity of substitution. Furthermore, households have recursive preferences (Epstein and Zin (1989), Weil (1989, 1990))

$$
\begin{aligned}
V_{t}(h) & =u\left(\tilde{C}_{t}(h), \tilde{Z}_{t}, L_{t}(h)\right)+\beta\left(E_{t} V_{t+1}(h)^{1-\gamma}\right)^{\frac{1}{1-\gamma}} \\
V_{t}^{*}(f) & =u\left(\tilde{C}_{t}^{*}(f), \tilde{Z}_{t}^{*}, L_{t}^{*}(f)\right)+\beta\left[E_{t}\left(V_{t+1}^{*}(f)\right)^{1-\gamma}\right]^{\frac{1}{1-\gamma}}
\end{aligned}
$$


The attractive feature of the Epstein-Zin preference is that it breaks the link between the intertemporal elasticity parameter and the coefficient of relative risk aversion, which is now controlled by the risk parameter $\gamma$. Aggregate consumption is function of domestically produced and imported consumption

$$
\begin{aligned}
& \tilde{C}_{t}(h)^{\frac{\theta-1}{\theta}}=(1-n)^{\frac{1}{\theta}} \tilde{C}_{H, t}(h)^{\frac{\theta-1}{\theta}}+n^{\frac{1}{\theta}} \tilde{C}_{F, t}(h)^{\frac{\theta-1}{\theta}} \\
& \tilde{C}_{t}^{*}(f)^{\frac{\theta-1}{\theta}}=(1-n)^{\frac{1}{\theta}}\left(\tilde{C}_{F, t}^{*}(f)\right)^{\frac{\theta-1}{\theta}}+n^{\frac{1}{\theta}}\left(\tilde{C}_{H, t}^{*}(f)\right)^{\frac{\theta-1}{\theta}}
\end{aligned}
$$

The elasticity of substitution between domestic and foreign goods in given by $\theta$ and $n$ measures the 'trade openness'. The maximisation of 51 subject to the budget constraint $P_{t} \tilde{C}_{t}(h)=P_{H, t} \tilde{C}_{H, t}(h)+P_{F, t} \tilde{C}_{F, t}(h)$ delivers the following demand functions

$$
\begin{aligned}
& \tilde{C}_{H, t}(h)=(1-n)\left(\frac{P_{H, t}}{P_{t}}\right)^{-\theta} \tilde{C}_{t}(h) \\
& \tilde{C}_{F, t}(h)=n\left(\frac{P_{F, t}}{P_{t}}\right)^{-\theta} \tilde{C}_{t}(h) \\
& \tilde{C}_{F, t}^{*}(f)=(1-n)\left(\frac{P_{F, t}^{*}}{P_{t}^{*}}\right)^{-\theta} \tilde{C}_{t}(f) \\
& \tilde{C}_{H, t}^{*}(f)=n\left(\frac{P_{H, t}^{*}}{P_{t}^{*}}\right)^{-\theta} \tilde{C}_{t}^{*}(f)
\end{aligned}
$$

Plugging (53) and (54) into the budget constraint we obtain the definition of the consumer price index - CPI

$$
\begin{aligned}
P_{t} & =\left[(1-n) P_{H, t}^{1-\theta}+n P_{F, t}^{1-\theta}\right]^{\frac{1}{1-\theta}} \\
P_{t}^{*} & =\left[(1-n)\left(P_{F, t}^{*}\right)^{1-\theta}+n\left(P_{H, t}^{*}\right)^{1-\theta}\right]^{\frac{1}{1-\theta}}
\end{aligned}
$$

Household's budget constraint is given by

$$
\begin{aligned}
\tilde{C}_{t}(h)+\frac{Q_{t} \tilde{D}_{t}(h)}{B_{t}} & =\tilde{W}_{t} L_{t}(h)+\left[\frac{\tilde{D}_{t-1}(h)}{\Pi_{t}}-\Phi\left(\tilde{D}_{t}(h), \tilde{Z}_{t-1}\right)\right]+\Xi_{t}(h) \\
\tilde{C}_{t}^{*}(f)+\frac{Q_{t}^{*} \tilde{D}_{t}^{*}(f)}{B_{t}^{*}} & =\tilde{W}_{t}^{*} L_{t}^{*}(f)+\frac{\tilde{D}_{t-1}^{*}(h)}{\Pi_{t}^{*}}+\Xi_{t}^{*}(f)
\end{aligned}
$$

where $\tilde{D}_{t}(h)$ denotes the holding of the internationally traded riskless bond, $Q_{t}$ is its prices, $\Xi_{t}(h)$ represents the dividends distributed by the intermediate goods producers,

$$
\Phi\left(\tilde{D}_{t}(h), \tilde{Z}_{t-1}\right)=\frac{\phi}{2} \tilde{Z}_{t-1}\left(\frac{\tilde{D}_{t}(h)}{\tilde{Z}_{t-1}}\right)^{2}
$$

is an adjustment cost function that ensures balanced growth and

$$
\begin{aligned}
\log \left(B_{t}\right) & =\rho_{B} \log \left(B_{t-1}\right)+\sigma_{B} \epsilon_{B, t} \\
\log \left(B_{t}^{*}\right) & =\rho_{B^{*}} \log \left(B_{t-1}^{*}\right)+\sigma_{B^{*}} \epsilon_{B^{*}, t}
\end{aligned}
$$

is an exogenous premium shock in the return to bonds (see Smets and Wouters (2007)).

\subsection{Monetary policy}

The monetary authority sets its instrument short-term interest rate according to a Taylor rule

$$
\begin{aligned}
\frac{R_{t}}{R} & =\left(\frac{R_{t-1}}{R}\right)^{\rho_{R}}\left(\frac{\Pi_{t}}{\Pi}\right)^{\left(1-\rho_{R}\right) \zeta_{\Pi}}\left(\frac{Y_{t}}{Y}\right)^{\left(1-\rho_{R}\right) \zeta_{Y^{d}}} e^{\sigma_{R} \epsilon_{R, t}} \\
\frac{R_{t}^{*}}{R} & =\left(\frac{R_{t-1}^{*}}{R}\right)^{\rho_{R}}\left(\frac{\Pi_{t}^{*}}{\Pi}\right)^{\left(1-\rho_{R}\right) \zeta_{\Pi}}\left(\frac{Y_{t}^{*}}{Y}\right)^{\left(1-\rho_{R}\right) \zeta_{Y^{d}}} e^{\sigma_{R^{*}} \epsilon_{R^{*}, t}}
\end{aligned}
$$

In other words, the policymaker adjusts the nominal interest rate in response to its lag value, to inflation deviations from the target $-\Pi=1-$ and to output deviations from the long-run equilibrium $-Y^{d}$. 


\subsection{Market Clearing Conditions}

The model is closed with the following market clearing conditions in the final good (domestic and foreign) markets:

$$
\begin{aligned}
\tilde{Y}_{t}^{d} & =\tilde{C}_{H, t}+\tilde{C}_{H, t}^{*} \\
\tilde{Y}_{t} & =\Delta_{H, t} \tilde{Y}_{t}^{d} \\
\tilde{Y}_{t}^{d . *} & =\tilde{C}_{F, t}^{*}+\tilde{C}_{F, t} \\
\tilde{Y}_{t}^{*} & =\Delta_{F, t}^{*} \tilde{Y}_{t}^{d, *}
\end{aligned}
$$

and in the international bond market

$$
\tilde{D}_{t}^{*}=-\tilde{D}_{t}
$$

After some algebra the evolution of the net foreign asset position is given by

$$
\frac{Q_{t} D_{t}}{B_{t}}=\left[\frac{D_{t-1}}{\Gamma_{t-1}}-\frac{\psi}{2 \Gamma_{t}}\left(D_{t} \Gamma_{t}\right)^{2}\right]+C_{H, t}^{*}-\frac{\bar{P}_{F, t}}{\bar{P}_{H, t}} C_{F, t} \Omega_{t}
$$

where $\Omega_{t}=\frac{\tilde{Z}_{t}^{*}}{\tilde{Z}_{t}}$

\subsection{Steady-States}

After the stochastic trends are removed (the stationary equations can be found in the main text), the steady-states can be derived analytically. Since the model is symmetric these values are going to be the same for both economies. Given $\varepsilon$ then the marginal cost is given

$$
M C=\frac{\varepsilon-1}{\varepsilon}
$$

We assume that $L=1 / 3$ and $Y=1$ and we derive the steady-state of capital from the production function

$$
K^{\phi}=\left(\frac{Y}{L^{1-\phi}}\right)^{\frac{1}{\phi}}
$$

We assume further that $\Pi_{H}=\bar{\Pi}_{H}=1$ and this implies that $\Delta_{H}=1$, which helps to pin down the values of $Y^{d}$ and $W$ :

$$
\begin{gathered}
Y=\Delta_{H} Y^{d} \\
W=\frac{M C(1-\phi) Y^{d}}{L}
\end{gathered}
$$

We also assume that $\frac{P_{H}}{P}=\frac{P_{F}}{P}=\frac{P_{F}^{*}}{P^{*}}=\frac{P_{H}^{*}}{P^{*}}=1$ and this implies

$$
\begin{gathered}
\Upsilon=1 \\
\bar{P}_{H}=\bar{P}_{F, t}=1 \\
\frac{C_{H}}{C_{F}}=\frac{1-n}{n}
\end{gathered}
$$

There is no debt in the steady-state, meaning that $D=0$ and this help to pin down:

$$
\begin{gathered}
C_{H}^{*}=C_{F} \\
Y=C \\
\chi_{0}=\frac{W}{L^{\sigma_{L}} C^{\sigma_{C}}} \\
u(C, L)=\frac{C^{1-\sigma_{C}}}{1-\sigma_{C}}-\chi_{0} \frac{L^{1+\sigma_{L}}}{1+\sigma_{L}}
\end{gathered}
$$




$$
\begin{gathered}
V=\frac{u(C, L)}{1-\beta \Gamma^{1-\sigma_{C}}} \\
\breve{V} \equiv\left(V \Gamma^{1-\sigma_{C}}\right)^{1-\gamma} \\
M=\Gamma^{-\sigma_{C}} \\
Q=\beta M B \\
K_{H}=\frac{M C Y^{d}}{1-\beta \xi_{H} \Gamma^{1-\sigma_{C}}} \\
F_{H}=\frac{Y^{d}}{1-\beta \xi_{H} \Gamma^{1-\sigma_{C}}}
\end{gathered}
$$

\subsection{Calibration and Solution}

The two economies are treated symmetrically and we, therefore, discuss only one set of structural parameters. Commonly, the time discount rate $(\beta)$ and steady-state productivity growth $(\Gamma)$ have been set equal to 0.99 and 1.005 respectively, which imply an annul interest rate of $6 \%$. The (inverse) intertemporal substitution $\left(\sigma_{C}\right)$ and labour supply $\left(\sigma_{L}\right)$ elasticities equal to 2 and 3 respectively, a choice consistent with Rudebusch and Swanson (2012) and Fernández-Villaverde et al. (2011). The share of capital in the production $(\phi)$ has been calibrated to $0.36, \mathrm{a}$ number typically used in the literature (Christiano et al. (2005), Trabandt and Uhlig (2011) and Jermann and Quadrini (2012)). Following Rudebusch and Swanson (2012) $\gamma$ is -148.30 and this delivers a coefficient of relative risk aversion equal to $75^{3}$ Similar to Smets and Wouters (2007) and Christiano et al. (2005) the steady-state value of domestic producers' markup is $20 \%(\epsilon=6)$. The Calvo probability of not resetting prices $\left(\xi_{H}\right)$ equals 0.75 and this value lies between the estimates reported by Smets and Wouters (2007), Christiano et al. $(2005)\left(\xi_{H}=0.65\right)$ and Justiniano et al. (2010) $\left(\xi_{H}=0.84\right)$. The calibration of the Taylor rule is quite standard, namely the smoothing parameter has been set equal to 0.75 , the inflation and output reaction parameters to 1.50 and 0.125 , respectively. The elasticity of substitution between home-country and foreign-country consumption $(\theta)$ is 1.5 , a value used by Rabanal and Rubio-Ramirez (2015) and estimated by Chin et al. (2015). In the benchmark calibration the home bias parameter $1-n$ is set equal to 0.3 . Finally, the parameters that govern the non-stationary productivity process are taken from the work of Rabanal and Rubio-Ramirez (2015), while the calibration of the stationary, financial and policy shock rely on the estimates reported by Chin et al. (2015).

The model is solved using third-order perturbation methods. To avoid explosive solutions we follow Kim et al. (2008) and Andreasen et al. (2013) and we 'prune' all those terms that have an order that is higher than the approximation order ${ }^{4}$

\subsection{Supply Shock}

In this section we repeat the exercise undertaken in Section 4.2.1 in the paper but instead of the financial perturbation we simulate the model using only the stationary supply shock. The aim of this experiment is to illustrate that the mechanism discussed in the main text that induces endogenous conditional heteroscedasticity does not arise only after a financial shock. The following two picture confirms this assertion.

\section{Data}

The table below lists the variables used in the analysis. In terms of the data sources GFD refers to Global Financial Database, FRED is the Federal Reserve Bank of St Louis database and ONS refers to the Office of National Statistics. LD denotes the log difference transformation, while N denotes no transformation.

\footnotetext{
${ }^{3}$ The coefficient of relative risk aversion is a function of $\sigma_{L}, \gamma$ and the steady-state value of labour see Rudebusch and Swanson (2012) and Swanson (2012).

${ }^{4}$ All the calculations have implemented using Dynare 4.4.2. The model and replication files can be found here.
} 

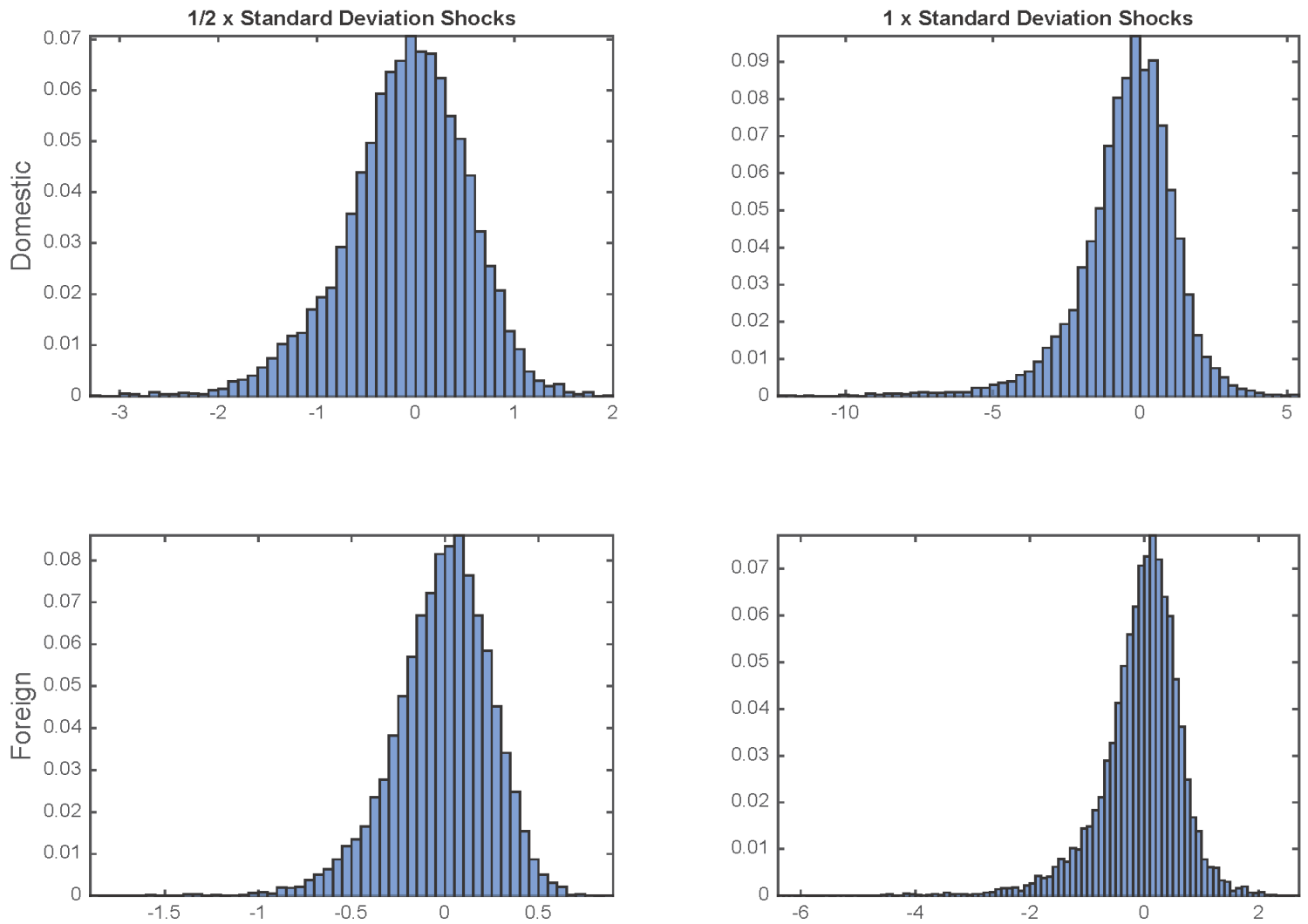

Figure 6: Starting from the stochastic steady state, the model is simulated from 50000 periods using only the domestic stationary supply shock. The histogram illustrates the distribution of the domestic and foreign GDP as deviation from their stochastic steady-state (Juillard and Kamenik, 2005) 
Table 2: Model Variables

\begin{tabular}{l|c|c}
\hline \hline Description & Domestic & Foreign \\
\hline \hline Domestic Relative Price & $\bar{P}_{H, t}$ & $\bar{P}_{F, t}^{*}$ \\
Import Relative Price & $\bar{P}_{F, t}$ & $\bar{P}_{H, t}^{*}$ \\
Domestic Consumption & $C_{H, t}$ & $C_{F, t}^{*}$ \\
Import Consumption & $C_{F, t}$ & $C_{H, t}^{*}$ \\
Total Consumption & $C_{t}$ & $C_{t}^{*}$ \\
Asset Price & $Q_{t}$ & \\
Total Consumption & $C_{t}$ & $C_{t}^{*}$ \\
Domestic Inflation & $\Pi_{H, t}$ & $\Pi_{F, t}^{*}$ \\
Utility & $V_{t}$ & $V_{t}^{*}$ \\
Wage & $W_{t}$ & $W_{t}^{*}$ \\
Price Dispersion & $\Delta_{H, t}$ & $\Delta_{F, t}^{*}$ \\
Aggregate Demand & $Y_{t}^{d}$ & $Y_{t}^{* d}$ \\
Relative Optimal Price & $\bar{\Pi}_{H, t}$ & $\Pi_{F, t}^{*}$ \\
Marginal Cost & $M_{t}$ & $M_{t}^{*}$ \\
Phillips Curve Term & $K_{H, t}$ & $K_{F, t}^{*}$ \\
Phillips Curve Term & $F_{H, t}$ & $F_{F, t}^{*}$ \\
Real Interest Rate & $\Upsilon_{t}$ & \\
Debt & $D_{t}$ & $D_{t}^{*}$ \\
CPI Inflation & $\Pi_{t}$ & $\Pi_{t}^{*}$ \\
Policy Rate & $R_{t}$ & $R_{t}^{*}$ \\
Stochastic Discount Factor & $M_{t}$ & $M_{t}^{*}$ \\
Stochastic Trend Differential & $\Omega_{t}$ & \\
Stationary Productivity Process & $A_{t}$ & $A_{t}^{*}$ \\
Non Stationary Productivity Process & $\Gamma_{t}$ & $\Gamma_{t}^{*}$ \\
Financial Shock Process & $B_{t}$ & $B_{t}^{*}$ \\
\hline \hline
\end{tabular}

Table 3: Model Structural Parameters

\begin{tabular}{l|c|c}
\hline \hline Description & Mnemonic & Value \\
\hline \hline Steady State Productivity Growth & $\Gamma, \Gamma^{*}$ & 1.005 \\
Steady State Output & $Y, Y^{*}$ & 1.00 \\
Steady State Labour & $L, L^{*}$ & $1 / 3$ \\
Steady State Real Exchange Rate & $\Upsilon$ & 1.00 \\
Steady State CPI Inflation & $\Pi, \Pi^{*}$ & 1.00 \\
Steady State Domestic Inflation & $\Pi_{H}, \Pi_{F}^{*}$ & 1.00 \\
Steady State Domestic Relative Prices & $\bar{P}_{H}, \bar{P}_{F}^{*}$ & 1.00 \\
Home Bias & $1-n$ & 0.70 \\
E.o.S between Domestic and Foreign Consumption & $\theta$ & 1.50 \\
Time Discount & $\beta$ & 0.99 \\
Intertemporal Substitution Elasticity & $\sigma_{C}$ & 2.00 \\
Labor Supply Frisch Elasticity & $\sigma_{L}$ & 3.00 \\
Risk Preference & $\gamma$ & -148.30 \\
Production Capital Share & $\phi$ & 0.36 \\
Calvo Non Reset Price Probability & $\xi_{H}$ & 0.75 \\
E.o.S between Intermediate Goods & $\varepsilon$ & 11.00 \\
Exchange Rate Risk Premium & $\psi$ & 0.05 \\
Policy Smoothness & $\rho_{R}$ & 0.75 \\
Policy Inflation Reaction & $\zeta_{\Pi}$ & 1.50 \\
Policy Output Reaction & $\zeta_{Y^{d}}$ & 0.25 \\
\hline \hline
\end{tabular}


Table 4: Model Shock Parameters

\begin{tabular}{l|c|c|c}
\hline \hline Description & Mnemonic & Domestic Value & Foreign Value \\
\hline \hline Stationary Productivity Process Persistence & $\rho_{A}$ & 0.90 & 0.90 \\
Stationary Productivity Shock Uncertainty & $100 \sigma_{A}$ & 0.87 & 0.87 \\
Non Stationary Productivity Process Persistence & $\rho_{\Gamma}$ & 0.35 & 0.35 \\
Non Stationary Productivity Shock Uncertainty & $100 \sigma_{\Gamma}$ & 0.88 & 0.88 \\
Error Correction & $\kappa$ & -0.007 & 0.007 \\
Financial Process Persistence & $\rho_{B}$ & 0.90 & 0.90 \\
Financial Shock Uncertainty & $100 \sigma_{B}$ & 0.30 & 0.30 \\
Policy Shock Uncertainty & $100 \sigma_{R}$ & 0.24 & 0.24 \\
\hline \hline
\end{tabular}

Table 5: Domestic Economy

\begin{tabular}{|c|c|}
\hline Name & Equation \\
\hline CPI Definition & $1=(1-n) \bar{P}_{H, t}^{1-\theta}+n \bar{P}_{F, t}^{1-\theta}$ \\
\hline Domestic Consumption Demand & $C_{H, t}=(1-n) \bar{P}_{H, t}^{-\theta} C_{t}$ \\
\hline Foreign Consumption Demand & $C_{F, t} \Omega_{t}=\bar{P}_{F, t}^{-\theta} C_{t}$ \\
\hline Asset Pricing Equation & $\frac{Q_{t}}{B_{t}}=\beta E_{t}\left\{M_{t+1} \frac{\bar{P}_{H, t+1}}{P_{H, t}}\right\}-\psi D_{t} \Gamma_{t}$ \\
\hline Utility Function & $u\left(C_{t}, L_{t}\right)=\frac{C_{t}^{1-\sigma_{C}}}{1-\sigma_{C}}-\chi_{0} \frac{L_{t}^{1+\sigma_{L}}}{1+\sigma_{L}}$ \\
\hline Utility Continuation Value & $\breve{V}_{t} \equiv E_{t}\left(V_{t+1} \Gamma_{t+1}^{1-\sigma_{C}}\right)^{1-\gamma}$ \\
\hline $\begin{array}{l}\text { Preferences Expected Term } \\
\text { Recursive Preferences } \\
\text { Labour Supply }\end{array}$ & $\begin{array}{l}\dddot{V_{t}} \equiv \breve{V}_{t}^{\frac{1}{1-\gamma}} \\
V_{t}=u\left(C_{t}, L_{t}\right)+\beta \dddot{V}_{t} \\
\chi_{0} L_{t}^{\sigma_{L}} C_{t}^{\sigma_{C}}=W_{t}\end{array}$ \\
\hline Stochastic Discount Factor & $M_{t+1}=\left[\frac{V_{t+1}}{V_{t}} \Gamma_{t+1}^{1-\sigma_{C}}\right]^{-\gamma}\left(\frac{C_{t}}{C_{t+1} \Gamma_{t+1}}\right)^{\sigma_{C}}$ \\
\hline $\begin{array}{l}\text { Production Function } \\
\text { Marginal Cost }\end{array}$ & $\begin{array}{l}Y_{t}=A_{t} K^{\phi} L_{t}^{1-\phi} \\
M C_{t}=\frac{W_{t} L_{t}}{\bar{P}_{H, t}(1-\phi) Y_{t}^{d}}\end{array}$ \\
\hline Domestic Producer Phillips Curve & $K_{H, t}=M C_{t} Y_{t}^{d}+\beta \xi_{H} E_{t} M_{t+1}\left(\frac{1}{\Pi_{H, t+1}}\right)^{-\varepsilon} K_{H, t+1} \Gamma_{t+1}$ \\
\hline Domestic Producer Phillips Curve & $F_{H, t}=Y_{t}^{d}+\beta \xi_{H} E_{t} M_{t+1}\left(\frac{1}{\Pi_{H, t+1}}\right)^{1-\varepsilon} F_{H, t+1} \Gamma_{t+1}$ \\
\hline Domestic Producer Phillips Curve & $\bar{\Pi}_{H, t}=\frac{\varepsilon}{\varepsilon-1} \frac{K_{H, t}}{F_{H, t}}$ \\
\hline Domestic Producer Phillips Curve & $1=\xi_{H}\left(\frac{1}{\Pi_{H, t}}\right)^{1-\varepsilon}+\left(1-\xi_{H}\right) \bar{\Pi}_{H, t}^{1-\varepsilon}$ \\
\hline Price Dispersion & $\left(\Delta_{H, t}\right)^{\frac{1}{1-\phi}}=\left(1-\xi_{H}\right)\left(\bar{\Pi}_{H, t}\right)^{-\frac{\varepsilon}{1-\phi}}+\xi_{H}\left(\frac{1}{\Pi_{H, t}}\right)^{-\frac{\varepsilon}{1-\phi}}\left(\Delta_{H, t-1}\right)^{\frac{1}{1-\phi}}$ \\
\hline Import Relative Prices & $\bar{P}_{F, t}=\Upsilon_{t} \bar{P}_{F, t}^{*}$ \\
\hline Net Foreign Assets & $\frac{Q_{t} D_{t}}{B_{t}}=\left[\frac{D_{t-1}}{\Gamma_{t-1}}-\frac{\psi}{2 \Gamma_{t}}\left(D_{t} \Gamma_{t}\right)^{2}\right]+C_{H, t}^{*}-\frac{\bar{P}_{F, t}}{\bar{P}_{H, t}} C_{F, t} \Omega_{t}$ \\
\hline $\begin{array}{l}\text { Aggregate Demand } \\
\text { Market Clearing Condition }\end{array}$ & $\begin{array}{l}Y_{t}^{d}=C_{H, t}+C_{H, t}^{*} \\
Y_{t}=\Delta_{H, t} Y_{t}^{d}\end{array}$ \\
\hline UIP Condition & $E_{t}\left\{\frac{M_{t+1}}{\Pi_{t+1}}\right\} B_{t}-E_{t}\left\{\frac{M_{t+1}^{*}}{\Pi_{t+1}^{*}} \frac{\Upsilon_{t}}{\Upsilon_{t+1}} \Omega_{t}\right\} B_{t}^{*}=\psi D_{t} \Gamma_{t}$ \\
\hline Policy Rule & $\frac{R_{t}}{R}=\left(\frac{R_{t-1}}{R}\right)^{\rho_{R}}\left(\frac{\Pi_{t}}{\Pi}\right)^{\left(1-\rho_{R}\right) \zeta_{\Pi}}\left(\frac{Y_{t}^{d}}{Y^{d}}\right)^{\left(1-\rho_{R}\right) \zeta_{Y^{d}}} e^{\sigma_{R} \epsilon_{R, t}}$ \\
\hline Price-Yield Relation & $R_{t}=\frac{1}{Q_{t}}$ \\
\hline CPI Inflation & $\frac{P_{H, t}}{\bar{P}_{H, t-1}}=\frac{\Pi_{H, t}}{\Pi_{t}}$ \\
\hline $\begin{array}{l}\text { Financial Process } \\
\text { Productivity Stationary Process }\end{array}$ & $\begin{array}{l}\log \left(B_{t}\right)=\rho_{B} \log \left(B_{t-1}\right)+\sigma_{B} \epsilon_{B, t} \\
\log \left(A_{t}\right)=\rho_{A} \log \left(A_{t-1}\right)+\sigma_{A} \epsilon_{A, t}\end{array}$ \\
\hline Productivity Non Stationary Process & $\log \left(\frac{\Gamma_{t}}{\Gamma}\right)=\kappa \log \left(\Omega_{t}\right)+\rho_{\Gamma} \log \left(\frac{\Gamma_{t-1}}{\Gamma}\right)+\sigma_{\Gamma} \epsilon_{\Gamma, t}$ \\
\hline Stochastic Trend Differential & $\log \left(\Omega_{t}\right)=\log \left(\frac{Z_{t}^{*}}{Z_{t}}\right)=\log \left(\Omega_{t-1}\right)+\log \left(\frac{\Gamma_{t}^{*}}{\Gamma_{t}}\right)$ \\
\hline
\end{tabular}


Table 6: Foreign Economy

\begin{tabular}{|c|c|}
\hline$\overline{\text { Name }}$ & Equation \\
\hline CPI Definition & $\overline{1} 1=(1-n) \bar{P}_{F, t}^{* 1-\theta}+n \bar{P}_{H, t}^{* 1-\theta}$ \\
\hline Domestic Consumption Demand & $C_{F, t}^{*}=(1-n) \bar{P}_{F, t}^{*-\theta} C_{t}^{*}$ \\
\hline Foreign Consumption Demand & $C_{H, t}^{*} \Omega_{t}=\bar{P}_{F, t}^{*-\theta} C_{t}^{*}$ \\
\hline Asset Pricing Equation & $\frac{1}{R_{t}^{*}}=\beta E_{t}\left\{M_{t+1}^{*} \frac{\bar{P}_{F, t+1}^{*}}{\bar{P}_{F, t}^{*}}\right\} B_{t}^{*}$ \\
\hline Utility Function & $u\left(C_{t}^{*}, L_{t}^{*}\right)=\frac{C_{t}^{* 1-\sigma_{C}}}{1-\sigma_{C}}-\chi_{0} \frac{L_{t}^{* 1+\sigma_{L}}}{1+\sigma_{L}}$ \\
\hline Utility Continuation Value & $\breve{V}_{t}^{*} \equiv E_{t}\left(V_{t+1}^{*} \Gamma_{t+1}^{* 1-\sigma_{C}}\right)^{1-\gamma}$ \\
\hline Preferences Expected Term & $\dddot{V}_{t}^{*} \equiv \breve{V}_{t}^{* \frac{1}{1-\gamma}}$ \\
\hline Recursive Preferences & $V_{t}^{*}=u\left(C_{t}^{*}, L_{t}^{*}\right)+\beta \dddot{V}_{t}^{*}$ \\
\hline Labour Supply & $\chi_{0} L_{t}^{* \sigma_{L}} C_{t}^{* \sigma_{C}}=W_{t}^{*}$ \\
\hline Stochastic Discount Factor & $M_{t+1}^{*}=\left[\frac{V_{t+1}^{*}}{V_{t}^{*}} \Gamma_{t+1}^{* 1-\sigma_{C}}\right]^{-\gamma}\left(\frac{C_{t}^{*}}{C_{t+1}^{*} \Gamma_{t+1}^{*}}\right)^{\sigma_{C}}$ \\
\hline Production Function & $Y_{t}^{*}=A_{t}^{*} K^{* \phi} L_{t}^{* 1-\phi}$ \\
\hline Marginal Cost & $M C_{t}^{*}=\frac{W_{t}^{*} L_{t}^{*}}{\bar{P}_{F, t}^{*}(1-\phi) Y_{t}^{* d}}$ \\
\hline Domestic Producer Phillips Curve & $K_{F, t}^{*}=M C_{t}^{*} Y_{t}^{* d}+\beta \xi_{H} E_{t} M_{t+1}^{*}\left(\frac{1}{\Pi_{F, t+1}^{*}}\right)^{-\varepsilon} K_{F, t+1}^{*} \Gamma_{t+1}^{*}$ \\
\hline Domestic Producer Phillips Curve & $F_{F, t}^{*}=Y_{t}^{* d}+\beta \xi_{H} E_{t} M_{t+1}^{*}\left(\frac{1}{\Pi_{F, t+1}^{*}}\right)^{1-\varepsilon} F_{F, t+1}^{*} \Gamma_{t+1}^{*}$ \\
\hline Domestic Producer Phillips Curve & $\bar{\Pi}_{F, t}^{*}=\frac{\varepsilon}{\varepsilon-1} \frac{K_{F, t}^{*}}{F_{F, t}^{*}}$ \\
\hline Domestic Producer Phillips Curve & $1=\xi_{H}\left(\frac{1}{\Pi_{F, t}^{*}}\right)^{1-\varepsilon}+\left(1-\xi_{H}\right) \bar{\Pi}_{F, t}^{* 1-\varepsilon}$ \\
\hline Price Dispersion & $\left(\Delta_{F, t}^{*}\right)^{\frac{1}{1-\phi}}=\left(1-\xi_{H}\right)\left(\bar{\Pi}_{F, t}^{*}\right)^{-\frac{\varepsilon}{1-\phi}}+\xi_{H}\left({\frac{1}{\Pi_{F, t}}}^{*}\right)^{-\frac{\varepsilon}{1-\phi}}\left(\Delta_{F, t-1}^{*}\right)^{\frac{1}{1-\phi}}$ \\
\hline Import Relative Prices & $\bar{P}_{H, t}^{*}=\frac{\bar{P}_{H, t}}{\Upsilon_{t}}$ \\
\hline Net Foreign Assets & $D_{t}^{*}=-D_{t}^{t}$ \\
\hline Aggregate Demand & $Y_{t}^{* d}=C_{F, t}^{*}+C_{F, t}$ \\
\hline Market Clearing Condition & $Y_{t}^{*}=\Delta_{F, t}^{*} Y_{t}^{* d}$ \\
\hline Policy Rule & $\frac{R_{t}^{*}}{R}=\left(\frac{R_{t-1}^{*}}{R}\right)^{\rho_{R}}\left(\frac{\Pi_{t}^{*}}{\Pi}\right)^{\left(1-\rho_{R}\right) \zeta_{\Pi}}\left(\frac{Y_{t}^{* d}}{Y^{d}}\right)^{\left(1-\rho_{R}\right) \zeta_{Y^{d}}} e^{\sigma_{R} \epsilon_{R^{*}, t}}$ \\
\hline CPI Inflation & $\frac{\bar{P}_{F, t}^{*}}{\bar{P}_{F, t-1}^{*}}=\frac{\Pi_{F, t}^{*}}{\Pi_{t}^{*}}$ \\
\hline Financial Process & $\log \left(B_{t}^{*}\right)=\rho_{B} \log \left(B_{t-1}^{*}\right)+\sigma_{B} \epsilon_{B^{*}, t}$ \\
\hline Productivity Stationary Process & $\log \left(A_{t}^{*}\right)=\rho_{A} \log \left(A_{t-1}^{*}\right)+\sigma_{A} \epsilon_{A^{*}, t}$ \\
\hline Productivity Non Stationary Process & $\log \left(\frac{1_{t}}{\Gamma}\right)=-\kappa \log \left(\Omega_{t}\right)+\rho_{\Gamma} \log \left(\frac{t_{t-1}}{\Gamma}\right)+\sigma_{\Gamma} \epsilon_{\Gamma^{*}, t}$ \\
\hline
\end{tabular}



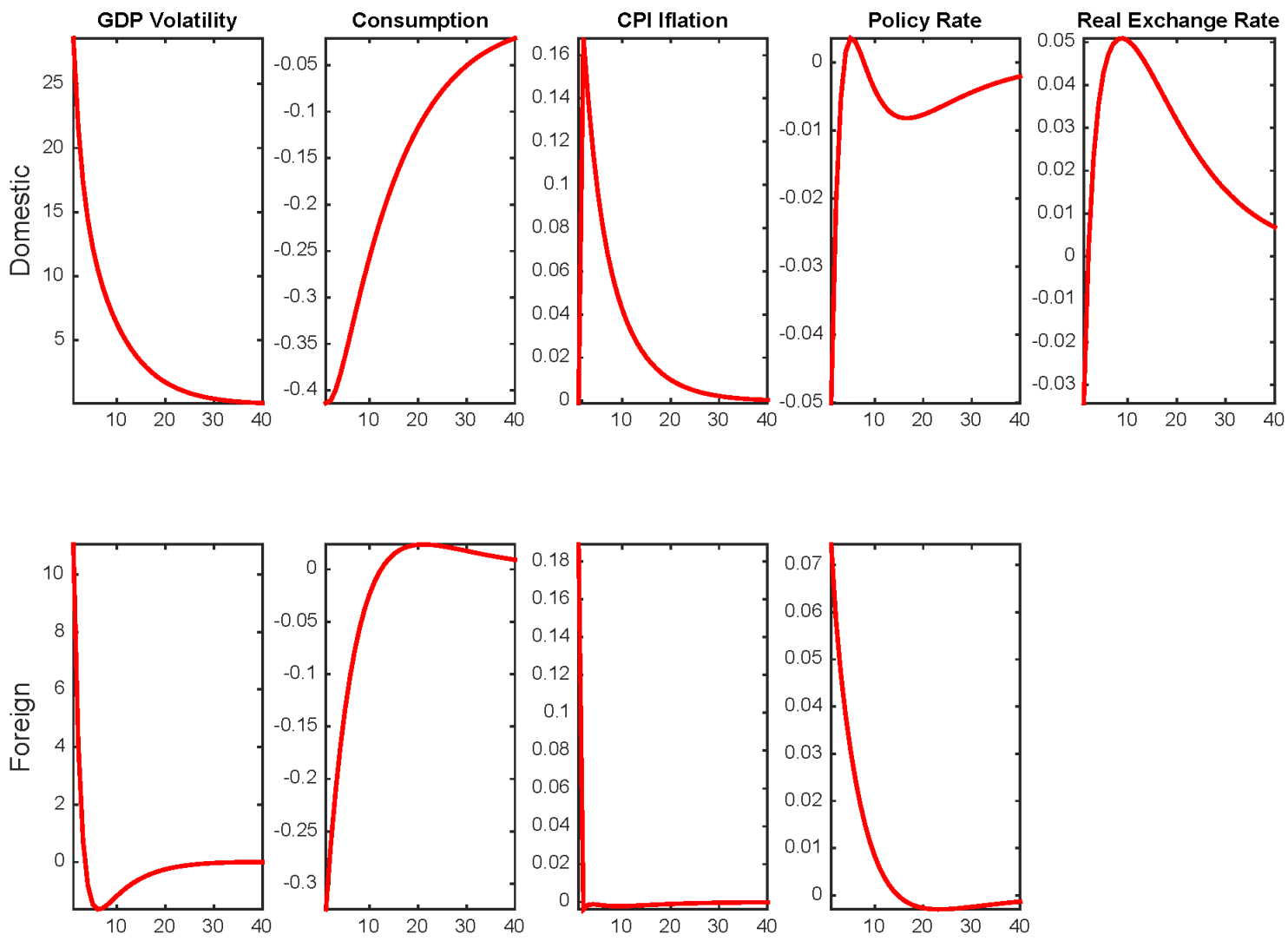

Figure 7: The responses are calculated relative to the stochastic steady state (Juillard and Kamenik, 2005). 


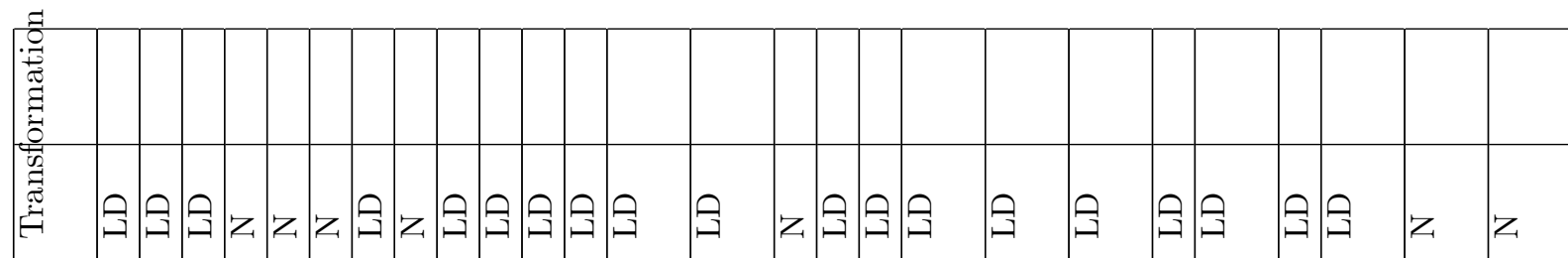

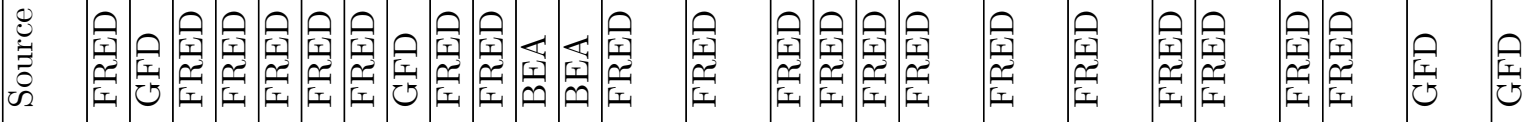

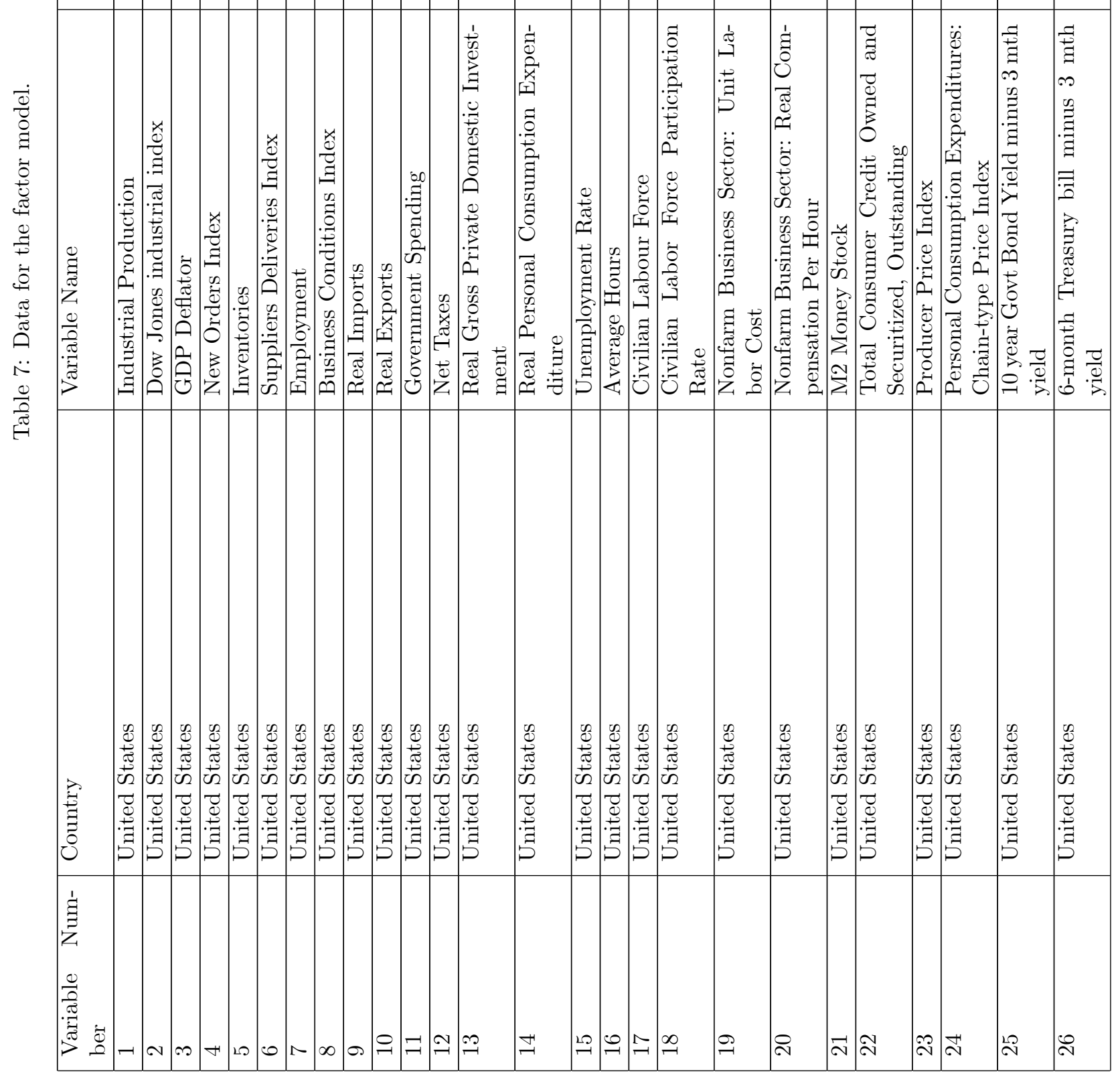


z z

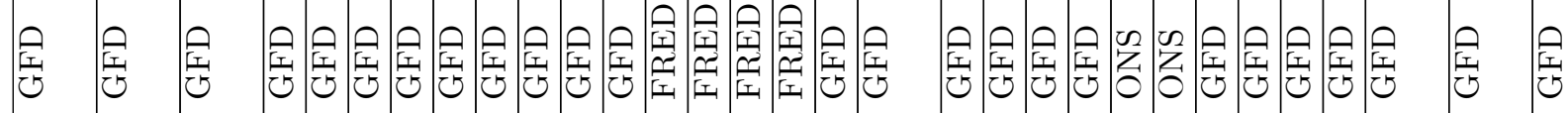

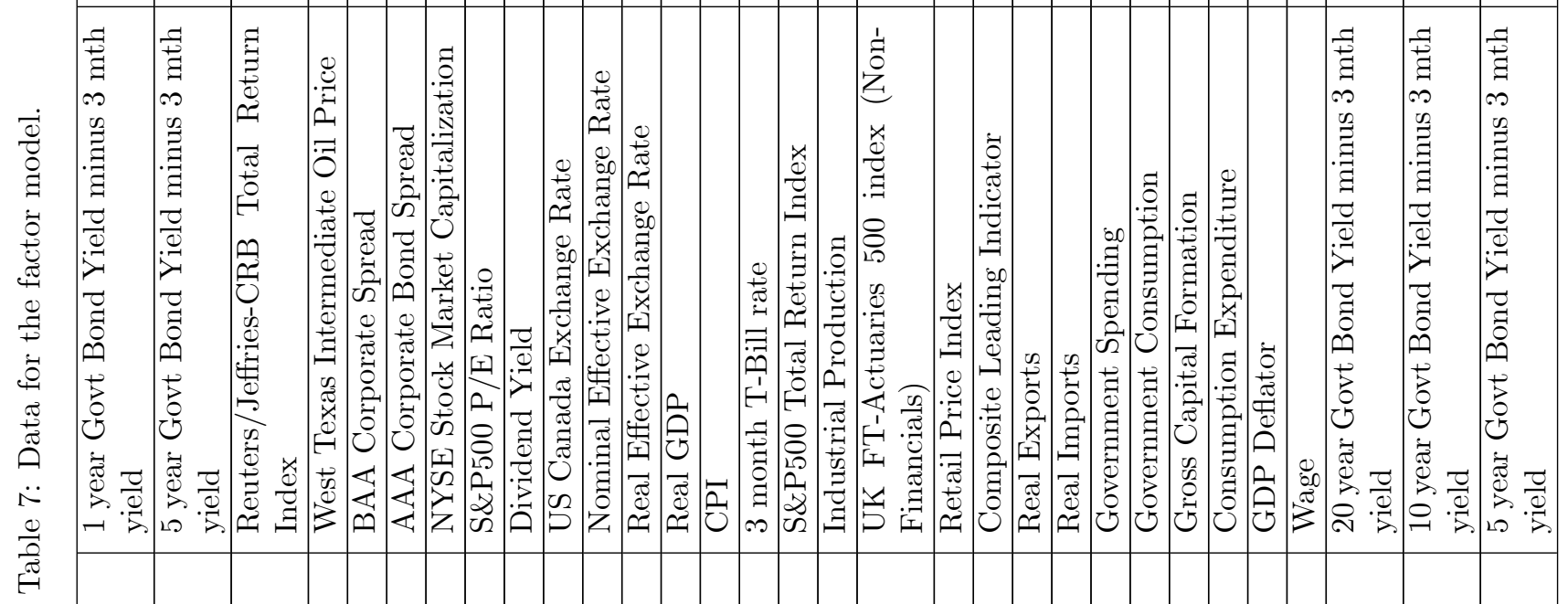

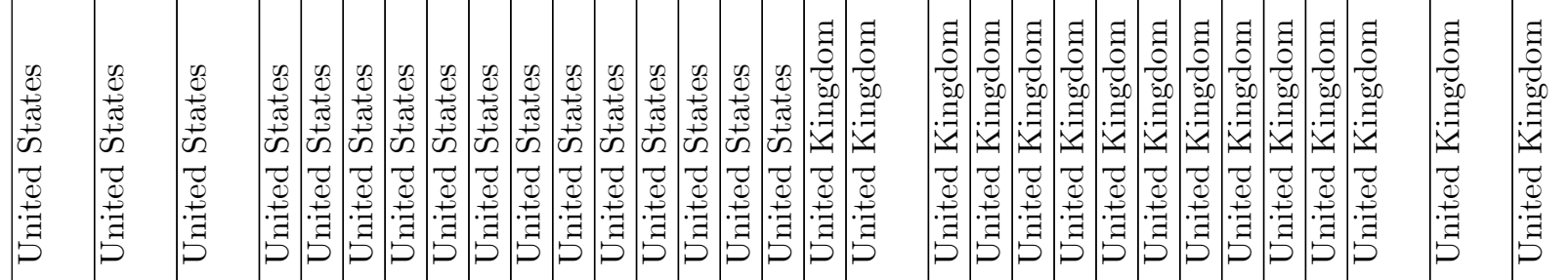

ล 


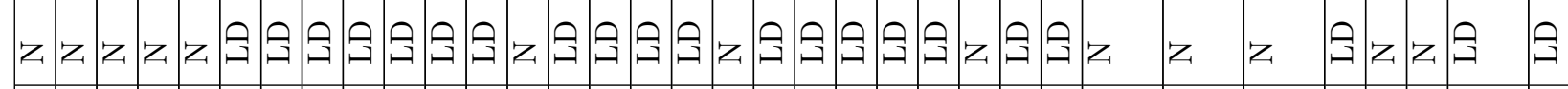

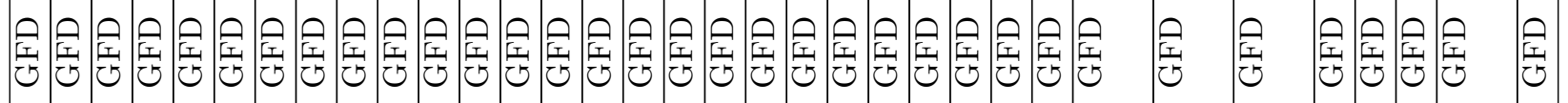

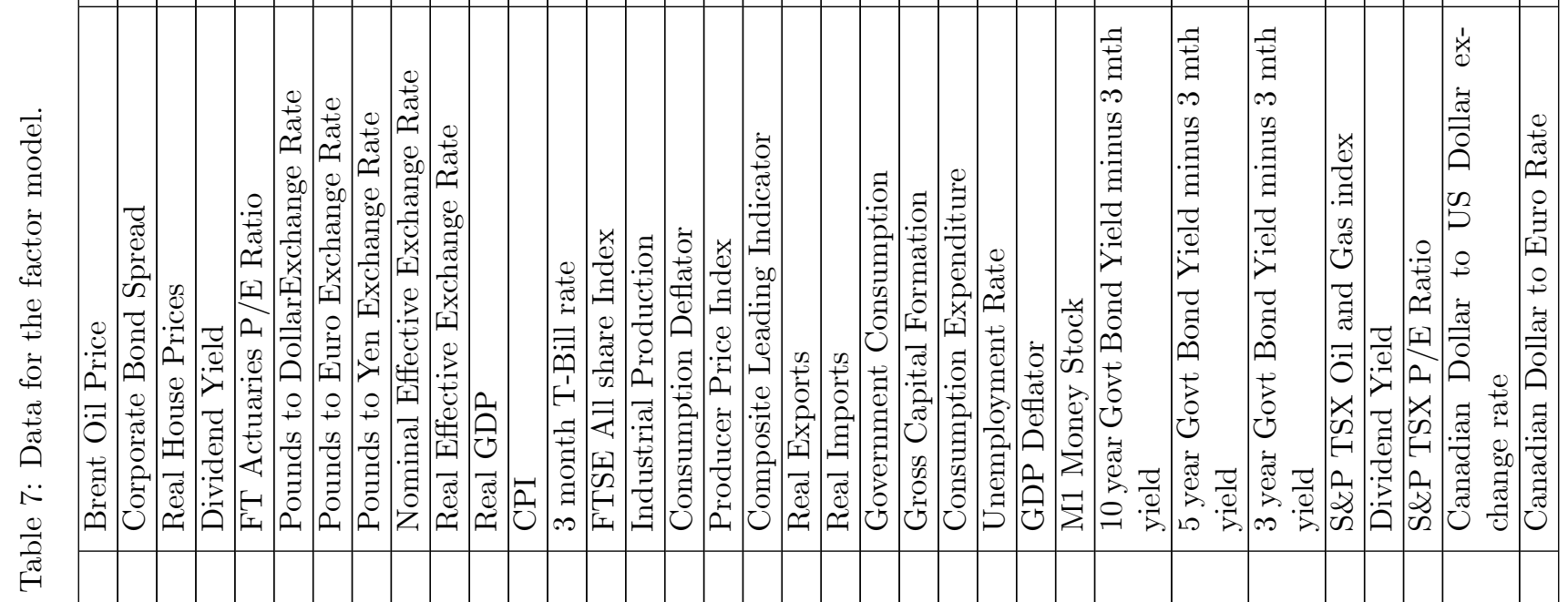

:

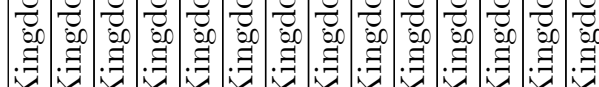

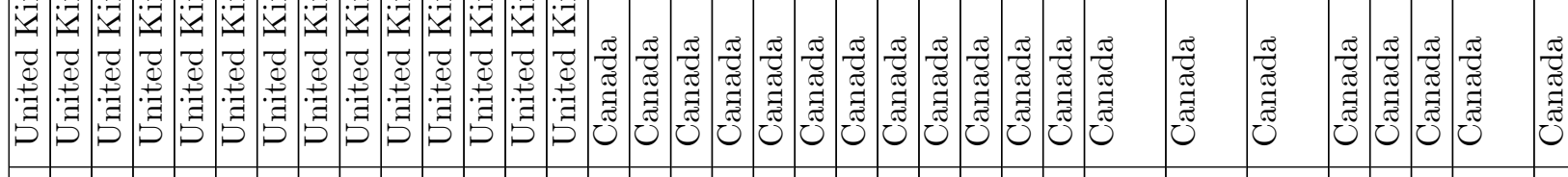

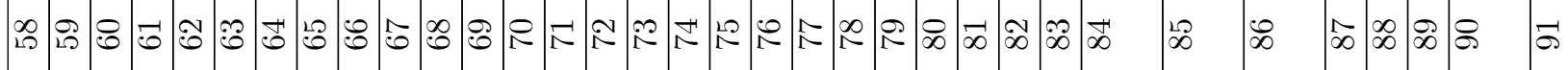




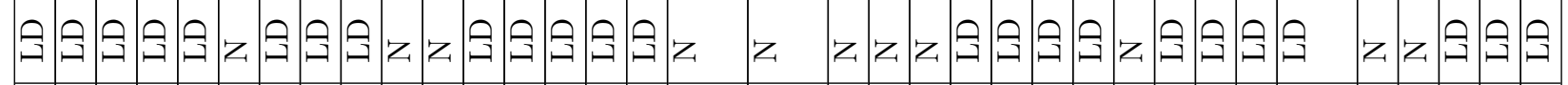

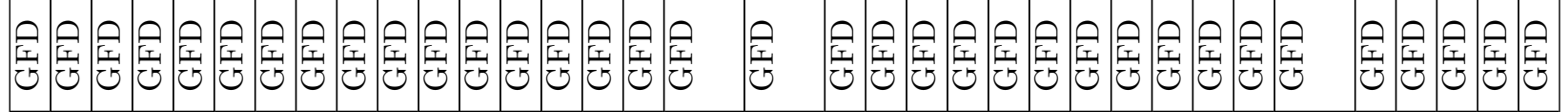

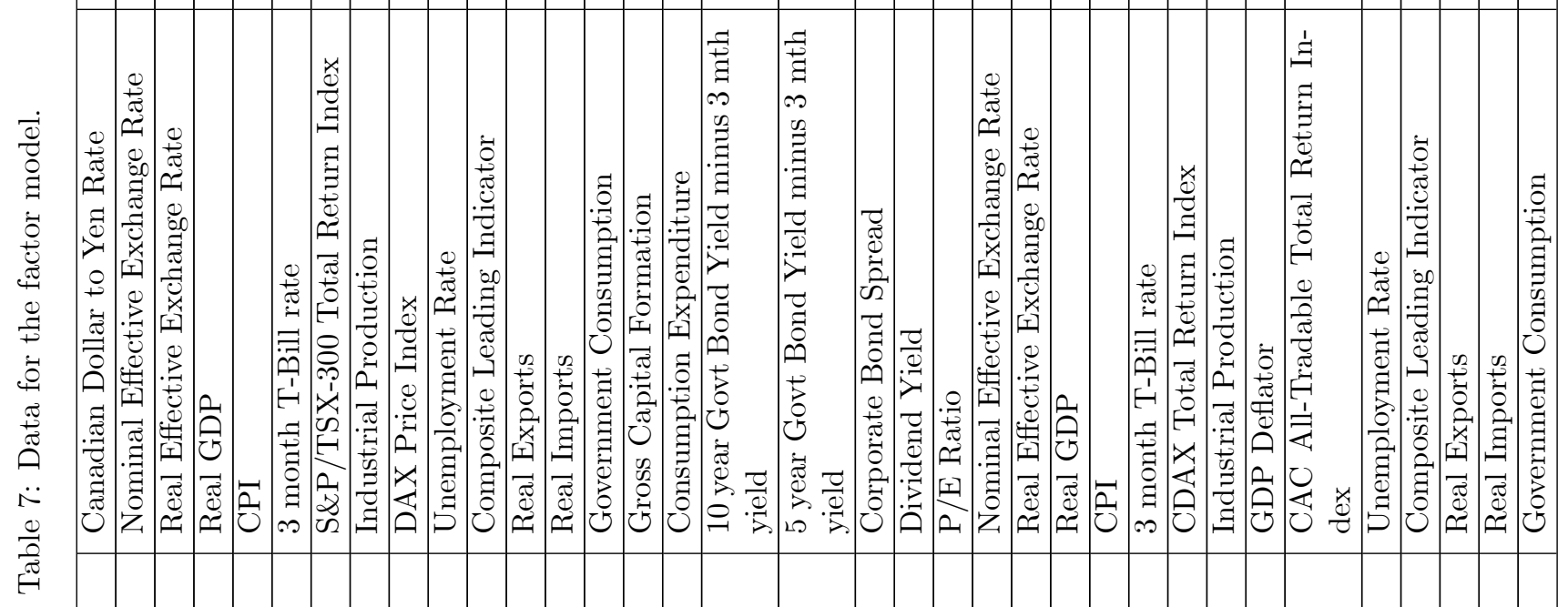

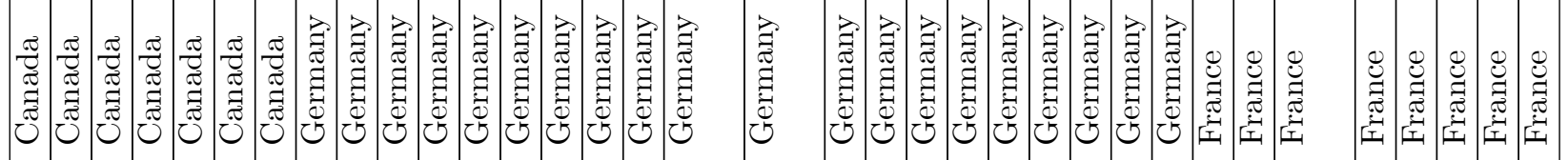

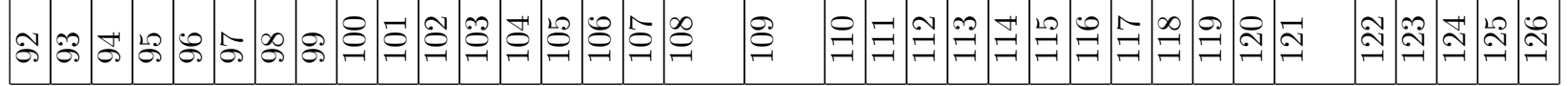




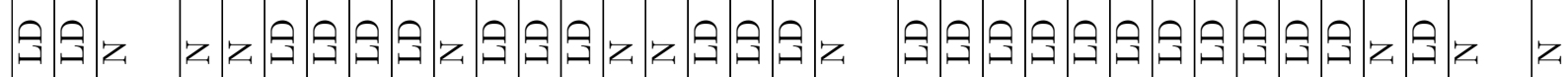

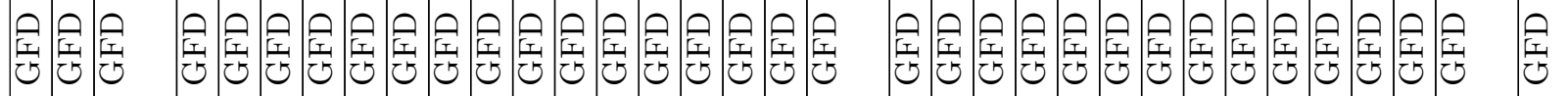

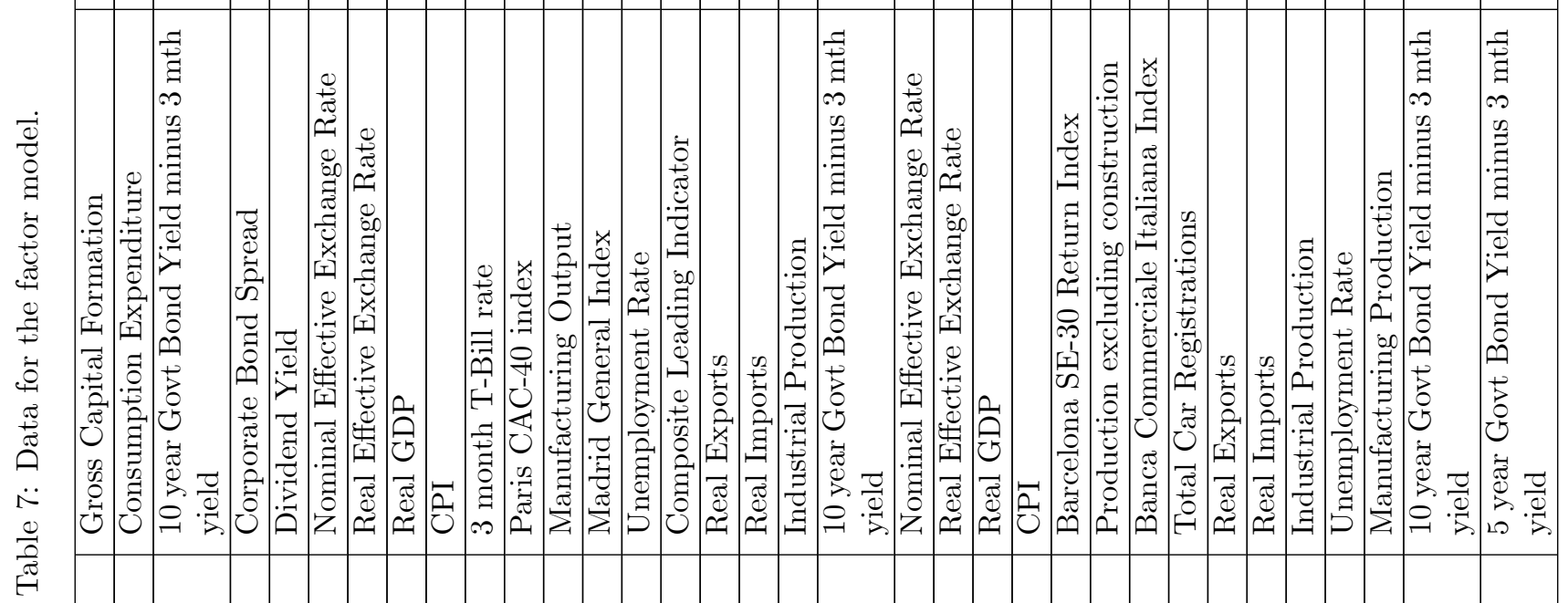

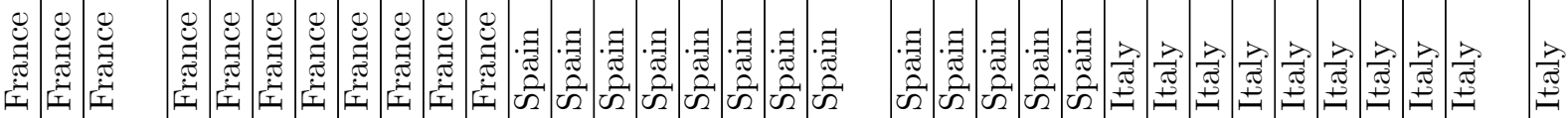

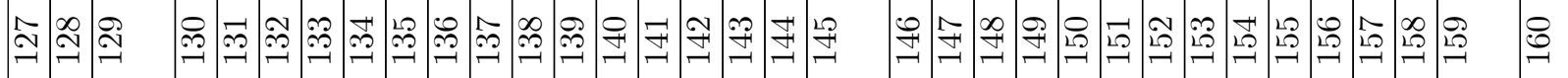




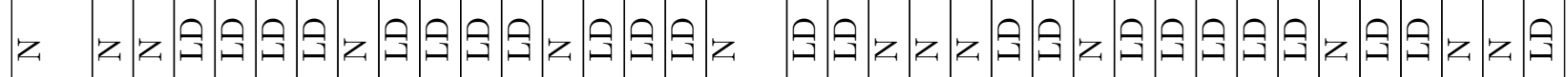

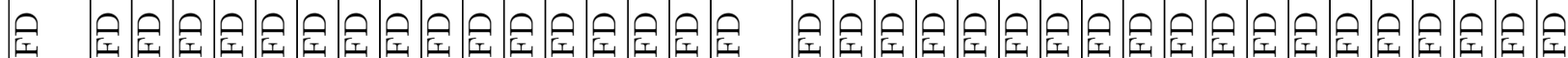

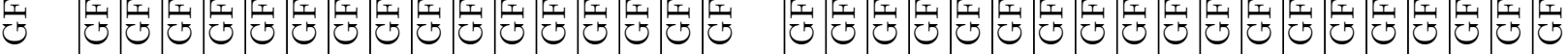

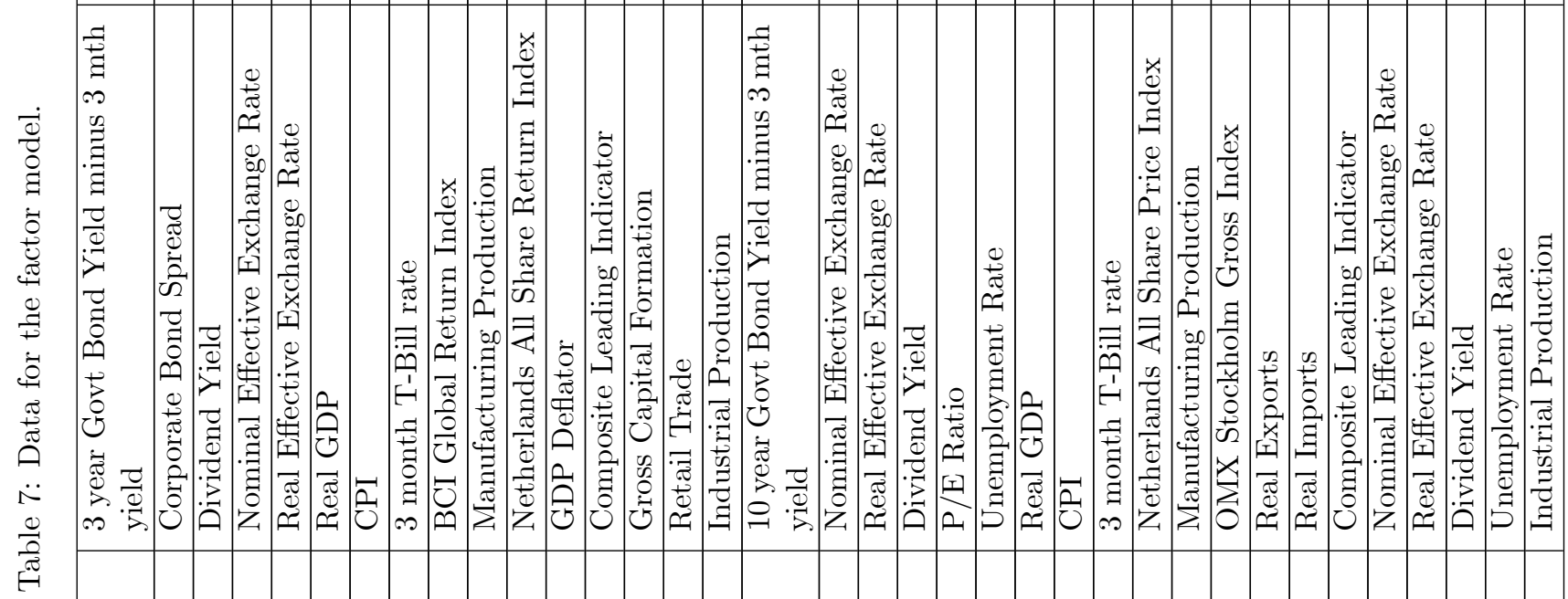

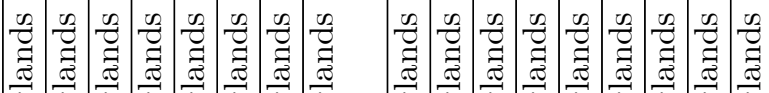

勾 


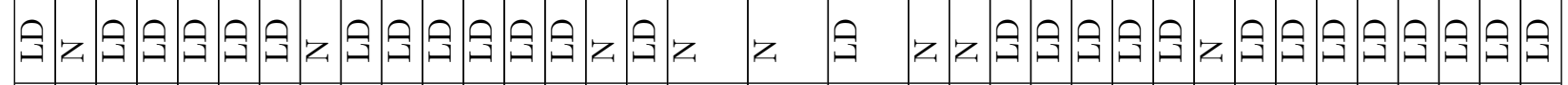

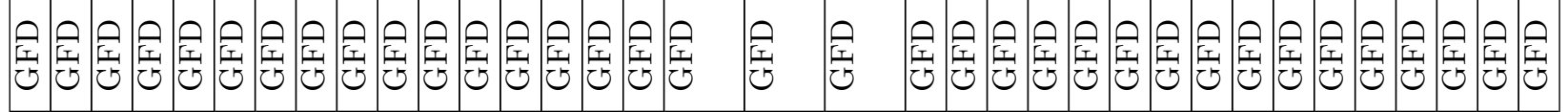

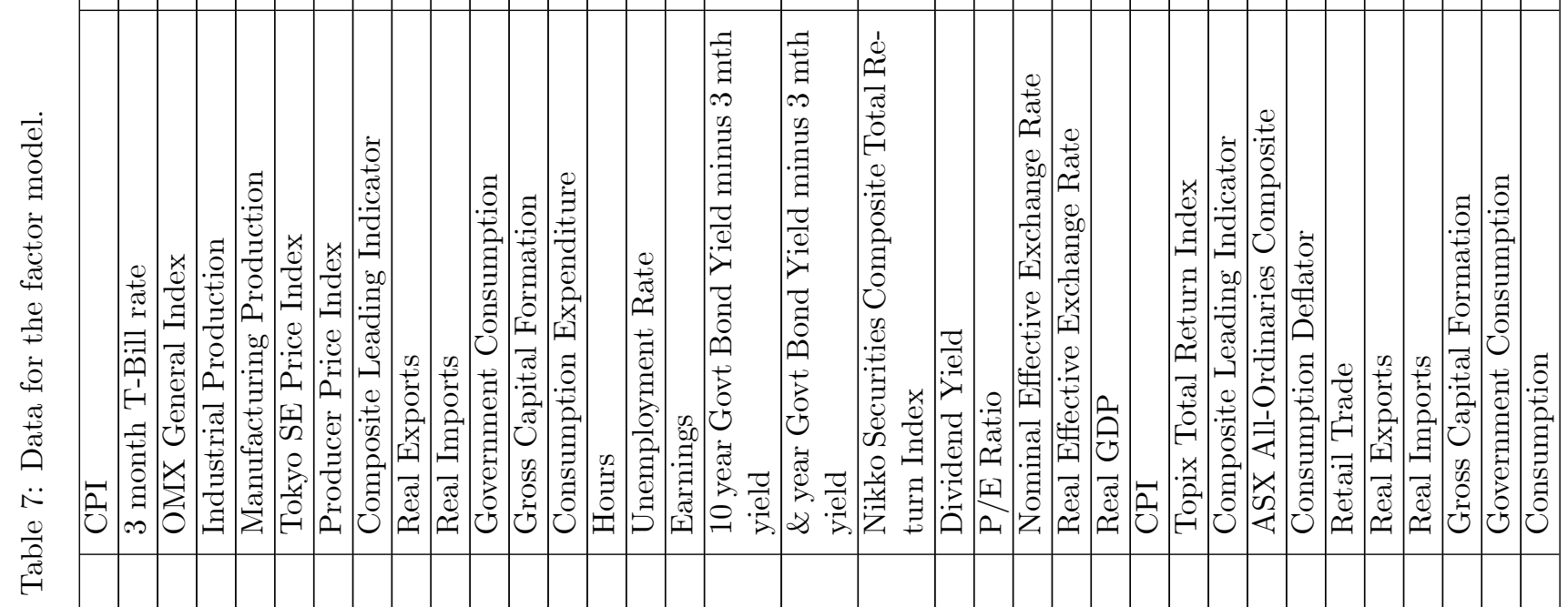

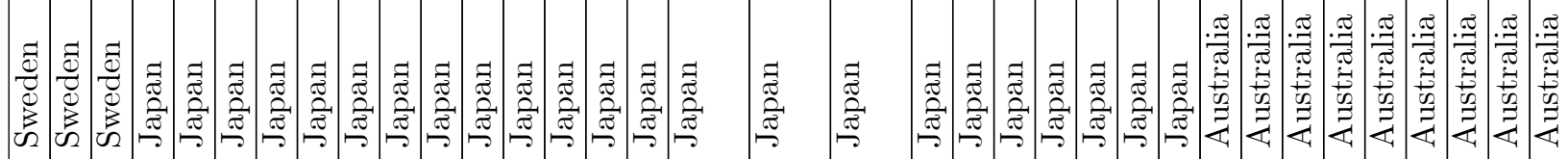

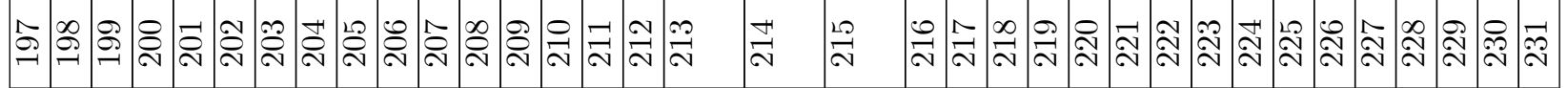




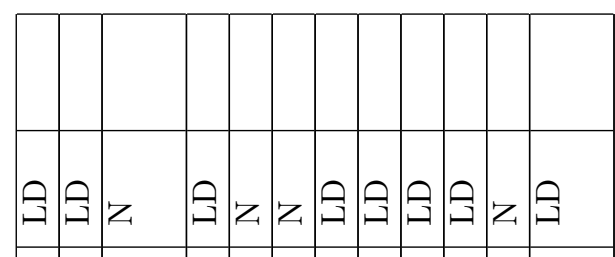

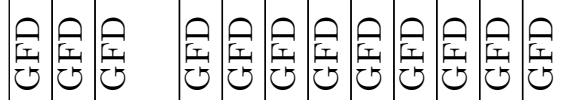

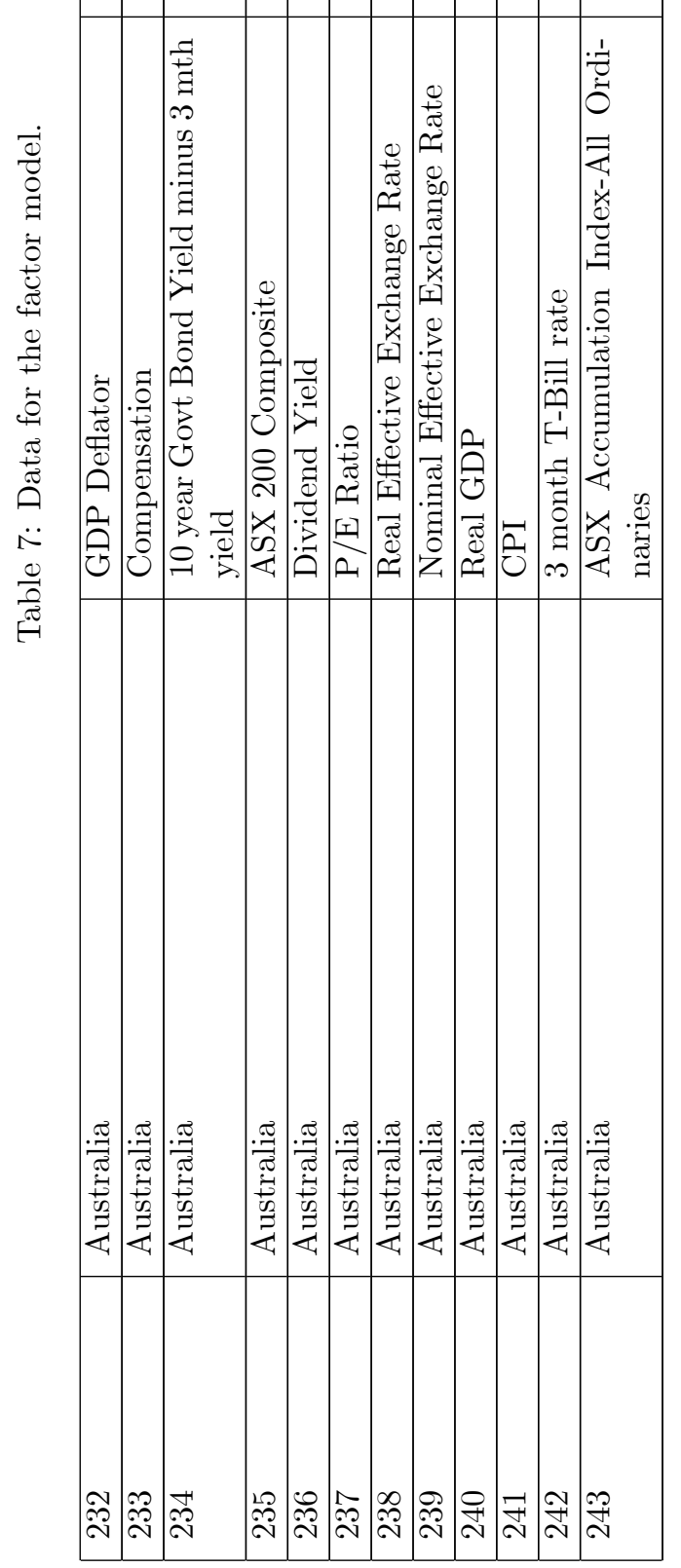




\section{References}

Andreasen, Martin M., Jesus Fernandez-Villaverde and Juan Rubio-Ramirez, 2013, The Pruned State-Space System for Non-Linear DSGE Models: Theory and Empirical Applications, Working Paper 18983, National Bureau of Economic Research.

Banbura, Marta, Domenico Giannone and Lucrezia Reichlin, 2010, Large Bayesian vector auto regressions, Journal of Applied Econometrics 25(1), 71-92.

Berger, Tino, Sibylle Grabert and Bernd Kempa, 2016, Global and Country-Specific Output Growth Uncertainty and Macroeconomic Performance, Oxford Bulletin of Economics and Statistics 78(5), 694-716.

Calvo, Guillermo A., 1983, Staggered prices in a utility-maximizing framework, Journal of Monetary Economics 12(3), 383-398.

Carlin, Bradley P., Nicholas G. Polson and David S. Stoffer, 1992, A Monte Carlo Approach to Nonnormal and Nonlinear State-Space Modeling, Journal of the American Statistical Association 87(418), 493-500.

Carter, C and P Kohn, 2004, On Gibbs sampling for state space models, Biometrika 81, 541-53.

Chin, Michael, Thomai Filippeli and Konstantinos Theodoridis, 2015, Cross-country co-movement in long-term interest rates: a DSGE approach, Bank of England working papers 530, Bank of England.

Christiano, Lawrence, Martin Eichenbaum and Charles Evans, 2005, Nominal Rigidities and the Dynamic Effects of a shock to Monetary Policy, Journal of Political Economy 113, 1-45.

Colacito, Riccardo and Mariano M. Croce, 2013, International Asset Pricing with Recursive Preferences, Journal of Finance 68(6), 2651-2686.

Creal, D., 2009, A survey of sequential Monte Carlo methods for economics and finance, Technical report.

Delnegro, Marco and Christopher Otrok, 2005, Dynamic factor models with time-varying parameters, Mimeo, Federal Reserve Bank of Atlanta.

Epstein, Larry G and Stanley E Zin, 1989, Substitution, Risk Aversion, and the Temporal Behavior of Consumption and Asset Returns: A Theoretical Framework, Econometrica 57(4), 937-69.

Fernandez-Villaverde, Jesus, Pablo Guerron-Quintana, Juan F. Rubio-Ramirez and Martin Uribe, 2011, Risk Matters: The Real Effects of Volatility Shocks, American Economic Review 101(6), 2530-61.

Fernández-Villaverde, Jesús, Pablo A. Guerrón-Quintana, Keith Kuester and Juan Rubio-Ramírez, 2011, Fiscal Volatility Shocks and Economic Activity, NBER Working Papers 17317, National Bureau of Economic Research, Inc.

Geweke, John and Guofu Zhou, 1996, Measuring the Pricing Error of the Arbitrage Pricing Theory, Review of Financial Studies 9(2), 557-87.

Gourio, Francois, Michael Siemer and Adrien Verdelhan, 2013, International risk cycles, Journal of International Economics 89(2), 471 - 484 .

Jacquier, E, N Polson and P Rossi, 1994, Bayesian analysis of stochastic volatility models, Journal of Business and Economic Statistics 12, 371-418.

Jermann, Urban and Vincenzo Quadrini, 2012, Macroeconomic Effects of Financial Shocks, American Economic Review 102(1), 238-71.

Juillard, Michel and Ondra Kamenik, 2005, Solving SDGE Models: Approximation About The Stochastic Steady State, Computing in Economics and Finance 2005 106, Society for Computational Economics.

Justiniano, Alejandro, Giorgio Primiceri and Andrea Tambalotti, 2010, Investment shocks and business cycles, Journal of Monetary Economics 57(2), 132-45.

Kim, Jinill, Sunghyun Kim, Ernst Schaumburg and Christopher Sims, 2008, Calculating and using second-order accurate solutions of discrete time dynamic equilibrium models, Journal of Economic Dynamics and Control 32(11), $3397-414$. 
Kollmann, Robert, 2015, Exchange Rates Dynamics with Long-Run Risk and Recursive Preferences, Open Economies Review 26(2), 175-196.

Mumtaz, Haroon and Konstantinos Theodoridis, 2015, The International Transmission of Volatility Shocks: An Empirical Analysis, Journal of the European Economic Association 13(3), 512-533.

Rabanal, Pau and Juan F. Rubio-Ramirez, 2015, Can international macroeconomic models explain low-frequency movements of real exchange rates?, Journal of International Economics 96(1), 199-211.

Rudebusch, Glenn D. and Eric T. Swanson, 2012, The Bond Premium in a DSGE Model with Long-Run Real and Nominal Risks, American Economic Journal: Macroeconomics 4(1), 105-43.

Smets, Frank and Rafael Wouters, 2007, Shocks and Frictions in US Business Cycles: a Bayesian DSGE Approach, American Economic Review 97, 586-606.

Swanson, Eric, 2015, A Macroeconomic Model of Equities and Real, Nominal, and Defaultable Debt, Mimeo.

Swanson, Eric T., 2012, Risk Aversion and the Labor Margin in Dynamic Equilibrium Models, American Economic Review 102(4), 1663-91.

Trabandt, Mathias and Harald Uhlig, 2011, The Laffer curve revisited, Journal of Monetary Economics 58(4), 305 -327 .

Weil, Philippe, 1989, The equity premium puzzle and the risk-free rate puzzle, Journal of Monetary Economics 24(3), 401-421.

Weil, Philippe, 1990, Nonexpected Utility in Macroeconomics, The Quarterly Journal of Economics 105(1), 29-42. 